\author{
Universidade de São Paulo \\ Instituto de Física
}

\title{
Enovelamento de proteínas e ligações de hidrogênio - estudo de modelos mínimos
}

Fernando Takeshi Tanouye

Orientadora: Prof(a). Dr(a). Vera Bohomoletz Henriques

Dissertação de mestrado apresentada ao Instituto de Física para a obtenção do título de Mestre em Ciências

Banca Examinadora:

Prof(a). Dr(a). Vera Bohomoletz Henriques (IFUSP)

Prof. Dr. Carlos Eduardo Fiore dos Santos (IFUSP)

Prof. Dr. Mário Noboru Tamashiro (UNICAMP) 

$\mathrm{Na}$ vida interessa $\circ$ que não é vida

$\mathrm{Na}$ morte interessa $\circ$ que não é morte

$\mathrm{Na}$ arte interessa $\circ$ que não é arte

$\mathrm{Na}$ ciência interessa $\circ$ que não é ciência

[...]

PIGNATARI, Décio. "Interessere"

As ciências e as técnicas não são notáveis por serem verdadeiras

ou eficazes - estas propriedades lhes são fornecidas por acréscimo e por razões outras que não as dos epistemólogos -, mas sim porque multiplicam os não-humanos envolvidos na construção dos coletivos e porque tornam mais íntima a comunidade que formamos com estes seres.

LATOUR, Bruno. "Jamais fomos modernos" 


\section{Agradecimentos}

À bolsa concedida através do CNPq, ao corpo técnico-administrativo do Instituto de Física e à professora Vera Henriques, a orientação; aos mais que colegas de departamento: Jo, Carol (co-orientadores, pra todos os efeitos), Wagner, Helder, Masa, etc.

Aos colegas que me receberam no primeiro semestre, Juan, Saeed, Túlio etc.

Ao Clube de Biologia Sintética (Synbio), o que não se aprende pelos meios oficiais, mas que valeria outro tipo de tese;

À família, o apoio maior;

\& a todos com quem convivi na USP durante os últimos anos,

presto estes agradecimentos. 
Este estudo tem como finalidade principal a análise termodinâmica e estatística de proteínas através de modelos mínimos. Uma proteína é um polímero de aminoácidos, cuja função está essencialmente relacionada às conformações espaciais que ela adota em solução aquosa. Na forma funcional (dita nativa), essas conformações flutuam levemente em torno de um mínimo de energia-livre. O processo pelo qual uma cadeia protéica transita de estados não-nativos para a estrutura nativa é chamado de enovelamento, ou dobramento. Uma questão em aberto no campo de estudo de proteínas consiste justamente em entender a fundo o processo de enovelamento, cujo avanço tem um vasto potencial de aplicação, desde a predição de estruturas a partir de sequências de aminoácidos até o planejamento de fármacos e moléculas bioativas.

Nossa investigação teórica procura abordar aspectos do enovelamento expressos através de grandezas termodinâmicas (energia média, calor específico, número de ligações de hidrogênio, entre outras) derivadas de modelos estatísticos na rede. Assim, num primeiro momento, analisamos o chamado modelo HP, ora por meio de enumeração exata, para cadeias curtas, ora por simulações de Monte Carlo, para cadeias maiores. No primeiro caso, propusemos a existência de uma relação entre a ocorrência de um segundo pico no calor específico - associado na literatura à transição de congelamento - com uma drástica redução no número de configurações entre os primeiros estados excitados e aqueles de menor energia. Observamos, também, que esse pico pode aparecer tanto para homopolímeros quanto para heteropolímeros, em ambas as redes quadrada e triangular.

Num segundo momento, nosso enfoque se voltou para a inclusão de um solvente aquoso (dado pelo modelo de Bell-Lavis) ao sistema inicial. Isso nos possibilitou verificar, usando exclusivamente simulações de Monte Carlo e o algoritmo de Metropolis, o 
comportamento e a competição das ligações de hidrogênio água-água, água-proteína, proteína-proteína e na primeira camada de solvatação. O modelo acoplado exibiu algumas características do enovelamento, como o colapso hidrofóbico e a separação de monômeros (apolares no núcleo e polares na superfície), embora não capture a desnaturação fria.

No apêndice, adicionamos algumas propostas para realização do cálculo numérico da pressão no ensemble canônico, desenvolvidas em paralelo ao projeto principal desta dissertação, mas que, numa primeira análise, verificamos serem consistentes e passíveis de futuros desdobramentos.

Palavras-chave: enovelamento de proteínas, modelo de rede, física estatística 


\section{Abstract}

The finality of this study is to analyse proteins thermodynamics and statistics through minimal models. A protein is a polymer of amino acids, whose spatial conformations in aqueous solution determine its function. In the functional form (said native), those conformations fluctuates slightly around a free-energy minimum. The process by which a protein chain passes from non-native states to a stable native structure is called protein folding. An open question in the field of protein studies is to understand more deeply the folding process, whose advance can find a wide range of potential applications, since ab initio structure prediction from the amino acids sequence to biomolecules design.

The theoretical approaches used here focus on aspects of protein folding given by some thermodynamic quantities (as mean energy, specific heat, number of hydrogen bonds and so on) obtained from statistical lattice models. Initially, we analyse the so-called HP model, at first using exact enumeration for short chains, then by Monte Carlo simulations for longer chains. In the first case, we propose a correlation between the occurrence of a second peak in the specific heat - associated in the literature with a freezing transition - and a sharp reduction on the number of configurations from the first excited states to the lowest energy states. In addition, we observe that this peak may appear to both homopolymers and heteropolymers on square and triangular lattices.

At a second moment, our focus turned to the introduction of a water-like solvent (Bell-Lavis model) to the initial system. This allowed us to verify, exclusively by means of Monte Carlo simulations with Metropolis algorithm, the behavior and competition of hydrogen bonds between water-water molecules, water-protein, and protein-protein monomers and at the first hydration layer. The combined model showed some classical folding properties, as hydrophobic collapse and monomers segregation (apolar residues at 
the core and polar residues at the surface), although it did not capture cold denaturation.

We have included in the appendix some proposals to perform numerical calculations of the canonical pressure, which were developed alongside the main subject of this thesis and a first analysis has proved to be consistent and susceptible to further developments.

Keywords: protein folding, lattice model, statistical physics 


\section{Sumário}

1 Introdução 1

1.1 Estrutura hierárquica . . . . . . . . . . . . . . . 3

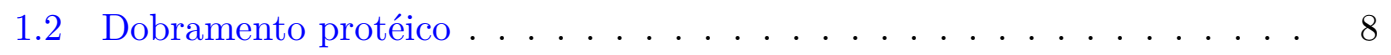

1.2.1 Fatores determinantes . . . . . . . . . . . . . . . 9

1.2 .2 Evolução temporal . . . . . . . . . . . . . . . . . . . . . 12

2 Proteínas de Rede: Modelo HP $\quad 15$

2.1 O modelo HP . . . . . . . . . . . . . . . . . . . . . . . . . 17

2.2 Enumeração Exata . . . . . . . . . . . . . . . . . . . . . 19

2.2.1 Resultados para homopolímeros . . . . . . . . . . . . . 26

2.2.2 Discussão sobre o duplo pico no calor específico . . . . . . . . . . 33

2.2.3 Resultados para heteropolímeros . . . . . . . . . . . . 39

2.3 Monte Carlo . . . . . . . . . . . . . . . . . . . . . 45

2.3.1 Resultados para cadeias maiores . . . . . . . . . . . . 50

3 Água: Modelo de Bell-Lavis $\quad 61$

3.1 Modelo de Bell-Lavis . . . . . . . . . . . . . . . . . . . . . 65

3.2 Breve exploração do modelo . . . . . . . . . . . . . . . . . 67

$3.2 .1 \quad$ Energia média e calor específico . . . . . . . . . . . . . 67

3.2.2 Cálculo do potencial químico: o método de Widom . . . . . . . . 68 
3.2.3 Cálculo da pressão: proposta de uma nova metodologia . . . . 74

4 Proteína HP no solvente de Bell-Lavis $\quad 77$

4.1 Inclusão do solvente . . . . . . . . . . . . . . . . . 77

4.2 Descrição do modelo . . . . . . . . . . . . . . . . . . . . 79

4.2.1 Dinâmica de Monte Carlo . . . . . . . . . . . . . . . . . . . . . 80

4.2 .2 Sequências . . . . . . . . . . . . . . . . . . . . 81

4.3 Resultados . . . . . . . . . . . . . . . . . . . . . 82

5 Considerações Finais $\quad 99$

$\begin{array}{ll}\text { Referências Bibliográficas } & 101\end{array}$

$\begin{array}{ll}\text { A Cálculos de Pressão no Ensemble Canônico } & 105\end{array}$

A.1 Método I: Cálculo com segmentos vazios . . . . . . . . . . . . . . 106

A.1.1 redes sem contorno periódico . . . . . . . . . . . . 107

A.1.2 redes com contorno periódico . . . . . . . . . . . . . . 110

A.2 Método II: Cálculo com segmentos ocupados . . . . . . . . . . . . . . . 114

A.2.1 redes sem contorno periódico . . . . . . . . . . . . . 115

A.2.2 redes com contorno periódico . . . . . . . . . . . . . . 117

A.3 Soluções analíticas em uma dimensão . . . . . . . . . . . . . . . . . . . 119

A.3.1 Gás de Rede 1D . . . . . . . . . . . . . . . . . . . . . . . 119

A.3.2 Mistura Binária 1D . . . . . . . . . . . . . . . . . . 123

A.3.3 Modelo de Bell-Lavis 1D . . . . . . . . . . . . . . . . . . . . 129

A.4 Método III . . . . . . . . . . . . . . . . . . . . . . . 133

A.4.1 redes sem contorno periódico . . . . . . . . . . . . . . 133

A.4.2 redes com contorno periódico . . . . . . . . . . . . 137 


\section{Capítulo 1}

\section{Introdução}

As proteínas são polímeros de aminoácidos responsáveis pela execução da maior parte das atividades codificadas em nossos genes. Tais atividades incluem a catálise de reações químicas (nesse caso as chamamos de enzimas), o controle do fluxo de substâncias através das membranas celulares, a regulação da expressão gênica, a sinalização entre os meios intra e extra celular, o fornecimento de rigidez estrutural, a geração de movimento, entre muitas outras. É bastante comum que várias dessas funções necessitem do esforço coordenado de vários tipos de proteínas e da formação de enormes arranjos macromoleculares. Elas são, assim, consideradas as grandes protagonistas dos processos celulares.

Enquanto tal as proteínas constituem um objeto de estudo fundamental para a compreensão dos sistemas vivos. O barateamento progressivo das tecnologias de sequenciamento de DNA têm possibilitado a catalogação de genomas completos de diversos organismos e, a partir deles ${ }^{1}$, do conjunto protéico total que os constituem, ou seja, seus proteomas. No entanto, não basta listar todas as peças funcionais de um organismo

\footnotetext{
${ }^{1} \mathrm{O}$ material genético carrega a informação que especifica as sequências de aminoácidos das proteínas. De acordo com o chamado dogma central da biologia molecular, o DNA é transcrito em vários tipos de ácido ribonucléico (RNA) os quais participam da síntese da proteína num processo conhecido por tradução.
} 
para compreendê-lo, é preciso igualmente conhecer as funções específicas de cada um desses elementos e como que eles se relacionam entre si e com o meio no qual estão imersos. Aqui, os pesquisadores se valem de um princípio geral, a saber, que "a função é derivada da estrutura tridimensional, e a estrutura tridimensional é especificada pela sequência de aminoácidos ${ }^{\prime 2}$, ou seja, o modo como uma proteína se organiza no espaço é o que determinará a sua função. Em última instância, é a sequência particular de aminoácidos (os monômeros que compõem a cadeia protéica) quem dita a sua forma espacial, e a maneira pela qual esse processo ${ }^{3}$ acontece é o que ficou conhecido na literatura como o problema do enovelamento protéico, ou ainda, a segunda metade do código genético (King, 1989).

Diversos campos de pesquisa têm atuado na elucidação estrutural de proteínas através de diferentes abordagens, como a cristalografia, a ressonância magnética, a microscopia eletrônica, as espectroscopias, simulações de dinâmica molecular, a bioinformática e, no caso que nos interessa, a física termo-estatística. O problema do enovelamento tem sido assim objeto de estudo durante décadas, ainda antes da resolução, em 1958, das primeiras estruturas da hemoglobina e da mioglobina por Max Perutz e John Kendrew, respectivamente. A persistência da questão é um indício de sua grande complexidade, de onde fica cada vez mais clara a necessidade de uma complementação de perspectivas trazidas pelos diversos métodos atualmente disponíveis.

Neste capítulo iremos abordar algumas das principais características estruturais dessa grande classe de moléculas, assim como as forças que as estabilizam e dirigem seu dobramento. Em seguida, desenvolveremos melhor a questão central da dissertação, a saber, o papel das interações de hidrogênio dentro do problema do enovelamento protéico visto sob o ponto de vista de modelos mínimos. Outros aspectos relevantes serão apropriadamente levantados nos capítulos posteriores.

\footnotetext{
${ }^{2}$ LODISH, Harvey et al. Biologia celular e molecular. 5. ed. Porto Alegre : Artmed, 2004. p. 60.

${ }^{3} \mathrm{O}$ processo de enovelamento é comumente chamado de folding.
} 


\subsection{Estrutura hierárquica}

A unidade básica de qualquer proteína é o aminoácido, nome genérico dado a uma classe de moléculas que têm em comum um átomo de carbono (chamado carbono alpha $C_{\alpha}$ ) ligado a quatro grupos químicos: um átomo de hidrogênio, um grupo amina (figura 1.1 em verde), um grupo ácido carboxílico (amarelo) e um grupo variável (vermelho) que diferencia os aminoácidos entre si. Assim, se esse grupo variável for um outro átomo de hidrogênio teremos o aminoácido glicina, se for um metil $\left(-\mathrm{CH}_{3}\right)$ teremos uma alanina e assim por diante. Porém, apesar do grande número de possibilidades que essa fórmula sugere, em geral observa-se que as proteínas são constituídas em sua vasta maioria por apenas vinte tipos de aminoácidos ${ }^{4}$.

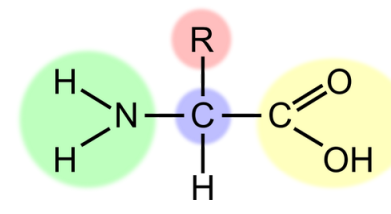

Figura 1.1: Composição genérica de um aminoácido.

Esses aminoácidos principais podem ser divididos em dois tipos: os polares/hidrofílicos e os apolares/hidrofóbicos, o critério de classificação sendo a polaridade da cadeia lateral (grupo variável). Entre os apolares temos, por exemplo, a glicina, a alanina, valina $\left(-\mathrm{CH}\left(\mathrm{CH}_{3}\right)_{2}\right)$, metionina $\left(-\mathrm{CH}_{2}-\mathrm{CH}_{2}-\mathrm{S}-\mathrm{CH}_{3}\right)$, entre outros. Já os polares podem ser subdivididos entre os neutros (serina, cisteína), os carregados positivamente ou básicos (lisina, arginina) e os carregados negativamente ou ácidos (aspartato, glutamato). Outra classificação geralmente usada distingue os aminoácidos que possuem cadeias laterais alifáticas, ou seja, com cadeias de carbono e hidrogênio abertas, e os aromáticos, que possuem cadeias fechadas, como o anel benzeno (fenilalanina, tirosina, triptofano). De maneira geral, as cadeias laterais dos aminoácidos apolares não fazem ligação de

\footnotetext{
${ }^{4}$ Cada um desses aminoácidos está associado a uma ou mais trincas de bases nitrogenadas (códons), as quais são formadas pelas letras $\mathrm{A}, \mathrm{T} / \mathrm{U}, \mathrm{C}$ ou $\mathrm{G}$, de modo que há uma limitação no número de aminoácidos que podem ser codificados pelo material genético. Um exemplo de aminoácido encontrado em proteínas e fora do grupo dos vinte é a selenocisteína, com cadeia lateral $-\mathrm{CH}_{2}-\mathrm{SeH}$.
} 
hidrogênio, ou as que fazem o fazem fracamente, enquanto que a dos polares podem participar umas como doadoras outras como aceptoras, ou às vezes ambas, desse tipo de ligação. No entanto, se levarmos em consideração os grupos amina e carboxílico ligados ao carbono $\alpha$, todos os aminoácidos podem realizar ligações de hidrogênio por meio deles.

As proteínas, sintetizadas nos ribossomos ${ }^{5}$, são montadas pela adição sucessiva de aminoácidos por meio de uma reação de síntese por desidratação (figura 1.2). Nessa reação, o carbono do grupo carboxílico de um aminoácido se liga covalentemente ao nitrogênio do grupo amina de outro, liberando como subproduto uma molécula de água. A ligação resultante, formadora de um grupo amida (em vermelho), é chamada de peptídica.

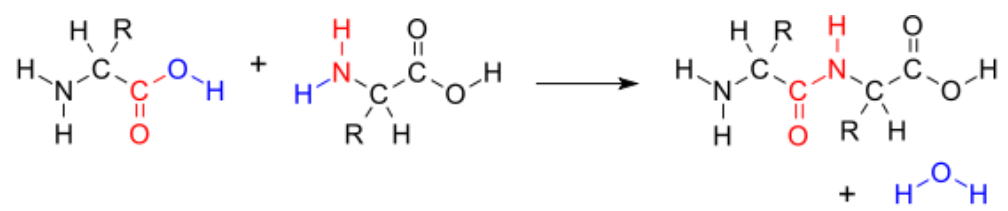

Figura 1.2: Formação da ligação peptídica.

Uma proteína é, portanto, um polímero linear de aminoácidos unidos por ligações peptídicas. Nesse ponto, chegamos ao primeiro nível estrutural de uma proteína, a saber, a sua sequência particular de aminoácidos:

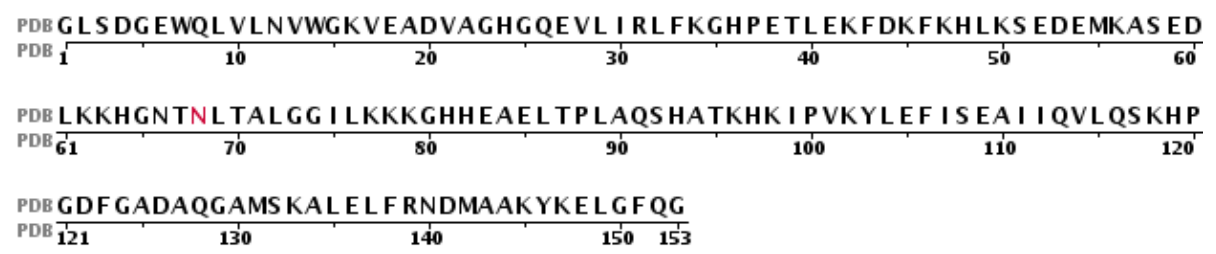

Figura 1.3: Estrutura primária da mioglobina. Cada um dos seus 153 aminoácidos está representado por uma letra específica do alfabeto. Fonte: PDB ID: 1M6C - Krzywda, S., Murshudov, G.N., Brzozowski, A.M., Jaskolski, M., Scott, E.E., Klizas, S.A., Gibson, Q.H., Olson, J.S., Wilkinson, A.J. (1998) Stabilizing bound O2 in myoglobin by valine68 (E11) to asparagine substitution. Biochemistry 37: 15896-15907.

\footnotetext{
${ }^{5}$ Para formar as proteínas, os ribossomos leem as fitas de mRNA códon por códon, de modo a adicionar sequencialmente um aminoácido de cada vez.
} 
O segundo nível estrutural das proteínas diz respeito a certos arranjos locais assumidos por fragmentos de suas sequências, podendo ser classificados segundo o padrão de ligações de hidrogênio estabelecido entre as aminas $(-\mathrm{NH}-)$ e as carbonilas $(-\mathrm{CO}-)$ da cadeia principal. Por exemplo, quando uma parte da sequência se organiza em formato helicoidal, de tal modo que cada amina faz ligação de hidrogênio com a carbonila do $4^{\mathrm{O}}$ aminoácido depois dela (ver figura 1.4), então dizemos que se trata de uma hélice$\alpha$, uma das estruturas secundárias mais recorrentes ${ }^{6}$. Ou então, quando algumas partes se alinham paralelamente (ou antiparalelamente, dependendo dos sentidos) de maneira a formar uma rede de ligações mais ou menos planar, teremos uma outra estrutura bastante comum denominada folha- $\beta$. As dobras- $\beta$, por sua vez, são regiões de alta curvatura compostas por uma sequência de quatro aminoácidos, onde o primeiro realiza ligação de hidrogênio com o último.

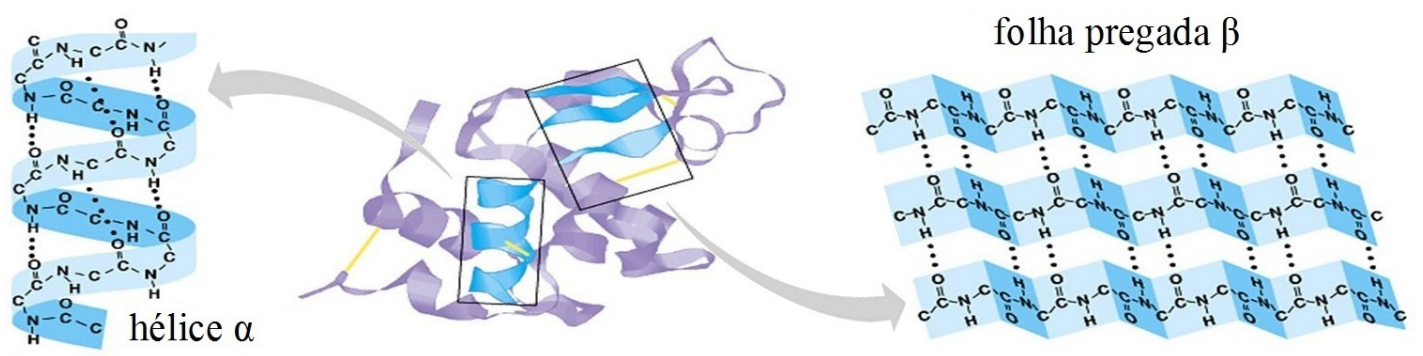

Figura 1.4: Principais estruturas secundárias: hélice- $\alpha$ e folha- $\beta$. As cadeias laterais foram omitidas para facilitar a visualização.

Alternativamente, pode-se classificar as estruturas secundárias através dos ângulos de torsão (diedrais) formados a cada par de aminoácidos. De fato, como a ligação peptídica apresenta um caráter parcial de ligação dupla, devido a um fenômeno de ressonância eletrônica, o qual restringe a rotação ao redor do seu eixo $C-N$, cada sequência de átomos $C_{\alpha}-C-N-C_{\alpha}$ da cadeia principal fica contida num plano. Assim, pode-se definir dois ângulos $(\phi$ e $\psi$ ) a cada dois planos sucessivos (figura 1.5): o

\footnotetext{
${ }^{6}$ Outras hélices possíveis, embora menos frequentes, são aquelas em que as ligações de hidrogênio ocorrem a cada 3 aminoácidos (hélice- $3_{10}$ ) ou a cada 5 aminoácidos (hélice- $\pi$ ).
} 
ângulo $\phi$ corresponde ao diedro definido pelas ligações $C-N-C_{\alpha}-C$ e o ângulo $\psi$ pelas ligações $N-C_{\alpha}-C-N$. As geometrias das estruturas secundárias podem então ser mapeadas num diagrama $(\phi \times \psi)$, proposto originalmente por (Ramachandran et al., 1963), onde elas tendem a formar clusteres (figura 1.5 b).

(A)
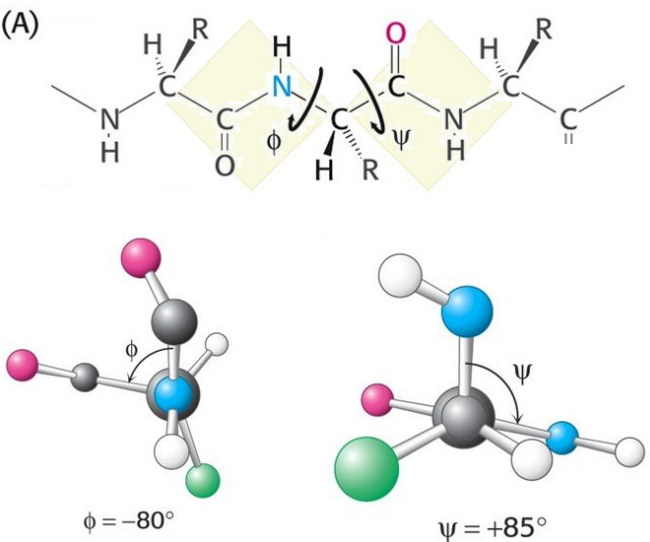

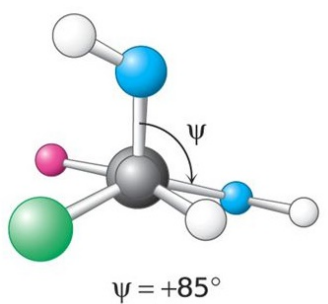

(B)

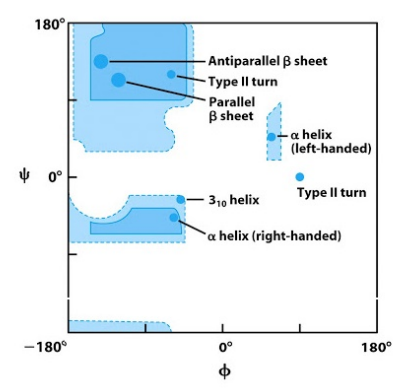

Figura 1.5: (a) Ângulos $(\phi, \psi)$ e (b) o diagrama de Ramachandran. Fonte: (a) adaptado de Biochemistry, 7ed. 2012 W.H. Freeman and Company e (b) adaptado de Principles of Biochemistry, 4ed. 2006 Pearson Prentice Hall, Inc.

A combinação de algumas estruturas secundárias pode dar origem a certos elementos estruturais regulares, ditos motivos $^{7}$, comumente encontrados em várias proteínas diferentes. Porém, é a combinação global de todos esses elementos secundários juntamente com as porções desordenadas da proteína, numa forma compacta e funcional, o que costuma-se chamar de estrutura terciária, ou o estado enovelado. Essa estrutura é energeticamente estável, sendo estabilizada pelo conjunto das interações eletrostáticas, hidrofóbicas, ligações de hidrogênio (tanto intramoleculares quanto com a água) e, dependendo do caso, por pontes dissulfeto - ligações covalentes $-S-S-$ entre cisteínas.

Finalmente, a estrutura quaternária é aquela em que algumas ou várias proteínas individuais se juntam, principalmente por forças eletrostáticas, para formar um complexo funcional maior. É o caso, por exemplo, da hemoglobina (figura 1.6), um tetrâmero

\footnotetext{
${ }^{7}$ Para citar alguns deles, temos: o barril beta, a super-hélice (coiled-coil), dedo de zinco, hélicealça-hélice, chave-grega, beta-alpha-beta etc. São elementos intermediários entre os níveis secundário e terciário, normalmente associados a funções específicas.
} 
composto em sua maioria por duas subunidades de globinas alpha e duas subunidades beta $\left(\alpha_{2} \beta_{2}\right)$, além de quatro grupos heme, responsáveis por transportar o oxigênio e o gás carbônico entre os pulmões e os tecidos do corpo. Além do número e tipo das subunidades a estrutura quaternária também abrange o modo como elas estão organizadas na proteína multimérica.

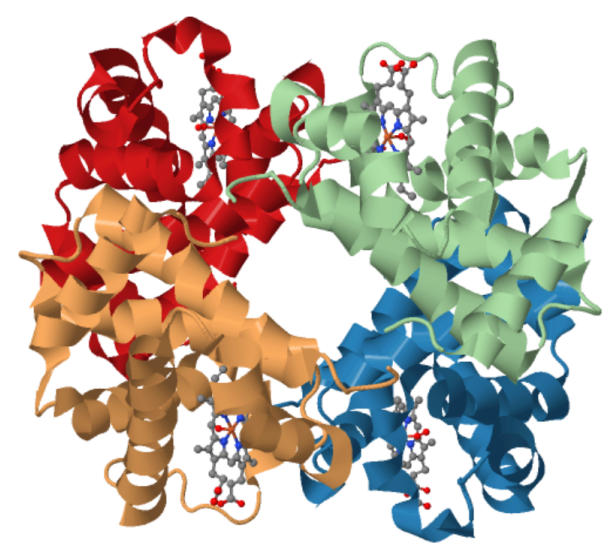

Figura 1.6: Estrutura quaternária da hemoglobina. Cada subunidade (globinas $\alpha$ e $\beta$ ) é uma proteína na forma terciária. Fonte: PDB ID: 1GZX - Paoli, M., Liddington, R., Tame, J., Wilkinson, A., Dodson, G. (1996) Crystal Structure of T State Haemoglobin with Oxygen Bound at All Four Haems. J.Mol.Biol. 256: 775 .

As células abrigam ainda uma série de processos complexos que necessitam da formação de enormes arranjos macromoleculares, os quais envolvem a atuação integrada de dezenas ou centenas de proteínas e outros tipos de biomoléculas. Esses grandes arranjos, uns com função estrutural (citoesqueleto, capsídeos virais) outros sendo verdadeiras máquinas moleculares (ribossomos, fotossistema, complexo de transcrição etc), constituem o mais alto grau de estrutura das proteínas.

Para os propósitos desta dissertação, estaremos interessados em modelar apenas a formação da estrutura nativa/terciária das proteínas ditas globulares ${ }^{8}$, ou seja, da grande classe das proteínas solúveis que possuem um núcleo hidrofóbico e superfície polar, de formato mais ou menos globular e compacto.

\footnotetext{
${ }^{8}$ Excluindo, portanto, as proteínas ditas de membrana, que possuem uma superfície hidrofóbica voltada para os lipídeos com os quais interagem, e as proteínas fibrosas, que não possuem uma estrutura compacta, mas alongada.
} 


\subsection{Dobramento protéico}

Apesar de todo conhecimento acumulado acerca dos componentes básicos das proteínas e de seus arranjos mais frequentes, nosso nível de compreensão acerca dos mecanismos que levam uma cadeia polipeptídica, estruturada aleatoriamente no espaço, a assumir sua conformação nativa ainda é bastante incompleto. Entender como esse processo acontece é uma das questões centrais para a biologia estrutural, com implicações que poderiam favorecer diversos campos aplicados. O objetivo ideal seria a capacidade de prever com precisão uma estrutura tridimensional unicamente a partir de sua sequência de aminoácidos, sem que fosse necessário para isso recorrer a técnicas mais complexas e demoradas.

A ideia de que a forma nativa é essencialmente determinada pela sequência específica dos aminoácidos, ou seja, de que ela é suficiente para levar uma conformação desenovelada à forma terciária em condições fisiológicas, é aceita como um dogma para a maioria das proteínas. Essa concepção remonta a uma série de experimentos de renaturação protéica conduzidos por Christian Anfinsen e colaboradores entre as décadas de 50-60 (Anfinsen, 1973), os quais estabeleceram que cadeias desnaturadas in vitro da RNase $\mathrm{A}^{9}$ podem voltar a suas conformações nativas quando expostas novamente a condições fisiológicas. Ficou demonstrado, com isso, que o enovelamento dessa proteína pode ser visto como um processo de automontagem espontâneo dirigido unicamente por seus aminoácidos (dentro do solvente adequado). Essa observação, apesar de não ser válida para todas as proteínas, em especial para aquelas que sofrem modificações pós-traducionais, como a insulina por exemplo, ainda assim é amplamente aceita e permite que possamos fazer modelos de enovelamento levando em conta apenas a cadeia do polipeptídeo.

É claro que nem toda sequência de aminoácidos apresenta uma conformação estável única. De fato, apenas uma pequena fração das inúmeras sequências possíveis, as quais

\footnotetext{
${ }^{9}$ Ribonuclease pancreática bovina.
} 
foram sendo adaptadas pela seleção natural para o uso em sistemas vivos, possui essa propriedade. A seguir, descrevemos resumidamente as principais características contidas nessas sequências que são determinantes para o dobramento nativo, assim como os eventos hipotéticos que transcorrem durante esse processo.

\subsubsection{Fatores determinantes}

É bem sabido, através das numerosas estruturas já resolvidas, que as proteínas globulares apresentam densidades de empacotamento elevadas, comparáveis àquelas de cristais orgânicos. A presença de um núcleo compacto, predominantemente apolar e desidratado indica que o processo de dobramento é dirigido em larga medida por forças hidrofóbicas. O colapso da estrutura protéica devido a essas forças, gerando o agregado de aminoácidos apolares no centro, é um fator limitante para o movimento das cadeias laterais, as quais precisam se reordenar para satisfazer o grau de empacotamento observado. Segundo Dill, as estruturas secundárias de hélice- $\alpha$ e folhas- $\beta$ da estrutura nativa se formariam principalmente em razão das limitações estereoquímicas provocadas pela agregação hidrofóbica e seriam uma forma eficiente de ocupar o pouco espaço disponível. De fato, as proteínas globulares apresentam uma alta porcentagem, cerca de $60 \%$ em média, desses dois arranjos secundários.

Entretanto, a força hidrofóbica sozinha não tem especificidade suficiente para a formação de uma estrutura nativa única, mas limita bastante o número de conformações, de modo que outras interações (ligações de hidrogênio, van der Waals, pontes salinas) devem contribuir para a estabilização dos elementos estruturais nativos. Talvez seja o conjunto total dessas pequenas forças que determina qual o modo de empacotamento, dentre aqueles possíveis para a estrutura colapsada, é o mais estável termodinamicamente. Nesse sentido, generalizando os diversos resultados dos experimentos de renaturação, Anfinsen propôs aquilo que ficou conhecido como "hipótese termodinâmica":

Essa hipótese afirma que a estrutura tridimensional de uma proteína nativa 
e seu meio fisiológico normal (solvente, $p H$, força iônica, presença de outros componentes tais como íns metálicos ou grupos prostéticos, temperatura e outros) é aquela para qual a energia livre de Gibbs do sistema como um todo é mínima; ou seja, que a conformação nativa é determinada pela totalidade das interações interatômicas e, consequentemente, pela sequência de aminoácidos ${ }^{10}$.

Assim, a estrutura nativa única seria determinada pelas interações específicas (ligações de hidrogênio, eletrostáticas etc.) além das restrições estéricas devido à compactação proveniente das forças hidrofóbicas. E as estruturas em forma de hélices e folhas são aptas a serem estabilizadas por esses tipos de interação e a preencher o espaço de maneira otimizada. A conformação resultante representaria um mínimo estável na energia livre de Gibbs total do sistema.

Para avaliar a influência específica que os diversos aminoácidos da cadeia podem ter sobre a estrutura final, foi realizada uma série de estudos envolvendo modificações nesses resíduos: adição ou remoção química de grupos, substituições por outros aminoácidos, análise evolutiva de sequências com estruturas homólogas etc. Uma conclusão importante a que se chegou foi de que a estrutura das proteínas é menos perturbada pela alteração de resíduos localizados em sua superfície do que por resíduos da parte interna. Proteínas muito próximas evolutivamente também apresentam mutações com maior frequência na superfície. Isso sugere que são os aminoácidos internos da cadeia que contribuem de maneira mais decisiva para a conformação nativa. Se pensarmos no elevado grau de compactação do núcleo protéico, vemos que é bem mais difícil acomodar variações internas, sem alterar de alguma maneira o dobramento final, do que mudanças provocadas em regiões externas e menos rígidas. No entanto, as proteínas geralmente conseguem adaptar bem mutações de aminoácidos internos alterando localmente as

\footnotetext{
${ }^{10}$ Anfinsen, C. B. (1973). Principles that govern the folding of protein chains. Science (New York, N.Y.), 181(4096):223-30. pg. 223.
} 
regiões em que ocorrem, sem com isso perder de forma significativa sua conformação global, o que mostra também que há muitos modos possíveis de empacotamento dos resíduos.

Outros experimentos procurando analisar as mudanças no dobramento das proteínas corroboram a noção de que certos aminoácidos em determinadas posições da sequência possuem pesos distintos para a determinação da estrutura. Foi mostrado (Dalal et al., 1997) que é possível inserir mutações específicas na sequência de tal modo a manter um grau de semelhança com a sequência original, porém resultando numa estrutura completamente diferente. Essa estrutura, por sua vez, pode ser bastante parecida com a conformação nativa de sequências ainda menos relacionadas com a primeira, mostrando que o nível de identidade entre sequências nem sempre se reflete numa semelhança estrutural e que dobramentos parecidos podem resultar de sequências pouco correlacionadas. Assim, um subconjunto da cadeia de aminoácidos pode ser suficiente para especificar um tipo de dobramento.

Por fim, embora longe de esgotar o tema, observa-se que muitas proteínas são compostas por subunidades contíguas e compactas da cadeia, chamadas de domínios, as quais possuem uma estrutura própria e relativamente independente do restante dela. Mesmo que se separe fisicamente essas regiões da proteína, elas podem frequentemente assumir a conformação que possuíam na cadeia de origem sem grandes alterações, o que permite, por exemplo, que estudos cristalográficos possam ser feitos apenas com partes da proteína de interesse ${ }^{11}$. Além disso, verifica-se que esses domínios podem, por sua vez, ser formados por vários subdomínios ou elementos locais e compactos menores. Segundo George Rose e Robert Baldwin (Baldwin e Rose, 1999), isso daria suporte à tese de que o enovelamento se daria de maneira hierárquica. De acordo com essa perspectiva, estruturas locais e de estabilidade marginal se formariam no início do dobramento, as quais interagiriam com outras estruturas adjacentes para formar agrupamentos

\footnotetext{
${ }^{11}$ Diversas estruturas do PDB consistem de domínios isolados.
} 
intermediários de complexidade cada vez maior, até se atingir a conformação nativa. Por oposição, a visão de dobramento como um processo não-hierárquico sugere que são as interações nativas (particularmente entre os resíduos hidrofóbicos) que estabilizam e guiam a formação das estruturas locais.

\subsubsection{Evolução temporal}

Para que possamos entender como que uma proteína se enovela precisamos conhecer, além dos fatores determinantes de sua estrutura, a sequência temporal dos eventos intermediários ocorrendo entre os estados desenovelado e nativo. A ideia de que deve haver mecanismos ou caminhos eficientes pelos quais a cadeia segue para atingir sua forma nativa num intervalo de tempo típico, da ordem de milissegundos a alguns segundos, pode ser facilmente deduzida de um experimento mental proposto por Cyrus Levinthal (Levinthal, 1969). Seu argumento pressupõe inicialmente que a busca pela conformação nativa acontece de maneira aleatória, com a sequência testando as várias configurações possíveis até encontrá-la por acaso. Como uma proteína de $n$ aminoácidos contém $2 n$ ângulos de torsão $(\phi$ e $\psi)$, se estimarmos por baixo que cada ângulo só pode assumir 10 valores possíveis e sem levarmos em conta os graus de liberdade das cadeias laterais, teríamos um total de $10^{2 n}$ configurações teóricas. Para uma proteína média de 150 resíduos isso daria $10^{300}$ estados diferentes. O paradoxo ou contradição dessa situação hipotética é que mesmo fixando um intervalo mínimo para cada troca de conformação

(digamos $10^{-13} s$, o tempo que uma ligação simples leva para se reorientar), ainda assim seria necessário um tempo insondável para completar essa busca (no nosso exemplo, $t=10^{300} \cdot 10^{-13}=10^{287} \mathrm{~s} \gg$ idade do universo). A premissa da aleatoriedade estaria assim tranquilamente descartada. Segundo Levinthal, ao que parece "o enovelamento é acelerado e guiado pela rápida formação de interações locais que então determinam o restante do dobramento do polipeptídeo".

Se o dobramento não é aleatório e deve seguir rotas eficientes, qual seria então 
a natureza dessas rotas? Devido a complexidade do processo e à limitação das técnicas disponíveis, até o momento só foi possível esboçar um quadro geral dos passos intermediários envolvidos. Para realizar este tipo de análise, as principais abordagens experimentais utilizadas têm sido a espectroscopia de dicroísmo circular (CD), a qual fornece um indicativo do conteúdo de estruturas secundárias na amostra - através da análise dos espectros característicos de hélices, folhas e voltas - e experimentos de troca pulsada H/D (hidrogênio/deutério) seguida de espectroscopia por RMN, onde podem se determinar os tempos de duração da formação de ligações de hidrogênio e de exclusão de certos grupos do solvente.

O evento mais marcante identificado por essas técnicas logo no início do enovelamento é o chamado colapso hidrofóbico ou fase explosiva, uma vez que ela ocorre em intervalos muito curtos em comparação com os eventos posteriores. Nessa fase, a estrutura mais ou menos aleatória da proteína desenovelada se contrai rapidamente numa forma mais compacta, o glóbulo fundido, na qual ocorre a formação de um núcleo hidrofóbico ainda não totalmente ordenado. O raio de giração da cadeia também é reduzido dramaticamente, num tamanho um pouco maior que o da forma nativa. Medidas de CD indicam que boa parte das estruturas secundárias presentes nas proteínas se formam poucos milissegundos após o início do dobramento. Analogamente, os experimentos de troca pulsada H/D sugerem que depois de aproximadamente $5 \mathrm{~ms}$ ocorre uma significativa proteção de grupos passíveis de realizar ligações de hidrogênio contra a troca de deutério com o solvente. Essa transição de colapso é uma característica comum entre polímeros apolares e acredita-se que o efeito hidrofóbico seja a principal força nessa etapa do enovelamento. Depois de colapsada, a proteína ainda precisa passar por diversos rearranjos, uma vez que as cadeias laterais continuam desordenadas e a estrutura flutua entre conformações instáveis.

Após o colapso inicial segue-se uma fase intermediária $(5-1000 \mathrm{~ms})$ onde as estruturas secundárias se tornam mais estáveis e ocorre a formação de estruturas terciárias 
semelhantes à conformação enovelada. Já no estágio final, que pode durar alguns segundos ou mais, a proteína atinge seu estado nativo por meio de uma série de movimentos lentos e complexos, os quais resultarão num núcleo rígido, denso e desidratado. A visão clássica do enovelamento supunha que durante esses passos intermediários a proteína assumia uma rota bem definida, com certas estruturas privilegiadas ocorrendo em sequência. No entanto, com o desenvolvimento das técnicas mencionadas de análise temporal, essa visão foi sendo substituída por uma outra perspectiva, a da teoria da paisagem, segundo a qual as proteínas poderiam percorrer diversas rotas possíveis até atingir o estado nativo. Nesse contexto, costuma-se representar pictoricamente o espaço conformacional projetado numa superfície (paisagem) de energia livre em forma de um funil acidentado, onde a estrutura nativa estaria num mínimo pronunciado de energia. A superfície traria, assim, a ideia de inúmeros trajetos não determinados, mas que convergiriam para uma mesma região bastante estável.

Vimos, portanto, que as proteínas são polímeros altamente organizados e cujas estruturas primárias (ou, sequências) evoluíram de tal modo a especificar conformações estáveis e funcionais, assim como possibilitar rotas eficientes para atingí-las. Entretanto, o acesso aos estados intermediários do processo de dobramento ainda nos é bastante limitado. Veremos, a seguir, como abordar essa dificuldade do ponto de vista de modelos mínimos. 


\section{Capítulo 2}

\section{Proteínas de Rede: Modelo HP}

Muitas das questões em aberto no campo de estudo de proteínas têm sido abordadas através dos mais variados modelos teórico-computacionais, os quais podem ser classificados de acordo com os graus de resolução assumidos. Modelos que se valem de um maior detalhamento atômico, como aqueles utilizados na área de dinâmica molecular, possuem a vantagem de representar as proteínas de maneira mais realista, porém apresentam limitações de amostragem devido ao alto custo de processamento. Essas limitações restringem a exploração das conformações protéicas a um número bastante reduzido, uma vez que os tempos de simulação costumam ficar na ordem de nano ou microssegundos, enquanto que um evento completo de enovelamento pode durar até alguns minutos. Já do outro lado do espectro, há os modelos que buscam reduzir ao máximo possível a resolução do sistema, para ganhar com isso precisão sobre o espaço conformacional. Diferentemente dos primeiros, estes adotam pouquíssimos parâmetros e omitem os campos de força de interações covalentes. Se, por um lado, eles perdem na representação de detalhes, por outro possibilitam uma exploração mais completa das variações estruturais, ampliam a escala de tempo acessível, além de facilitarem a interpretação de suas propriedades e o teste direto de hipóteses, muitas vezes dispondo de fórmulas analíticas. 


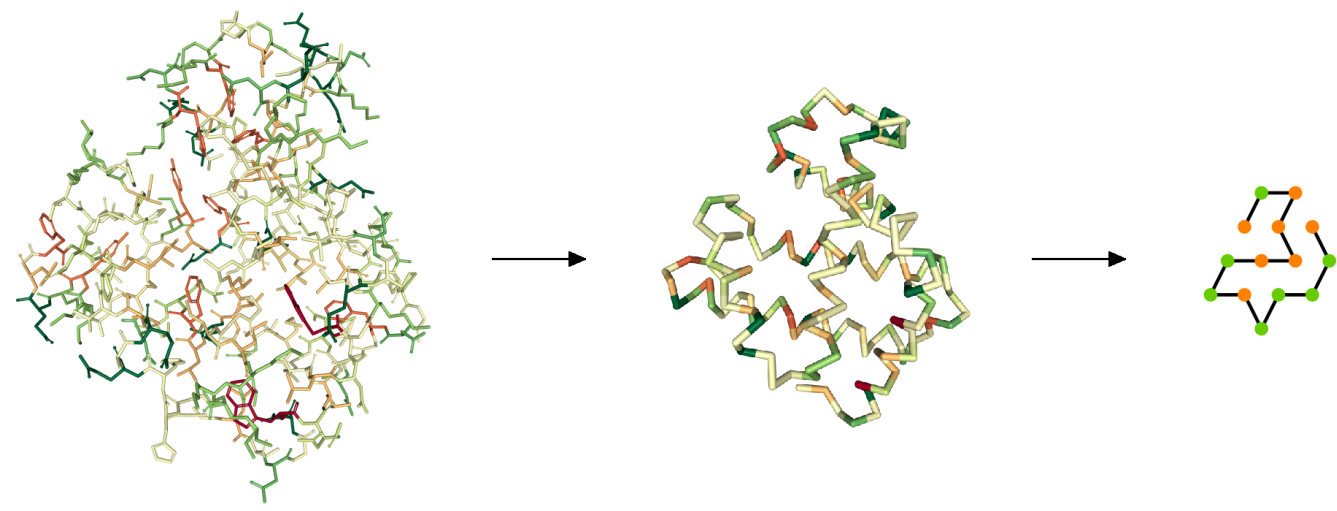

Figura 2.1: Modelos de proteínas podem ser explorados em diversos graus de resolução, desde aqueles com detalhamento atômico (à esquerda) até modelos simplificados na rede (à direita).

Neste capítulo, apresentaremos um modelo bastante simples (poucos parâmetros) e de baixa resolução, amplamente utilizado no estudo de proteínas, ou polímeros em geral, o chamado modelo HP. A abordagem será feita a partir de duas metodologias: para cadeias curtas, menores do que 20 monômeros, trataremos por (1) enumeração exata, ou seja, através da contagem completa das configurações do sistema, a qual nos permitirá obter funções de partição analíticas; e, para cadeias maiores, por (2) simulações de Monte Carlo. No primeiro caso, apesar da limitação quanto ao tamanho da cadeia peptídica, poderemos abordar propriedades que exigem um conhecimento detalhado dos espaços conformacionais. No segundo caso, poderemos aproximar as grandezas de interesse por meio de simulações capazes de percorrer um evento completo de dobramento, com cadeias mais extensas.

Ressaltamos que estes modelos simples não pretendem predizer uma estrutura protéica real a partir de sua sequência de aminoácidos, ou seja, resolver a questão central do enovelamento, mas tão somente fornecer informações de caráter geral. Por exemplo, uma perspectiva trazida por diversos estudos de modelos simples e exatos é a de que o código de enovelamento - o modo como a forma nativa e as rotas de dobramento estão codificadas na sequência - seria fundamentalmente binário e deslocalizado, isto 
é, que a disposição dos aminoácidos polares e apolares teria mais relevância do que o tipo específico da cadeia lateral, e que sequências dispersas ao longo da cadeia seriam mais importantes do que pequenas sequências de aminoácidos próximos entre si (Dill et al., 1995). Outros resultados gerais serão revistos a seguir.

\section{$2.1 \quad$ O modelo HP}

O uso de métodos na rede para o estudo de polímeros não é recente e remontam aos famosos trabalhos de Flory e Huggins (1941/1942). Em meados do século passado, W. J. C. Orr também propunha um tratamento estatístico para homopolímeros em duas e três dimensões (Orr, 1947), na rede quadrada. Seu modelo considerava interações de primeiros vizinhos e o efeito estérico devido à contiguidade da cadeia, isto é, ela não se cruza, porém se limitava a cadeias muito curtas e buscava extrair apenas uma configuração média por meio de aproximações analíticas. Somente a partir de 1975, com os trabalhos de Taketomi e Gō, que estes modelos passam a ser aplicados para se estudar também a estabilidade e cinética. Ficando conhecidos como Gō-models, eles utilizavam funções potenciais ad hoc que só contavam os pares de interações presentes em uma configuração nativa pré-estabelecida, assegurando que esta seria a de menor energia livre. Além do uso de um potencial artificial, o modelo não era exato, realizando as amostragens através do algoritmo de Metropolis.

Os primeiros modelos simples e exatos (com poucos parâmetros físicos e função de partição exata) só começaram a aparecer com os estudos de Ken Dill e colaboradores (Chan e Dill, 1989a,b; Lau e Dill, 1989), feitos na rede quadrada e também para cadeias maximamente compactas de 27 monômeros no cubo 3x3x3. O objetivo destes modelos era explorar as consequências de potenciais físicos e as propriedades dos espaços completos de conformações e de sequências. Desde então, diversos trabalhos da década de 90 em diante passaram a abordar as proteínas do ponto de vista de modelos simples e 
exatos, sendo um dos mais amplamente utilizados neste sentido o chamado modelo HP.

No modelo HP, os aminoácidos da proteína são representados por bolinhas conectadas covalentemente, formando uma espécie de "colar de contas", podendo assumir somente posições discretas na rede (figura 2.2). Omitindo-se as cadeias laterais, os resíduos são divididos em dois grupos: os hidrofóbicos $H$ e os polares $P$, sendo que um potencial de interação é associado a cada um dos três tipos de pares possíveis de primeiros vizinhos $(H H, H P$ e $P P)$. Em geral, um potencial atrativo e constante $-\epsilon$ (com $\epsilon>0$ ) é atribuído aos pares $H H$, uma vez que os resíduos apolares tendem a ser excluídos do ambiente aquoso por razões entrópicas, e os outros contatos são considerados como não interagentes. Assim, $\epsilon$ é interpretado no modelo como uma energia livre efetiva que faz com que os monômeros hidrofóbicos tendam a formar um núcleo compacto, embora não haja uma interação propriamente dita, atrativa e dominante, entre aminoácidos apolares no sistema real. É preciso ter isto em mente, pois, apesar de representar uma energia livre, estaremos tratando $\epsilon$ a seguir simplesmente como uma energia potencial.
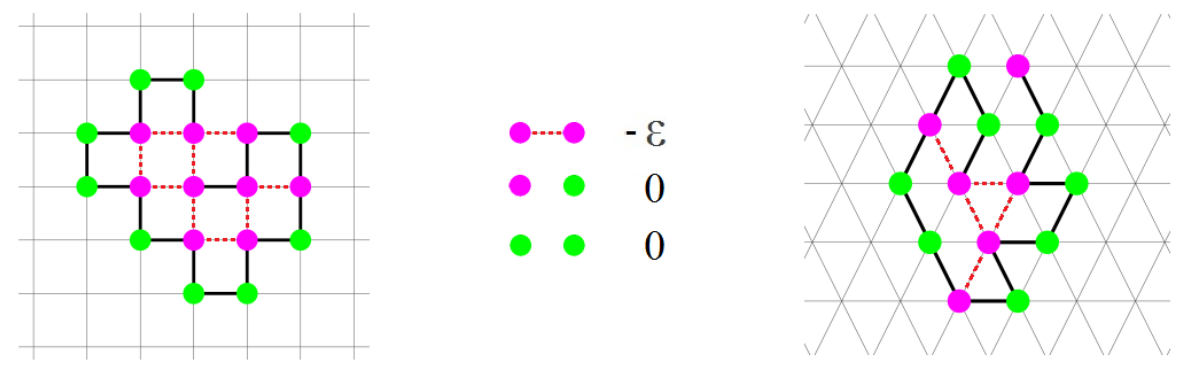

Figura 2.2: Modelo HP, monômeros $\mathrm{H}$ em rosa e P em verde, na rede quadrada e na rede triangular. As linhas tracejadas em vermelho indicam as interações atrativas entre vizinhos apolares.

Exploraremos o modelo HP primeiramente de maneira exata e, depois, por meio de simulações de Monte Carlo, utilizando polímeros tanto na rede quadrada quanto na triangular. A motivação para estudarmos o modelo HP na rede triangular é para 
ganharmos familiaridade com o sistema antes de acoplá-lo ao modelo de Bell-Lavis (capítulos 3 e 4), onde o solvente será representado na rede de maneira explícita e nos permitirá estudar a competição entre ligações de hidrogênio, tema que será melhor desenvolvido nos próximos capítulos.

\subsection{Enumeração Exata}

\section{Metodologia}

Em princípio, dentro do quadro da física estatística, é possível calcular as principais grandezas termodinâmicas de um sistema a partir do conhecimento de sua função de partição:

$$
Z=\sum_{i} e^{-\beta E_{i}},
$$

dada por uma soma que percorre todas as configurações $i$ possíveis do sistema e contabiliza suas respectivas energias dentro de termos exponenciais. A variável $\beta=1 / k_{b} T$ representando aqui o inverso da temperatura multiplicada pela constante de Boltzmann. Essa função conteria um conjunto de informações microscópicas suficiente para descrever as variáveis macroscópicas que caracterizariam tal sistema no equilíbrio. Contudo, calcular exatamente essa função é uma tarefa extremamente complicada, senão impraticável, para a maioria dos casos, uma vez que o número de estados envolvidos em geral é gigantesco.

Entretanto, para cadeias suficientemente pequenas, pode-se realizar essa conta manualmente ou com o auxílio de rotinas computacionais. Pensemos, a título de exemplo, numa cadeia de apenas 4 monômeros, sequência $H P P H$, inserida em uma rede quadrada. Digamos, a título de exemplo, que este pequeno sistema admite apenas quatro configurações (figura 2.3) distintas - sem levar em conta outros estados que podem ser gerados por meio de operações de rotação e reflexão -, onde três delas apresentam energia 0 e uma $-\epsilon$. Vamos interpretar a configuração de menor energia como sendo a 
forma nativa da cadeia e as outras três como as formas desnaturadas.

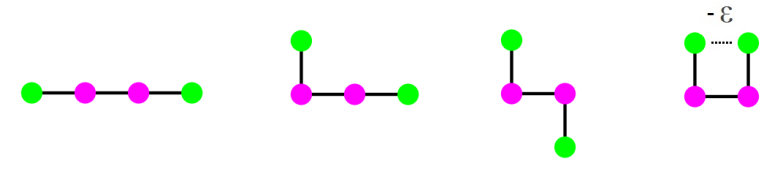

Figura 2.3: Contagem das configurações da cadeia HPPH. Para simplificar, estamos desconsiderando estados que podem ser obtidos por meio de operações de rotação e reflexão a partir dos já indicados.

Neste caso, a função de partição será dada por:

$$
Z(\beta)=3 . e^{-\beta .0}+1 . e^{\beta \epsilon}=3+e^{\beta \epsilon}
$$

de onde podemos deduzir a probabilidade de Boltzmann $P_{N}$ da proteína estar no seu estado nativo:

$$
P_{N}=\frac{e^{-\beta E_{N}}}{Z}=\frac{e^{\beta \epsilon}}{3+e^{\beta \epsilon}}
$$

e, analogamente, a probabilidade dela se encontrar desenovelada, $P_{D}$ :

$$
P_{D}=1-P_{N}=\frac{3}{3+e^{\beta \epsilon}}
$$
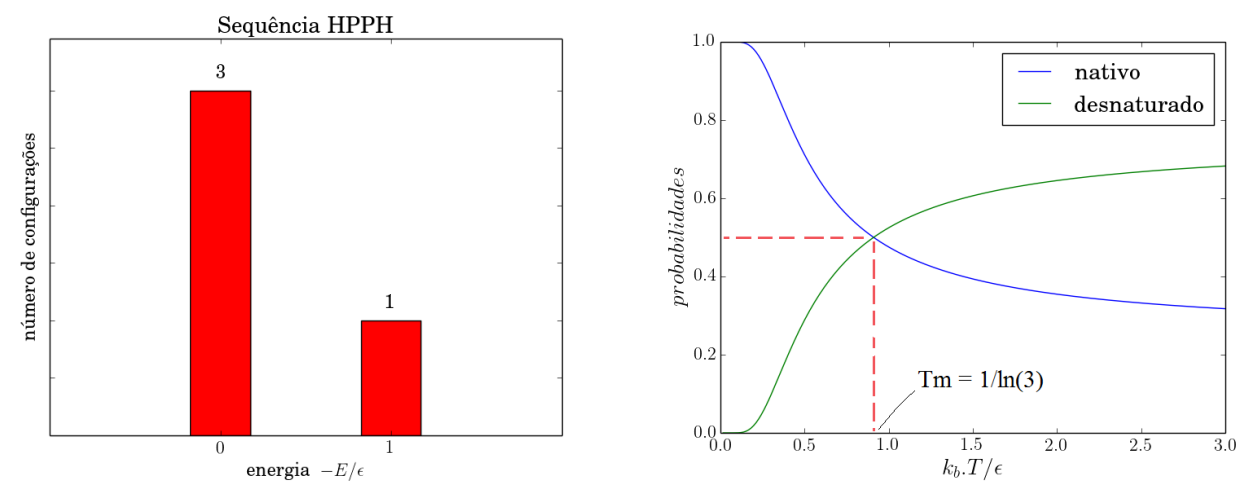

Figura 2.4: Histograma de energias e gráfico das probabilidades da cadeia estar na forma nativa $P_{N}$ (curva azul) e desnaturada $P_{D}=1-P_{N}$ (curva verde) em função da temperatura. A temperatura na qual metade das proteínas se encontram em média desenoveladas, $T_{m}$, vale exatamente $1 / \ln (3)$. 
Comparando-se as duas últimas equações, encontramos que a população de estados desenovelados supera a da forma nativa $\left(P_{D}>0.5\right)$ acima da temperatura $T_{m}=1 / \ln (3)$ (melting temperature), em unidades reduzidas de $\epsilon / k_{b}$. Porém, devido ao pequeno número de estados, vemos que a cadeia nunca se encontra completamente desnaturada. Mesmo a temperaturas bastante elevadas, onde todas as configurações se tornam equiprováveis, teríamos $P_{N} \approx 1 / 4$. Já em temperaturas baixas, menores do que $T_{m}$, é o estado nativo quem predomina sobre os demais, como pode ser visto na figura 2.4 à direita.

Outras grandezas de interesse que também podemos derivar da contagem de estados são, por exemplo, a energia média e a capacidade térmica. Usando a definição de valor médio no ensemble canônico, teremos que:

$$
\begin{gathered}
\langle E\rangle=\frac{\sum_{i=1}^{4} E_{i} \cdot e^{-\beta E_{i}}}{Z}=\frac{-\epsilon \cdot e^{\beta \epsilon}}{3+e^{\beta \epsilon}} \\
C_{v}=\frac{\left\langle E^{2}\right\rangle-\langle E\rangle^{2}}{k_{b} \cdot T^{2}}=\frac{1}{k_{b} \cdot T^{2}} \cdot\left(\frac{\epsilon^{2} \cdot e^{\beta \epsilon}}{3+e^{\beta \epsilon}}-\frac{\epsilon^{2} \cdot e^{2 \beta \epsilon}}{\left(3+e^{\beta \epsilon}\right)^{2}}\right)=k_{b}(\beta \epsilon)^{2} \cdot \frac{3 \cdot e^{\beta \epsilon}}{\left(3+e^{\beta \epsilon}\right)^{2}}
\end{gathered}
$$
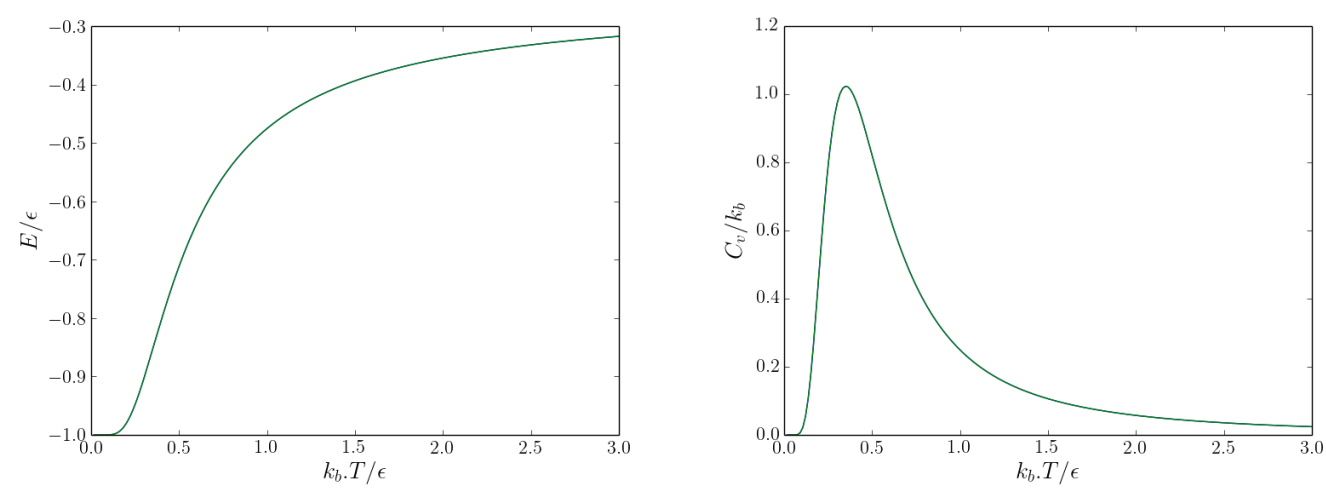

Figura 2.5: Energia média e capacidade térmica em função da temperatura.

A variação da energia média com a temperatura indica uma transição sigmoidal, correspondendo a um pico na curva da capacidade térmica (figura 2.5). O modelo prediz, portanto, uma passagem suave do estado nativo para o desenovelado mediante desnaturação térmica. Conforme se vai fornecendo energia ao sistema enovelado, as 
interações $H H$ vão sendo gradativamente rompidas. Assim, o calor que deve ser absorvido por essas "ligações"para que o sistema transite em direção ao estado desnaturado se reflete num pico da capacidade térmica. Esse comportamento suave, sem mudanças bruscas de um estado a outro, é geralmente chamado na literatura (Dill et al., 1995) de cooperatividade, denotando uma certa continuidade entre as etapas do enovelamento.

Apesar de bastante simples, o modelo de quatro resíduos já apresenta algumas características encontradas em polímeros reais com monômeros hidrofóbicos, como a "transição"contínua que acabamos de descrever. Naturalmente, o próximo nível de aproximação será aumentarmos o número de aminoácidos da cadeia, expandindo com isso o espaço conformacional e de sequências. Para tanto, precisaremos do auxílio de um algoritmo de contagem de estados, o qual descreveremos a seguir.

\section{Contagem das configurações permitidas}

No modelo HP, independente da sequência que escolhermos, haverá um conjunto de estados permitidos (ou seja, sem sobreposição de resíduos) para um dado tamanho da cadeia. Assim, se tivermos um polímero de $N$ resíduos, teremos um conjunto $C_{N}$ definido pelas configurações possíveis, sem choque estérico. A questão aqui será como gerar todas as configurações contidas em $C_{N}$.

Começamos por notar que qualquer configuração na rede pode ser completamente descrita pelos ângulos formados entre duas ligações sucessivas, ou então, por cada trio de monômeros (figura 2.6). Dessa forma, a sequência dos $N-2$ ângulos de uma cadeia de tamanho $N$ seria suficiente para especificar um único estado. Em uma rede quadrada, por exemplo, esses ângulos só podem assumir três valores distintos: $+90^{\circ}, 0^{\circ} \mathrm{e}-90^{\circ}$.

Se nomearmos estes ângulos de 0,1 e 2, respectivamente, então uma configuração qualquer poderá ser escrita simplesmente como uma sequência (120210...) desses valores, ou, visto de outra maneira, como um número na base 3 de $N-2$ dígitos. Tomemos 


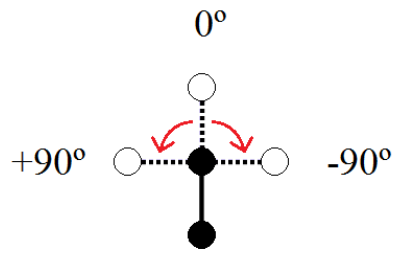

$$
\begin{aligned}
+90^{\circ} & =0 \\
0^{\circ} & =1 \\
-90^{\circ} & =2
\end{aligned}
$$

Figura 2.6: Duas ligações sucessivas definem um ângulo, dentre os três possíveis numa rede quadrada.

como exemplo um tetrâmero, $N=4$. Para descrever a conformação cujos ângulos são $1 \hat{2} 3=+90^{\circ}$ e $2 \hat{3} 4=-90^{\circ}$, usamos o número ternário 02, e assim por diante (ver figura abaixo).

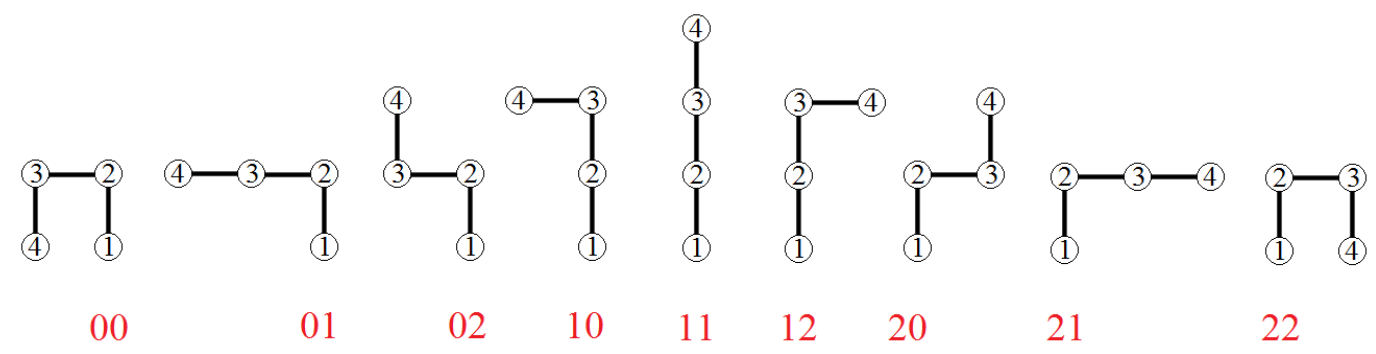

Figura 2.7: $C_{4}$ : conjunto das configurações com $N=4$ monômeros.

Uma primeira diferença com a análise da cadeia $H P P H$ que fizemos anteriormente é que, agora, estaremos considerando configurações simétricas por reflexão (no eixo vertical) como sendo distintas. Assim, $00 \neq 22$, embora para sequência-palíndromo HPPH elas sejam indistinguíveis. Uma segunda observação importante é que estaremos fixando as posições dos dois primeiros monômeros da cadeia na vertical, o monômero 1 em baixo e o 2 acima. A escolha é arbitrária, porém evita que contemos configurações rotacionadas. Como todas as configurações podem ser giradas de $90^{\circ}, 180^{\circ}$ e $270^{\circ}$, contá-las na função de partição seria o mesmo que multiplicá-la por um fator constante, não trazendo mudanças relevantes para o comportamento termodinâmico.

Por fim, se convertermos os números ternários em inteiros na base dez, teremos obtido um modo simples de enumerar todos os candidatos a configuração válida da proteína. 
Sendo assim, se o menor ternário $(000 \ldots 0)$ corresponde ao inteiro 0, e o maior ternário $(222 \ldots 2)$ ao número $2.3^{N-3}+2.3^{N-4}+\ldots+2.3^{1}+2.3^{0}=2 .\left(3^{N-2}-1\right) /(3-1)=3^{N-2}-1$, então, dentro da lista de inteiros contidos no intervalo $\left[0,3^{N-2}-1\right]$ estão todas as configurações em potencial do polímero de tamanho $N$.

$$
\begin{array}{lll}
00=0 & 10=3 & 20=6 \\
01=1 & 11=4 & 21=7 \\
02=2 & 12=5 & 22=8=3^{4-2}-1
\end{array}
$$

Figura 2.8: Cada conformação do tetrâmero é associada a um inteiro.

É claro, porém, que nem todos os números deste intervalo corresponderão a configurações permitidas. Basta ver, por exemplo, que para uma cadeia de tamanho $N=5$ os inteiros 0 (000) e 26 (222), levam à sobreposição dos monômeros da ponta, o que não é aceito como um estado válido (figura 2.9). A tarefa do algoritmo de enumeração exata é, portanto, eliminar da lista de candidatos aqueles que não correspondem a conformações permitidas.<smiles>[X][Ga]1CO[SiH2]1</smiles>
000

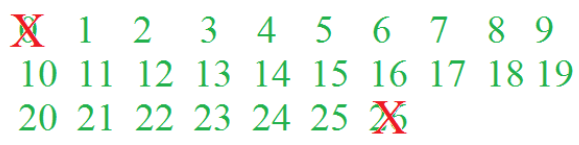

Figura 2.9: Sobreposição dos monômeros 1 e 5 de um pentâmero.

Em resumo, o algoritmo funciona do seguinte modo:

\section{Algoritmo de Enumeração Exata}

1. Inicie a rede com os dois primeiros monômeros na vertical.

2. Para cada número inteiro $n$ no intervalo $\left[0,3^{N-2}-1\right]$, repita os seguintes passos:

3. Converta $n$ para um número na base três e $N-2$ dígitos;

4. Adicione um por um os monômeros na rede conforme a ordem dos algarismos; 


\section{Se houver sobreposição de monômeros, pause o processo, reini- cie a rede e passe para o próximo inteiro $n+1$; \\ 6. Caso não haja sobreposição, adicione $n$ no conjunto das confi- gurações aceitas $C_{N}$.}

Tendo obtido, ao final do programa, a lista exata das configurações, $C_{N}$, podemos então calcular a função de partição e as outras grandezas de interesse para qualquer sequência escolhida. Para tanto, basta uma rotina que acesse a listagem dos inteiros em $C_{N}$, converta-os para a notação ternária e reconstrua as configurações a partir dos ângulos codificados. Uma vez montada a lista é fácil extrair dela valores como a energia, o raio de giro $\left(R_{g}\right)$, a distância entre as pontas $(D)$ etc.

$$
\begin{aligned}
& R_{g}=\sqrt{\frac{1}{N} \sum_{k=1}^{N}\left|\mathbf{r}_{k}-\mathbf{r}_{c m}\right|^{2}} \quad, \quad D=\left|\mathbf{r}_{1}-\mathbf{r}_{N}\right| \\
& \left\langle R_{g}\right\rangle=\frac{\sum_{i} R_{g}^{i} \cdot e^{-\beta E_{i}}}{Z} \quad, \quad\langle D\rangle=\frac{\sum_{i} D_{i} \cdot e^{-\beta E_{i}}}{Z}
\end{aligned}
$$

Note que o algoritmo foi descrito considerando polímeros na rede quadrada. No caso da rede triangular, o que muda é que haverá mais ângulos possíveis entre duas ligações sucessivas: $+120^{\circ},+60^{\circ}, 0^{\circ},-60^{\circ}$ e $-120^{\circ}$. Logo, ao invés de representarmos configurações por meio de números ternários, teremos de fazer o mesmo só que na base 5 (o loop no passo 2 . do algoritmo seria então no intervalo $\left[0,5^{N-2}-1\right]$ ). De resto, o procedimento é idêntico. É claro que, devido ao maior número de combinações com 5 algarismos, a busca por estados permitidos na rede triangular será mais custosa computacionalmente. 


\subsubsection{Resultados para homopolímeros}

O algoritmo descrito acima foi implementado para cadeias nas redes quadrada e triangular, variando-se o número $N$ de monômeros. No primeiro caso, foi possível determinar as configurações permitidas $\left(C_{N}\right)$ para as cadeias de até $N=19$ monômeros, e, no caso da rede triangular, até $N=14$. Devido à limitação de memória computacional, nossa análise de enumeração exata ficou então restrita a tamanhos reduzidos, típicos de pequenos peptídeos. Em primeiro lugar, iremos discutir algumas das propriedades das cadeias constituídas unicamente por monômeros apolares, os homopolímeros $H_{n}$, e depois passaremos ao estudo dos heteropolímeros.

\section{Homopolímeros}

Experimentos com polímeros hidrofóbicos, como o poliestireno, revelam que os mesmos tendem a colapsar para estruturas compactas em solventes hidrofílicos. Além disso, essas estruturas colapsadas não produzem estados únicos, isto é, as configurações de baixa energia livre são altamente degeneradas, o que indica que o código formado por apenas um tipo de monômero não possui especificidade suficiente para gerar um estado nativo $^{1}$. Por meio da contagem das configurações $\Omega_{N}\left(n_{H H}\right)$ de uma cadeia de tamanho $N$, possuíndo $n_{H H}$ contatos de primeiros vizinhos, podemos observar que os homopolímeros de rede também apresentam essa degenerescência elevada para os estados de menor energia, a qual tende a crescer conforme se aumenta o número de monômeros (figura 2.10). Nas tabelas a seguir, apresentamos a distribuição de configurações, para cada tamanho de cadeia, em função do número de contatos topológicos, nas duas redes em questão.

\footnotetext{
${ }^{1}$ No modelo HP, chamamos de estado nativo uma conformação de menor energia com degenerescência igual a 1. Alguns autores também utilizam a terminologia estado gemisch, mistura em alemão, para se referir aos estados de menor energia com degenerescência maior do que 1 .
} 
Tabela 2.1: Distribuição das configurações $\Omega_{N}\left(n_{H H}\right)$ em função do número de contatos topológicos $n_{H H}$ para cadeias de tamanho $N=5-19$ (rede quadrada).

\begin{tabular}{|c|c|c|c|c|c|c|c|c|c|c|c|c|c|}
\hline$\overline{\mathrm{N}}$ & $\overline{\Omega_{\text {total }}}$ & $\overline{n_{H H}}=0$ & $\bar{~} 1$ & $\overline{2}$ & 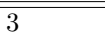 & 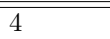 & $\overline{5}$ & $\bar{~} 6$ & 7 & $\overline{88}$ & $\overline{99}$ & 10 & 11 \\
\hline 5 & 25 & 17 & 8 & & & & & & & & & & \\
\hline 6 & 71 & 41 & 22 & 8 & & & & & & & & & \\
\hline 7 & 195 & 99 & 64 & 32 & & & & & & & & & \\
\hline 8 & 543 & 235 & 184 & 86 & 38 & & & & & & & & \\
\hline 9 & 1479 & 561 & 508 & 268 & 132 & 10 & & & & & & & \\
\hline 10 & 4067 & 1331 & 1344 & 850 & 346 & 196 & & & & & & & \\
\hline 11 & 11025 & 3167 & 3556 & 2458 & 1152 & 596 & 96 & & & & & & \\
\hline 12 & 30073 & 7485 & 9244 & 6900 & 3888 & 1606 & 888 & 62 & & & & & \\
\hline 13 & 81233 & 17753 & 23876 & 19250 & 11436 & 5660 & 2524 & 734 & & & & & \\
\hline 14 & 220375 & 41867 & 60884 & 52934 & 33472 & 19076 & 7444 & 3978 & 720 & & & & \\
\hline 15 & 593611 & 99043 & 154792 & 143140 & 96904 & 56594 & 27300 & 11310 & 4244 & 284 & & & \\
\hline 16 & 1604149 & 233157 & 389792 & 383628 & 276892 & 169214 & 91128 & 37466 & 17324 & 5410 & 138 & & \\
\hline 17 & 4311333 & 550409 & 979240 & 1018166 & 774040 & 500926 & 275232 & 134610 & 53040 & 21890 & 3780 & & \\
\hline 18 & 11616669 & 1293817 & 2442268 & 2681356 & 2149774 & 1459644 & 841890 & 444576 & 189650 & 79632 & 30716 & 3346 & \\
\hline 19 & 31164683 & 3048915 & 6080388 & 7008782 & 5894524 & 4168254 & 2537728 & 1362950 & 658576 & 267858 & 105212 & 30408 & 1088 \\
\hline
\end{tabular}

Tabela 2.2: Distribuição das configurações $\Omega_{N}\left(n_{H H}\right)$ em função do número de contatos topológicos $n_{H H}$ para cadeias de tamanho $N=5-14$ (rede triangular).

\begin{tabular}{ccllllllll}
\hline \hline $\mathrm{N}$ & $\Omega_{\text {total }}$ & $n_{H H}=0$ & 1 & 2 & 3 & 4 & 5 & 6 & 7 \\
\hline 5 & 103 & 27 & 32 & 24 & 20 & & & & \\
6 & 455 & 79 & 122 & 108 & 76 & 70 & & & \\
7 & 1991 & 233 & 422 & 470 & 366 & 264 & 216 & 20 & \\
8 & 8647 & 679 & 1458 & 1766 & 1746 & 1322 & 848 & 672 & 156 \\
9 & 37355 & 1983 & 4824 & 6758 & 6902 & 6536 & 4642 & 2760 & 2060 \\
10 & 160689 & 5759 & 15824 & 24290 & 28310 & 26898 & 23400 & 16478 & 9000 \\
11 & 688861 & 16717 & 50898 & 86396 & 107900 & 114940 & 101628 & 82360 & 58074 \\
12 & 2944823 & 48387 & 162158 & 299210 & 406820 & 457252 & 448830 & 376962 & 288266 \\
13 & 12559201 & 139897 & 510966 & 1021548 & 1489314 & 1796284 & 1857536 & 1708278 & 1377572 \\
14 & 53455781 & 403771 & 1597412 & 3435010 & 5359986 & 6855400 & 7555808 & 7318950 & 6385058
\end{tabular}

\begin{tabular}{clllllllll}
\hline \hline $\mathrm{N}$ & 8 & 9 & 10 & 11 & 12 & 13 & 14 & 15 & 16 \\
\hline 9 & 890 & & & & & & & & \\
10 & 6808 & 3532 & 390 & & & & & & \\
11 & 31770 & 22100 & 12606 & 3472 & & & & & \\
12 & 205522 & 116108 & 71966 & 42944 & 19414 & 984 & & & \\
13 & 1024262 & 720920 & 428574 & 239660 & 150838 & 78336 & 15216 & & \\
14 & 5025528 & 3666222 & 2524966 & 1555802 & 861174 & 516332 & 286056 & 103164 & 5142
\end{tabular}

Observa-se que os polímeros na rede triangular podem assumir uma quantidade maior de configurações e atingir energias mais baixas do que aquelas permitidas na rede quadrada. Essas características se devem à topologia da rede triangular, que fornece 
mais possibilidades de ordenação entre as ligações da cadeia e um maior número de vizinhos para os monômeros interagirem, 5 , ao invés de apenas 3 .

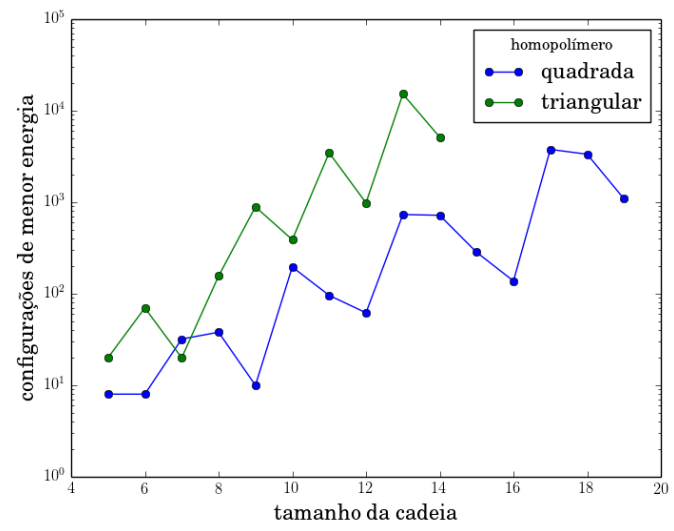

Figura 2.10: Estados com número máximo de contatos $H H$ em função do tamanho da cadeia. A degenerescência tende a aumentar junto com $N$.

A seguir, apresentamos os gráficos de energia média $(E)$, calor específico por resíduo $\left(c_{v}\right)$, distância entre as extremidades da cadeia $(D)$ e o raio de giro $\left(R_{g}\right)$ em função da temperatura, a qual realiza aqui o papel de fator desnaturante. As duas últimas variáveis citadas fornecem um indicativo das dimensões da proteína: quanto menos estendida ela estiver, menor serão os seus valores. De fato, observa-se o colapso das cadeias conforme a temperatura do sistema é reduzida, em ambas as redes e para todos os comprimentos testados (figuras 2.13, 2.14, 2.17 e 2.18). Essa transição, entre cadeia aberta e colapsada, se reflete em uma elevação do calor específico, presente em todas as cadeias a baixas temperaturas, uma vez que para atingir estruturas cada vez mais compactas a molécula precisa realizar mais interações entre seus monômeros. Curiosamente, há cadeias que apresentam um único pico na curva do calor específico, enquanto há outras que exibem dois picos ou uma composição não tão bem definida dos dois. O segundo pico, mais estreito e deslocado para a esquerda, é geralmente associado a uma transição dita de congelamento, na qual uma diversidade de estruturas compactas, não necessariamente de mínima energia, se converte para as conformações de menor energia. 


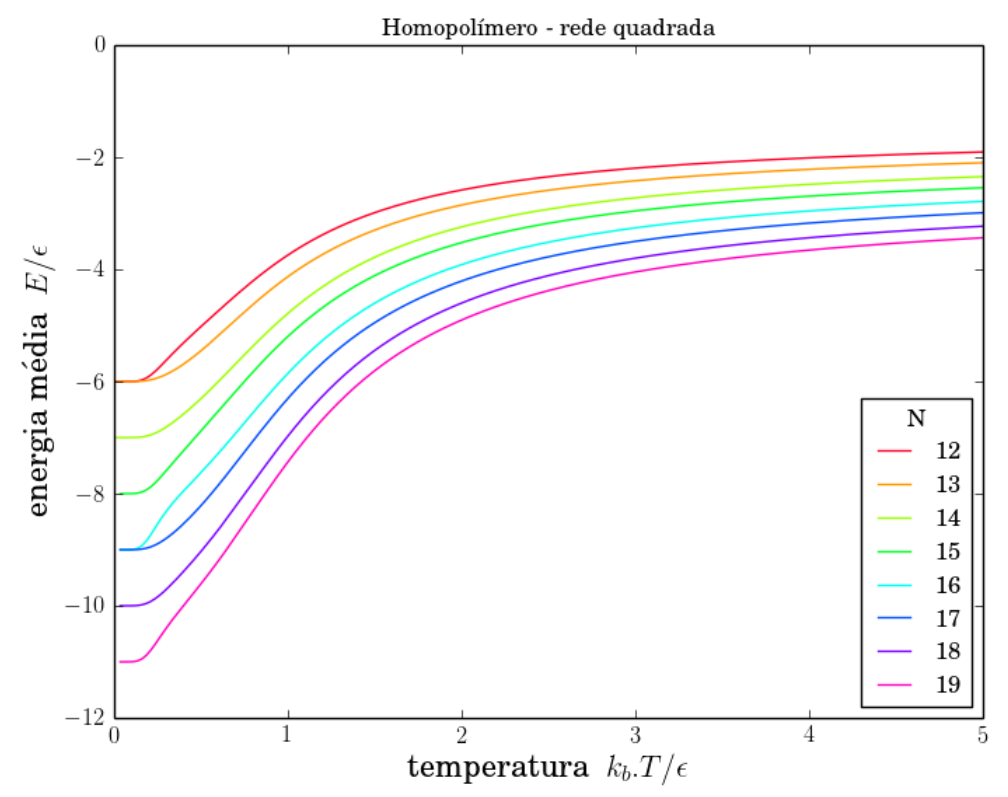

Figura 2.11: Energia média $\mathrm{x}$ temperatura, para homopolímeros $(N=12-19)$ na rede quadrada.

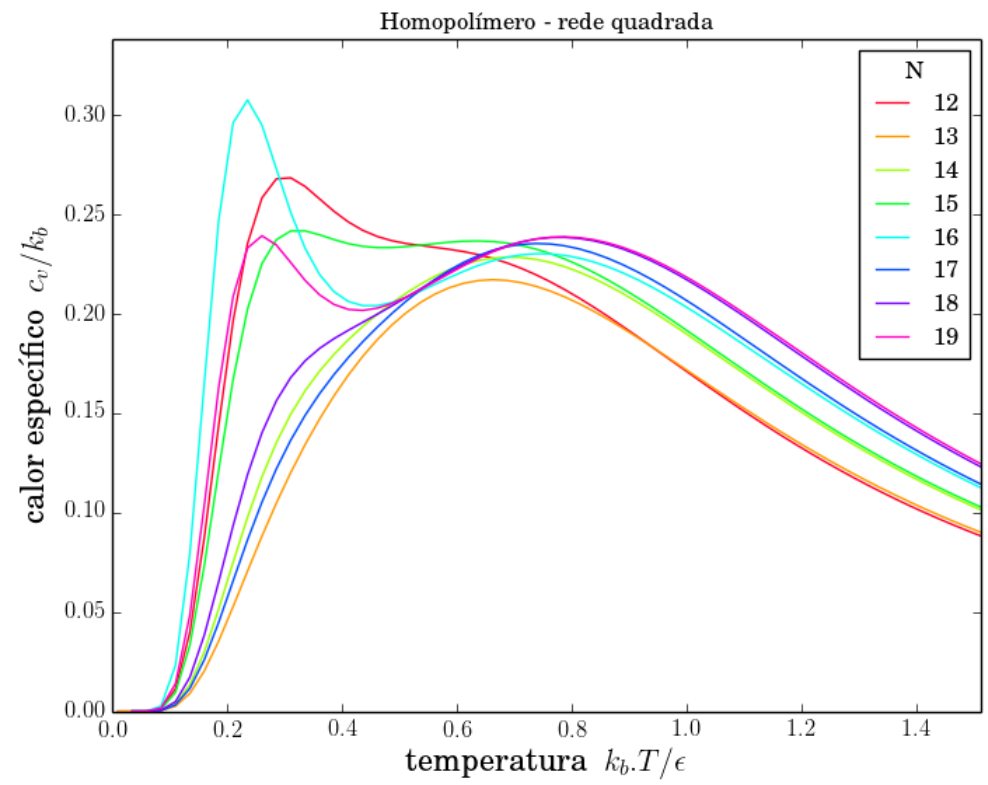

Figura 2.12: Calor específico por monômero x temperatura, para homopolímeros $(N=$ $12-19)$ na rede quadrada. 


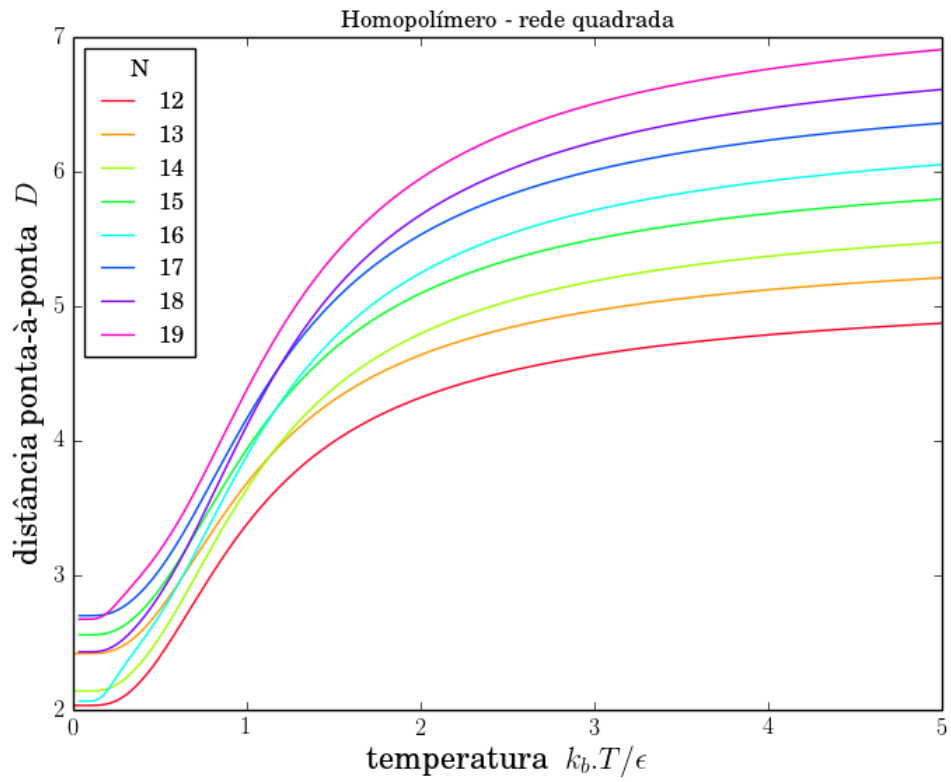

Figura 2.13: Distância entre pontas x temperatura, para homopolímeros $(N=12-19)$ na rede quadrada.

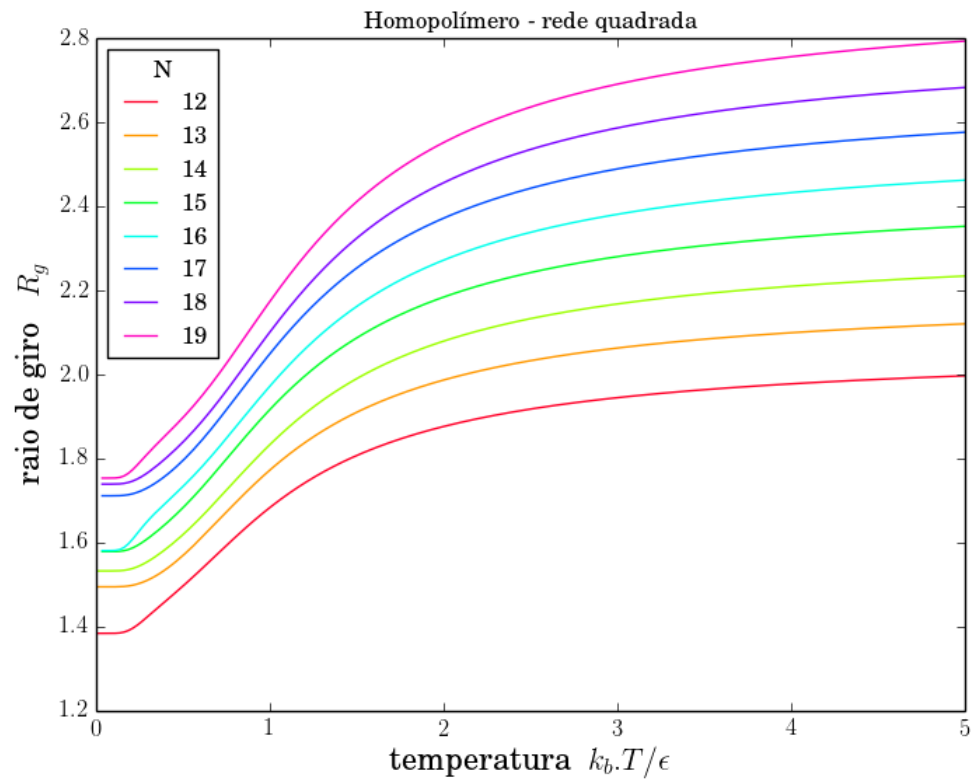

Figura 2.14: Raio de giro x temperatura, para homopolímeros $(N=12-19)$ na rede quadrada. 


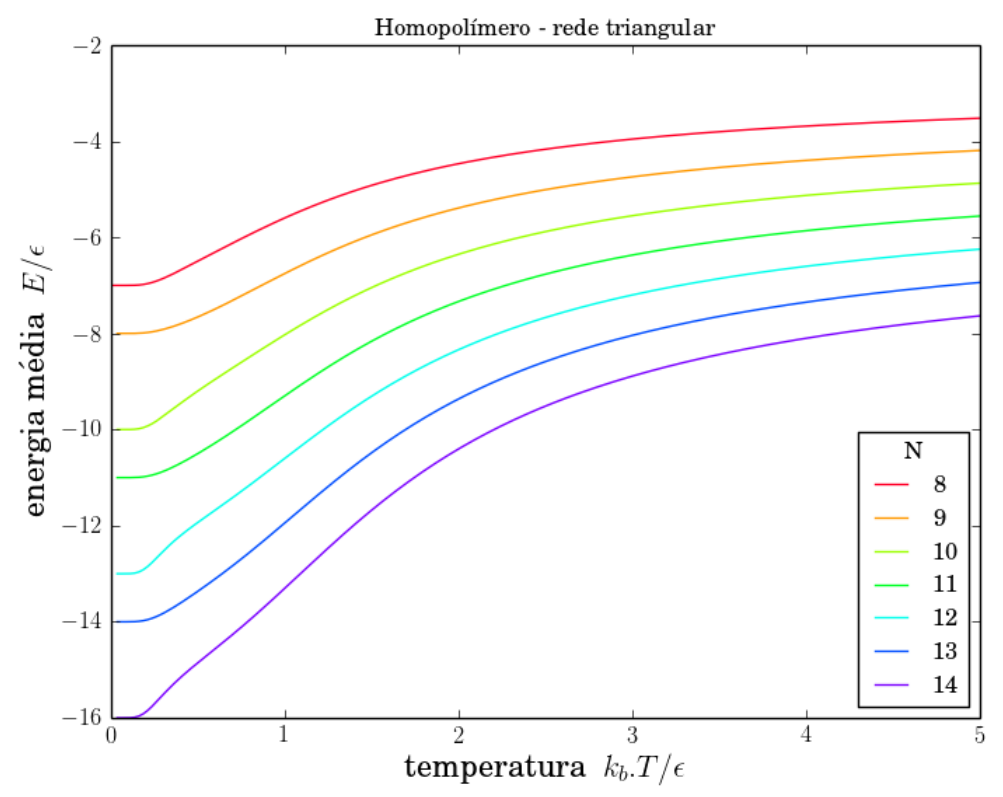

Figura 2.15: Energia média $\mathrm{x}$ temperatura, para homopolímeros $(N=8-14)$ na rede triangular.

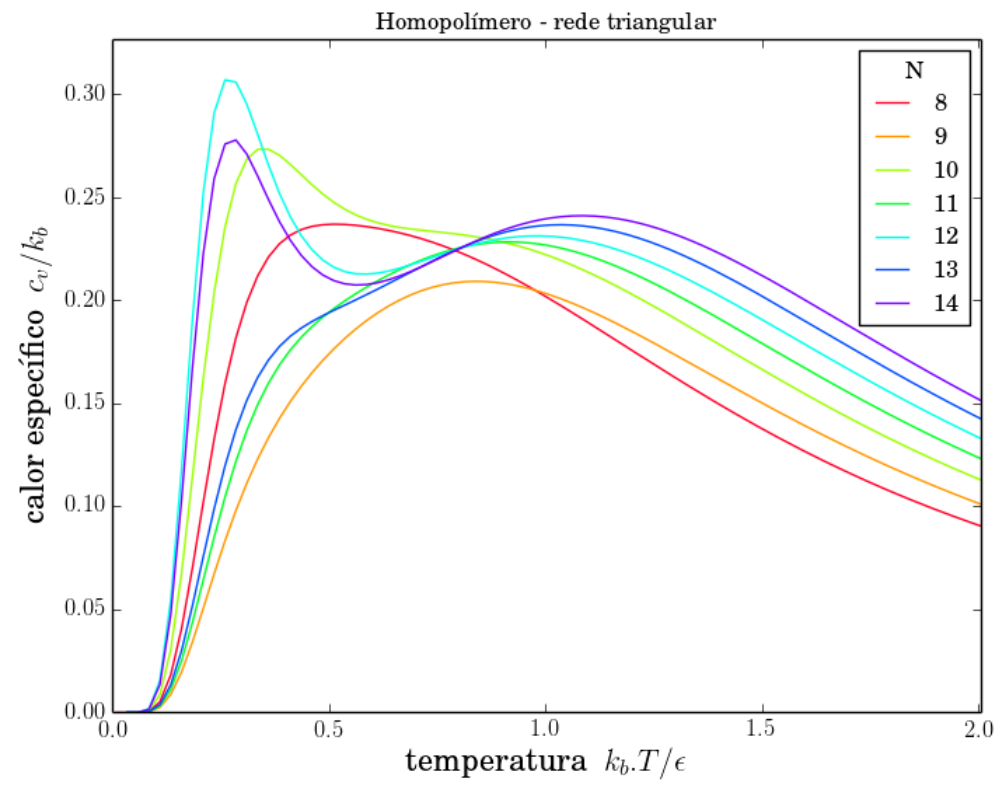

Figura 2.16: Calor específico por monômero x temperatura, para homopolímeros $(N=$ $8-14$ ) na rede triangular. 


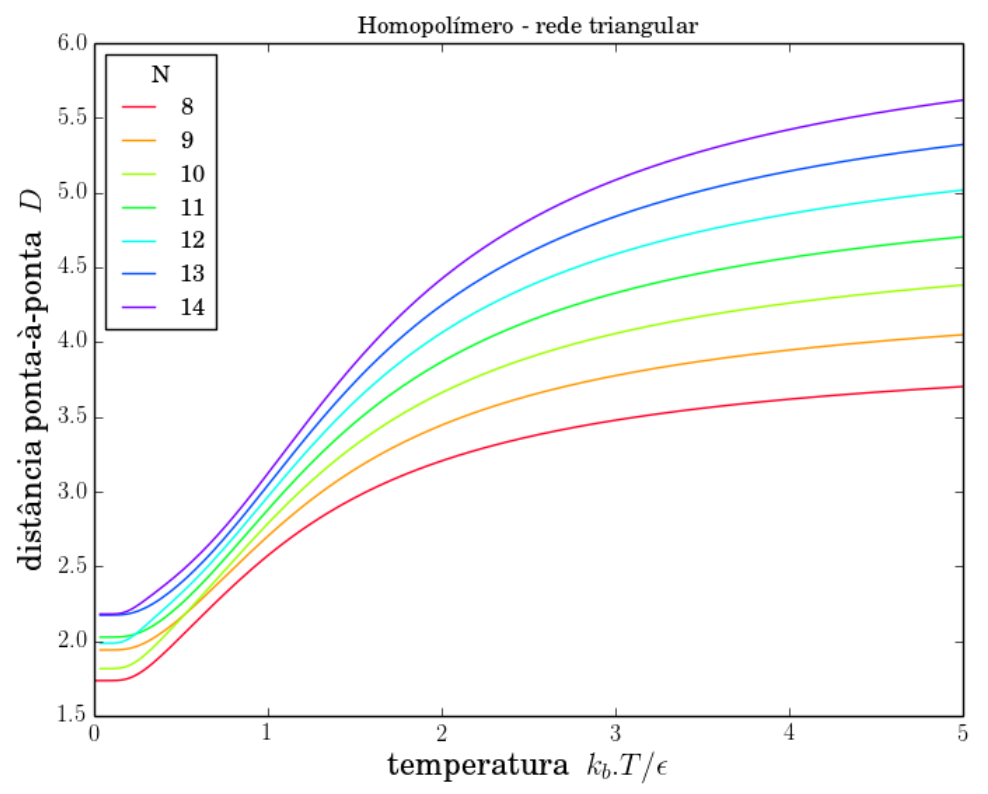

Figura 2.17: Distância entre pontas x temperatura, para homopolímeros $(N=8-14)$ na rede triangular.

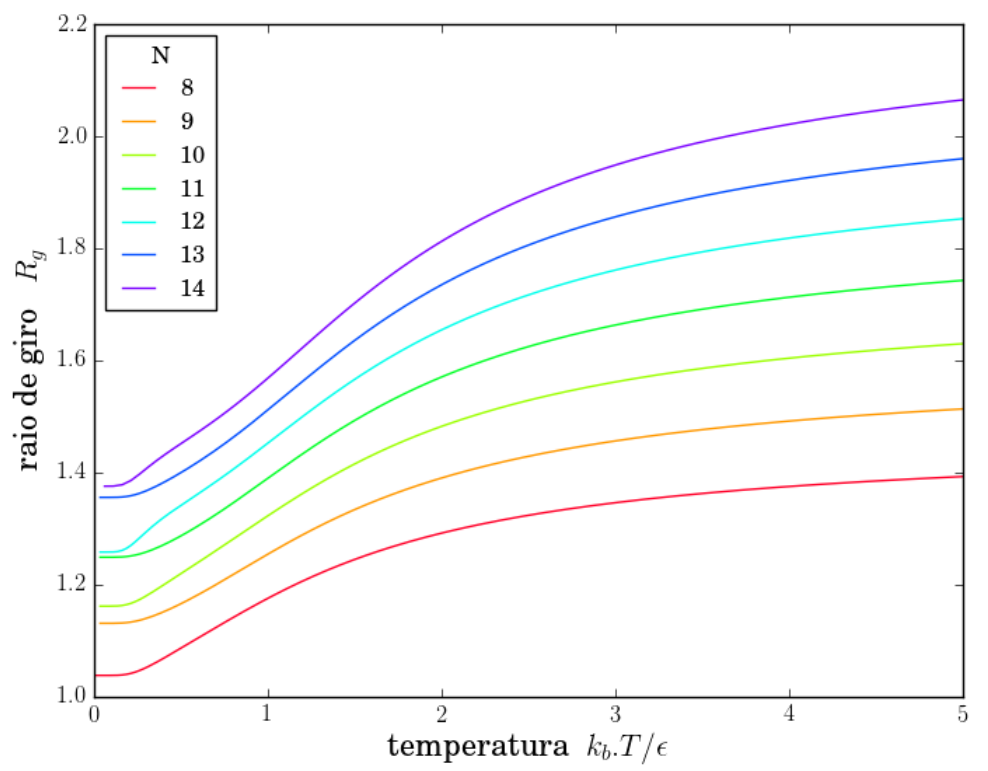

Figura 2.18: Raio de giro $\mathrm{x}$ temperatura, para homopolímeros $(N=8-14)$ na rede triangular. 


\subsubsection{Discussão sobre o duplo pico no calor específico}

Para entendermos melhor a presença de um segundo pico na curva do calor específico, selecionamos duas cadeias na rede quadrada $(N=16,17)$ com comportamentos bastante parecidos em relação a essa função, com exceção de que uma delas apresenta um único pico $(N=17)$ e a outra dois $(N=16)$, conferir figura 2.19 ; da mesma forma, também selecionamos duas cadeias desse tipo na rede triangular $(N=13,14)$, figura 2.21 . Em seguida, analisando o perfil dos histogramas de energia das cadeias - tabelas 2.1 e 2.2 -, buscamos identificar as diferenças que pudessem justificar a presença ou a ausência do referido pico.

Em primeiro lugar, nota-se que as cadeias que apresentam o segundo pico possuem um gap bastante pronunciado no número de conformações entre os primeiros estados excitados e os estados de menor energia. Em outras palavras, se o número máximo de contatos $H H$ for $n_{m a ́ x}$, então, observa-se que a razão do número de estados $\Omega\left(n_{m a ́ x}-1\right)$ por $\Omega\left(n_{m a ́ x}\right)$ é bem maior para as cadeias com duplo pico $(N=16$, na rede quadrada, e $N=14$, na triangular) do que para aquelas com apenas um:

rede quadrada:

$$
\frac{\Omega_{16}\left(n_{\text {máx }}-1\right)}{\Omega_{16}\left(n_{\text {máx }}\right)}=\frac{5410}{138}=39,202 \quad \frac{\Omega_{17}\left(n_{\text {máx }}-1\right)}{\Omega_{17}\left(n_{\text {máx }}\right)}=\frac{21890}{3780}=5,791
$$

rede triangular:

$$
\frac{\Omega_{13}\left(n_{m a ́ x}-1\right)}{\Omega_{13}\left(n_{m a ́ x}\right)}=\frac{78336}{15216}=5,148 \quad \frac{\Omega_{14}\left(n_{m a ́ x}-1\right)}{\Omega_{14}\left(n_{m a ́ x}\right)}=\frac{103164}{5142}=20,063
$$

Essa diferença fica ainda mais evidente quando observamos os gráficos de $\Omega\left(n_{H H}\right) / \Omega\left(n_{H H}+\right.$ 1) em função do número de contatos $n_{H H}$, ver figuras 2.19 e 2.21 à direita. Nota-se que essa razão possui um crescimento acentuado para as cadeias com duplo pico quando $n_{H H}$ atinge o valor correspondente ao primeiro estado excitado, indicando que o número 
de configurações desse estado é muito mais degenerado do que os do estado de mínima energia. Isso significa que, para a cadeia alcançar as configurações de menor energia, ela precisa reduzir bruscamente o seu espaço conformacional em relação ao primeiro estado excitado. Tal redução não seria tão drástica para as cadeias com um só pico.

A mudança na população de energias $P(E)$ em função da temperatura pode ser acompanhada nas figuras 2.20 e 2.22. Nelas podemos ver que, na região do segundo pico, acontece uma inversão entre as populações de menor energia e as do primeiro estado excitado para os homopolímeros que apresentam o duplo pico; o que não ocorre para as cadeias de um único pico, nas quais essa região de temperaturas é toda dominada pelos estados de mínima energia. Isso indica que, a baixas temperaturas, a competição entre os $\Omega\left(n_{\text {máx }}\right)$ estados de menor energia e os $\Omega\left(n_{\text {máx }}-1\right)$ estados um nível de energia acima depende fortemente da proporção entre eles: quanto maior for o gap de configurações, menor será a temperatura na qual haverá a inversão de populações, $P\left(E_{\text {mín }}\right)>P\left(E_{\text {mín }}+1\right)$, uma vez que haverá relativamente pouquíssimas configurações de menor energia competindo com um grande número de conformações do próximo estado excitado. Se o gap for suficientemente grande, a transição dessas populações se deslocará para regiões de temperaturas cada vez menores, o bastante para se descolar do pico principal e se distinguir na curva do calor específico.

Assim, o gap de configurações nos sugere um critério para indicar a ocorrência do segundo pico, embora possa não ser suficiente, já que nossa análise se limitou apenas às cadeias acima mencionadas. Não está claro também o quão grande deve ser essa diferença de configurações para podermos caracterizar com distinção o referido pico. No entanto, é interessante observar como cadeias tão simples, quanto as que estudamos no modelo HP, podem exibir comportamentos termodinâmicos diversos à medida que o espaço conformacional vai sendo reduzido. As transições de colapso e congelamento observadas até aqui têm se mostrado coerentes com os estágios de colapso hidrofóbico seguido de um ordenamento mais rígido para o estado nativo, descritos no capítulo 1. 

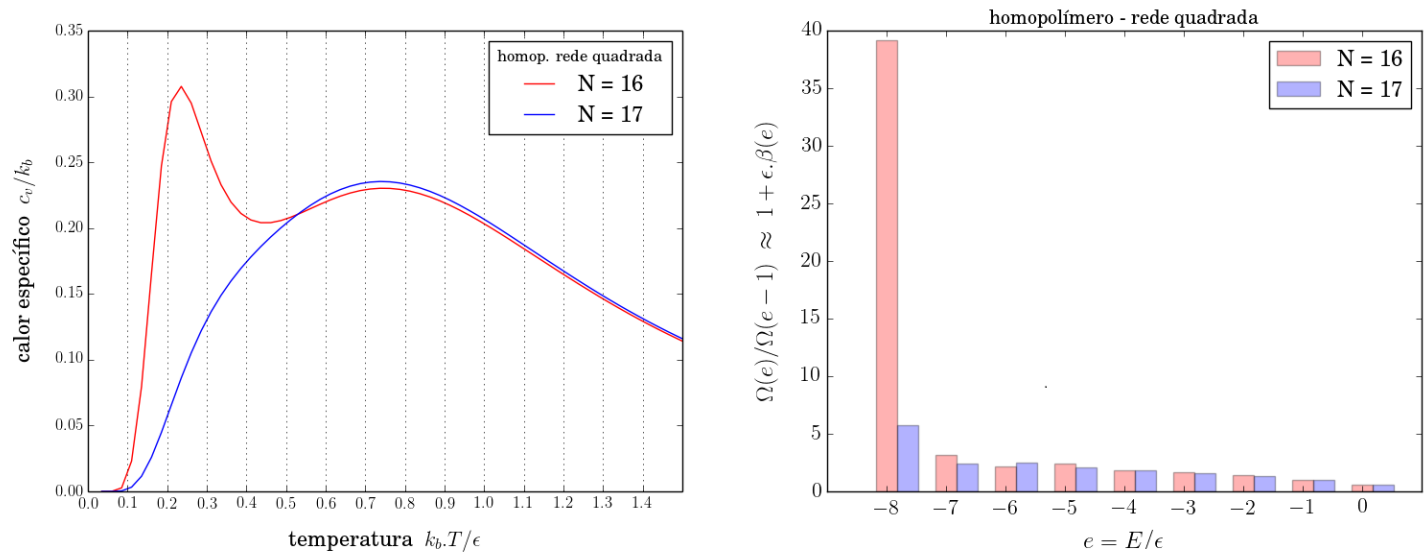

Figura 2.19: Comparação do calor específico (à esquerda) e da razão de estados (à direita) entre os homopolímeros $H_{16}$ e $H_{17}$ na rede quadrada. Obs. $e=E / \epsilon=-n_{H H}$.
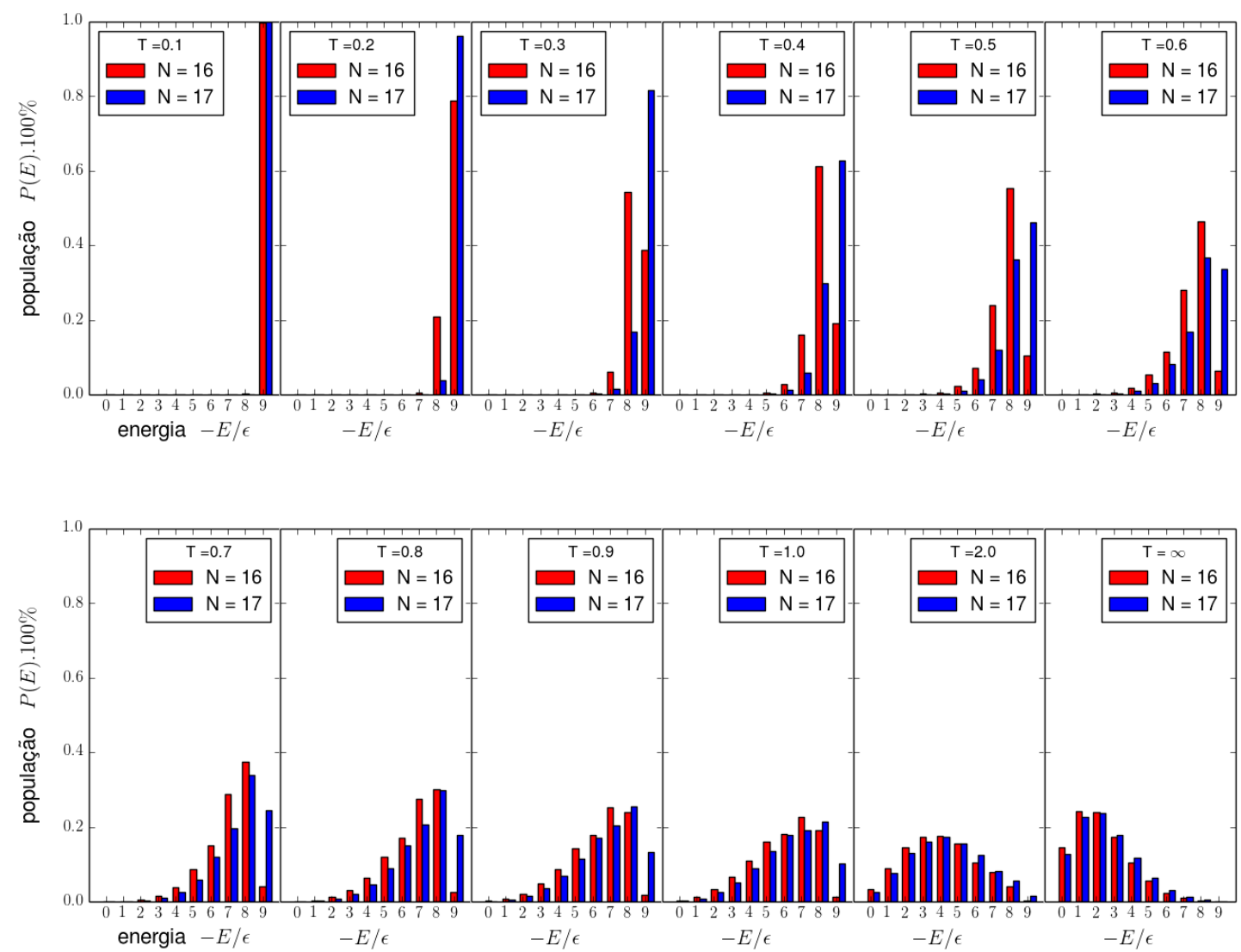

Figura 2.20: População de energias em função da temperatura para $H_{16}$ e $H_{17}$. 

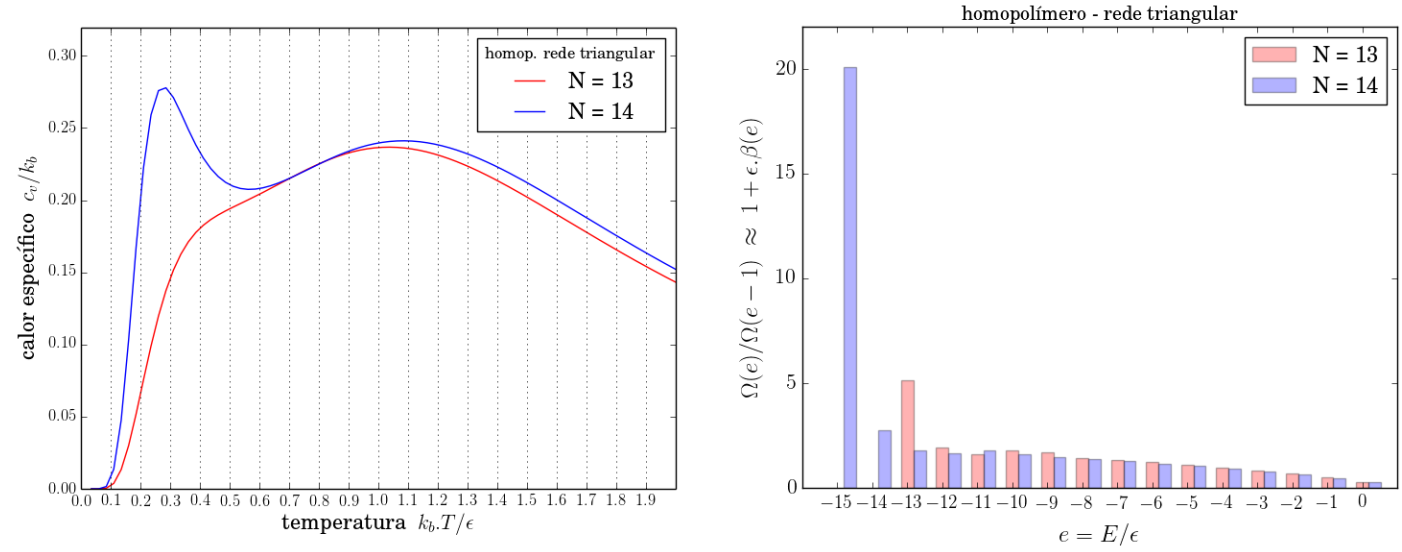

Figura 2.21: Comparação do calor específico (à esquerda) e da razão de estados (à direita) entre os homopolímeros $H_{13}$ e $H_{14}$ na rede triangular. Obs. $e=E / \epsilon=-n_{H H}$.
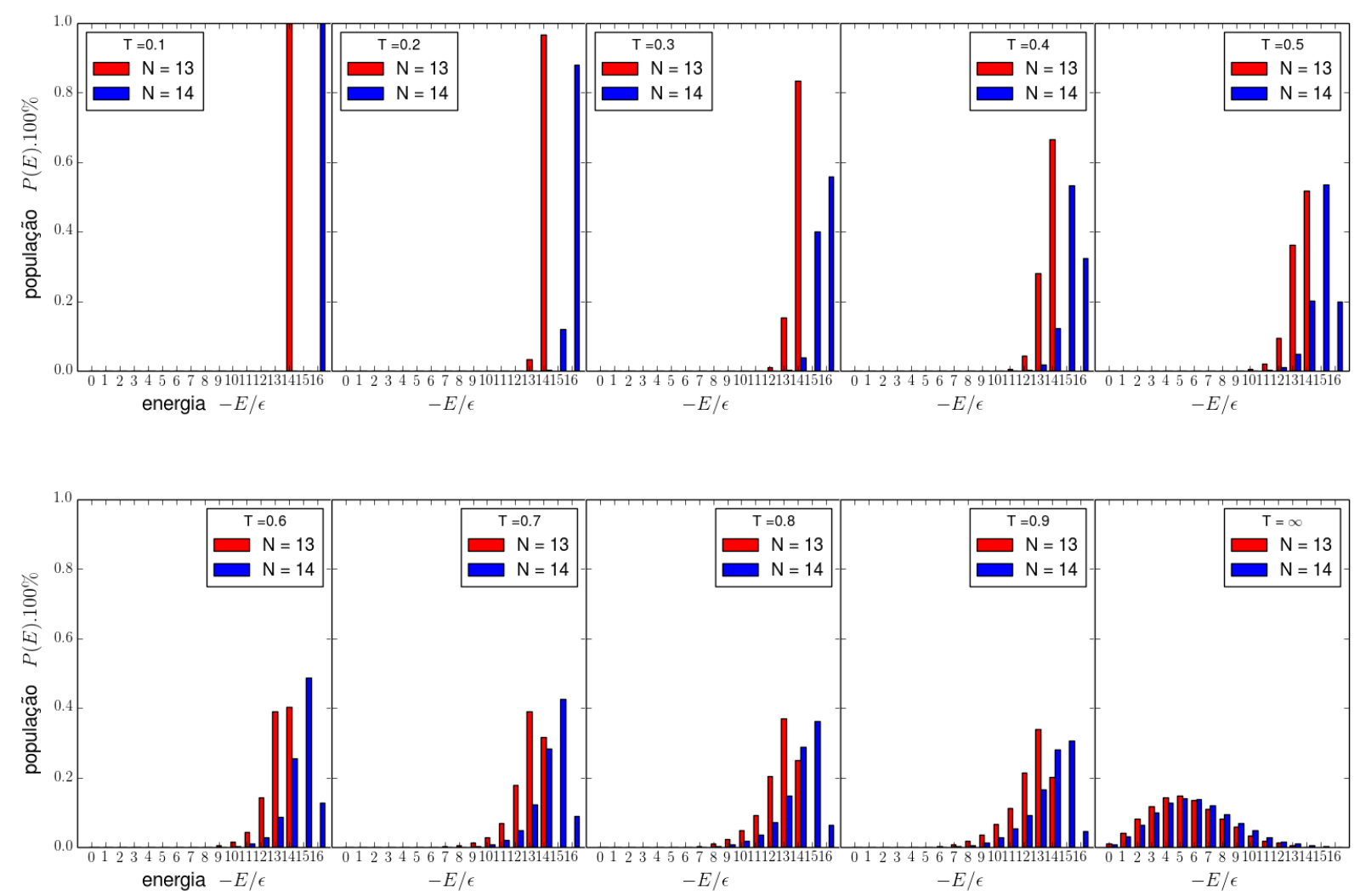

Figura 2.22: População de energias em função da temperatura para $H_{13}$ e $H_{14}$. 
Uma maneira de interpretar a razão $\Omega(n-1) / \Omega(n)$ é tentarmos relacioná-la com a variação de entropia microcanônica com a energia. Para isso, considere a seguinte aproximação:

$$
1-\frac{\Omega(n-1)}{\Omega(n)}=\frac{1}{\Omega(n)} \cdot \frac{\Omega(n)-\Omega(n-1)}{1} \approx \frac{1}{\Omega(n)} \cdot \frac{\partial \Omega(n)}{\partial n}=\frac{\partial \ln [\Omega(n)]}{\partial n}
$$

a qual será tanto mais válida quanto maior for o valor de $n(\Delta n=1 \ll n)$. Claro que, no nosso caso, esta será uma aproximação grosseira, uma vez que o número máximo de contatos $n_{m a ́ x}$ das sequências que estudamos não passa de duas dezenas. Se trocarmos a variável $n$ pela energia $E=-n \epsilon$, podemos obter a entropia microcanônica $S=$ $k_{b} \ln [\Omega(E)]$. Assim, aplicando a regra da cadeia na derivada anterior, teremos:

$$
=\frac{\partial \ln [\Omega(E)]}{\partial E} \cdot \frac{\partial E}{\partial n}=\frac{-\epsilon}{k_{b}} \cdot \frac{\partial S(E)}{\partial E}
$$

Portanto, a razão entre os ômegas fornece uma medida aproximada da taxa de variação da entropia microcanônica com a energia, ou então, uma estimativa da temperatura no ensemble canônico em torno da faixa de energias $(E(n-1), E(n))$ :

$$
\frac{\Omega(n-1)}{\Omega(n)}=1+\frac{\epsilon}{k_{b}} \cdot \frac{\partial S(E)}{\partial E}=1+\frac{\epsilon}{k_{b} T(E)}
$$

Segundo a equação 2.11 , a relação que havíamos postulado entre a presença do segundo pico no calor específico e a razão elevada dos ômegas de menor energia, $\Omega\left(n_{m a ́ x}-\right.$ 1) $/ \Omega\left(n_{\text {máx }}\right)$, também poderia ser expressa em termos de uma queda mais brusca na entropia do sistema a baixas energias, em comparação com as outras regiões de maior energia. Ou então, poderíamos supor que o pico seria mais evidente quanto menor fosse a temperatura necessária para o sistema atingir uma energia média próxima àquela do estado nativo, quando comparada com as temperaturas correspondentes às energias médias maiores. 

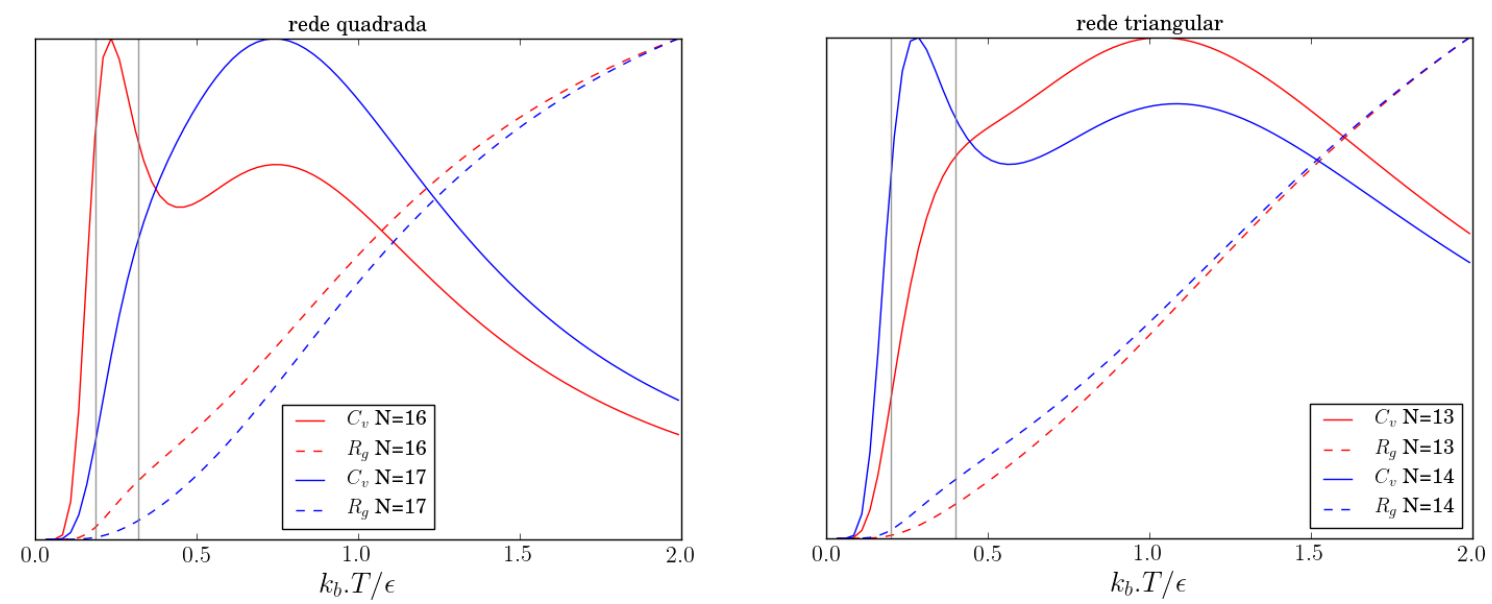

Figura 2.23: Comparação entre os calores específicos e os raios de giração de cadeias com um e dois picos. Na rede quadrada tomamos $N=16$ e 17 , na triangular $N=13$ e 14. As curvas estão escaladas de tal forma que os máximos e mínimos de cada um delas estejam limitados no mesmo intervalo do eixo vertical.

Uma outra comparação que podemos fazer entre as cadeias com um único pico e aquelas com duplo pico se dá pela verificação de que aquelas possuem um comportamento tipicamente sigmoidal no raio de giro, assim como na energia média e na distância entre as pontas (fig. 2.11-18), enquanto que nestas o comportamento sigmóide sofre um pequeno desvio (uma mudança de concavidade) na faixa de temperaturas onde se localiza o segundo pico, isto é, na região de congelamento. Na figura 2.23, sobrepomos no mesmo gráfico o calor específico e o raio de giração de algumas cadeias. Observa-se que, no caso das cadeias com dois picos, o raio de giro cresce mais rapidamente com a temperatura na região do pico mais estreito. Isso significa que, embora seja necessário fornecer mais calor para aumentar a temperatura do sistema, a compactação dessas cadeias sofre uma variação mais brusca nesta faixa de temperaturas. Como vimos, nela ocorre uma troca de populações entre os estados de menor energia (mais compactos devido ao maior número de contatos $\mathrm{HH}$ ) e os primeiros estados excitados (menos compactos), porém o número daqueles é relativamente bastante inferior a estes, $\Omega\left(E_{m i ́ n}\right) \ll \Omega\left(E_{m i ́ n}+\epsilon\right)$, de modo que as variações nas grandezas citadas são mais bruscas ali. 


\subsubsection{Resultados para heteropolímeros}

A introdução de mais uma letra $(\mathrm{P})$ no modelo, com a intenção de representar os monômeros polares, resulta imediatamente numa ampliação do espaço disponível de sequências: enquanto um homopolímero de tamanho $N$ só pode assumir uma única sequência $\left(H_{N}\right)$, um heteropolímero dispõe de $2^{N}$ combinações possíveis entre monômeros $\mathrm{H}$ e P. Por não serem interagentes no modelo, os monômeros polares tem o efeito de aumentar o número de conformações de alta energia e reduzir o espectro de energias, uma vez que eles estariam frustando interações que ocorreriam no caso de um homopolímero. A diferença mais notável, porém, entre as sequências HP com relação aos homopolímeros é o fato de que elas apresentam especificidade suficiente para gerar uma configuração de menor energia única, ou seja, de codificar um estado nativo. Desse ponto de vista, o código de duas letras seria mais adequado para a representação de proteínas. Nas figuras abaixo exibimos o histograma de três sequências nativas e suas respectivas conformações mais estáveis (observação: como estamos contando conformações relacionadas por reflexão, o estado nativo das sequências será formado por duas configurações espelhadas e não apenas uma).
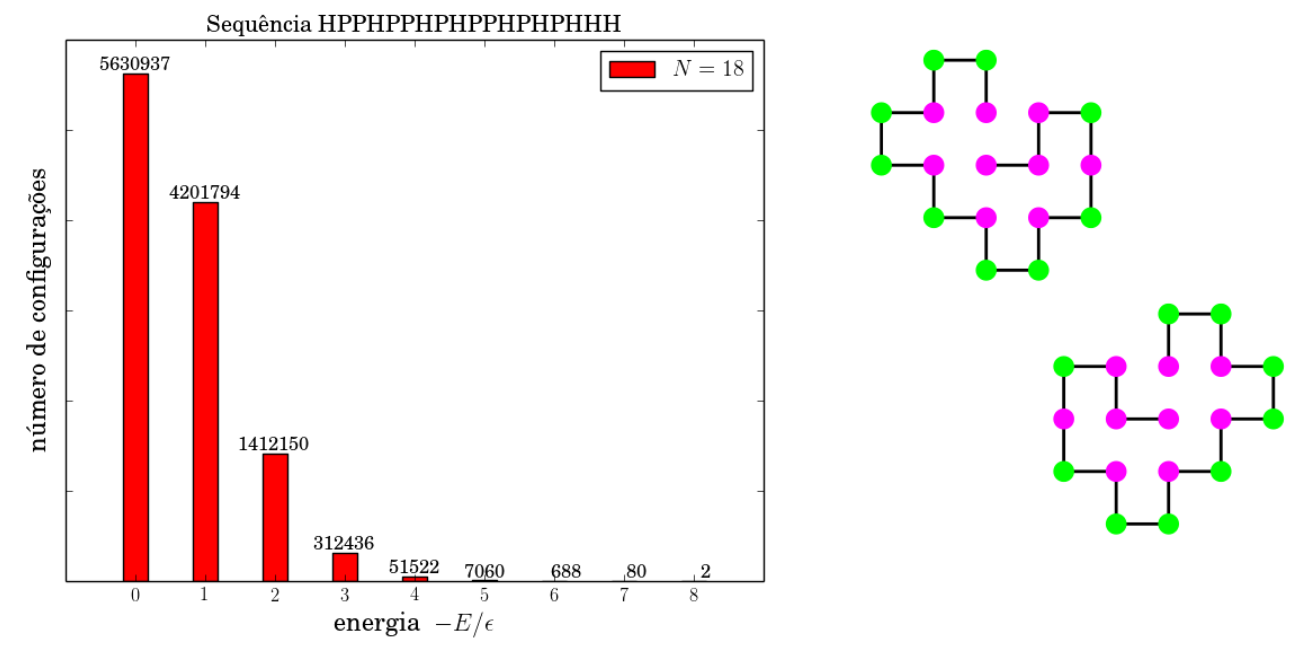

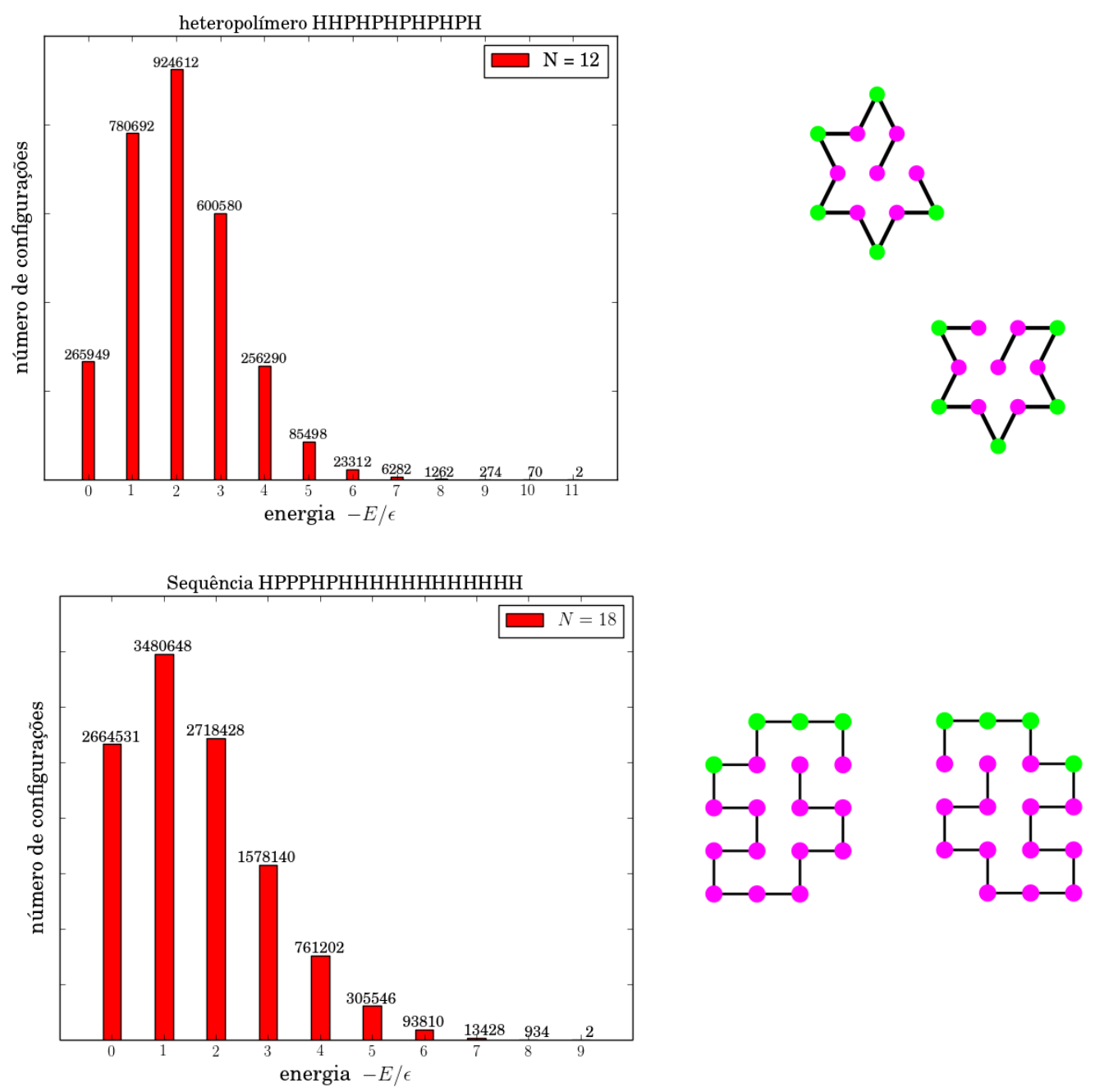

Figura 2.24: Sequências HP com suas respectivas configurações nativas. As sequências na rede quadrada foram selecionadas do trabalho de (Dill et al., 1995); já a da rede triangular foi encontrada por tentativa e erro.

Com relação às grandezas que viemos estudando até agora $\left(E, c_{v}, D\right.$ e $\left.R_{g}\right)$, observamos um comportamento qualitativo muito parecido ao dos homopolímeros: as sequências HP também sofrem um colapso hidrofóbico a baixas temperaturas e as curvas do calor específico também podem apresentar um ou dois picos, dependendo da sequência. Para exemplificar esses comportamentos, selecionamos sete sequências HP na rede quadrada (tabela 2.3) relacionadas entre si por algumas mutações pontuais, 
sendo que uma delas, Seq.4, é uma das sequências nativas exibidas acima.

Tabela 2.3: Sequências HP na rede quadrada $(\mathrm{N}=18)$.

\begin{tabular}{cl}
\hline \hline Número & Sequência \\
\hline 1 & HHPHHHHHHHHHHHHHHH \\
2 & HHPHHPHHHHHHHHHHHH \\
3 & HHPPHPHHHHHHHHHHHH \\
4 & HPPPHPHHHHHHHHHHHH \\
5 & HHPPHPHHHHPHHHHHHH \\
6 & HHPPHPHHHHPHPHHHHH \\
7 & HHPPHPHHHHPHPHPHHH
\end{tabular}
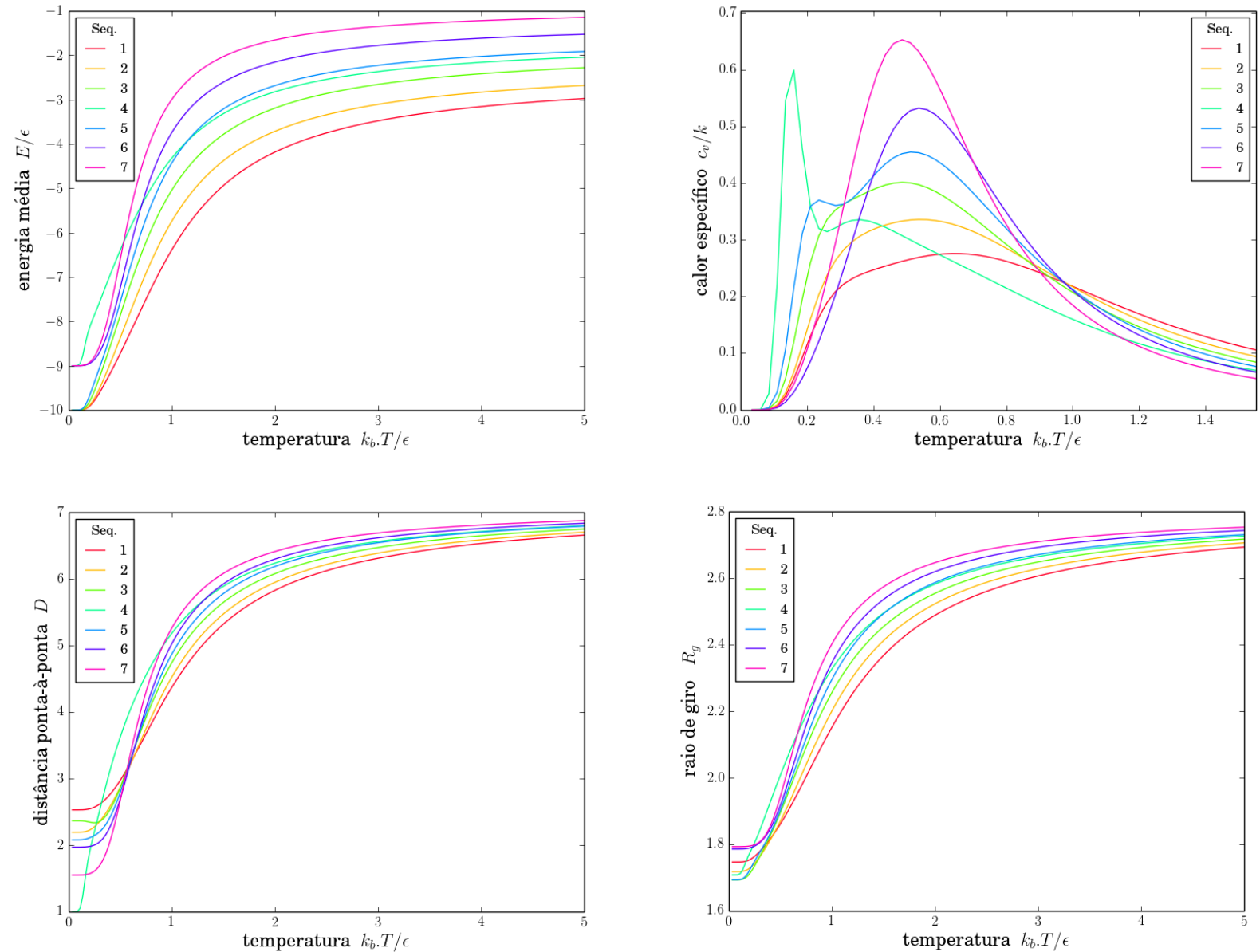

Figura 2.25: $E, c_{v}, D$ e $R_{g}$ em função da temperatura para sete heteropolímeros na rede quadrada. 
De forma consistente com a análise feita anteriormente para explicar a presença do segundo pico na curva de $c_{v}$, verifica-se que as duas sequências que exibem claramente dois picos (Seq. 4 e 5) na rede quadrada são aquelas para as quais a razão $\Omega\left(n_{m a ́ x}-\right.$ 1) $/ \Omega\left(n_{\text {máx }}\right)$ assume um valor relativamente alto, ver figura 2.25 . No caso, ele vale 467 e 60 para as sequências 4 e 5, respectivamente, enquanto que para as demais essa proporção não ultrapassa 30:

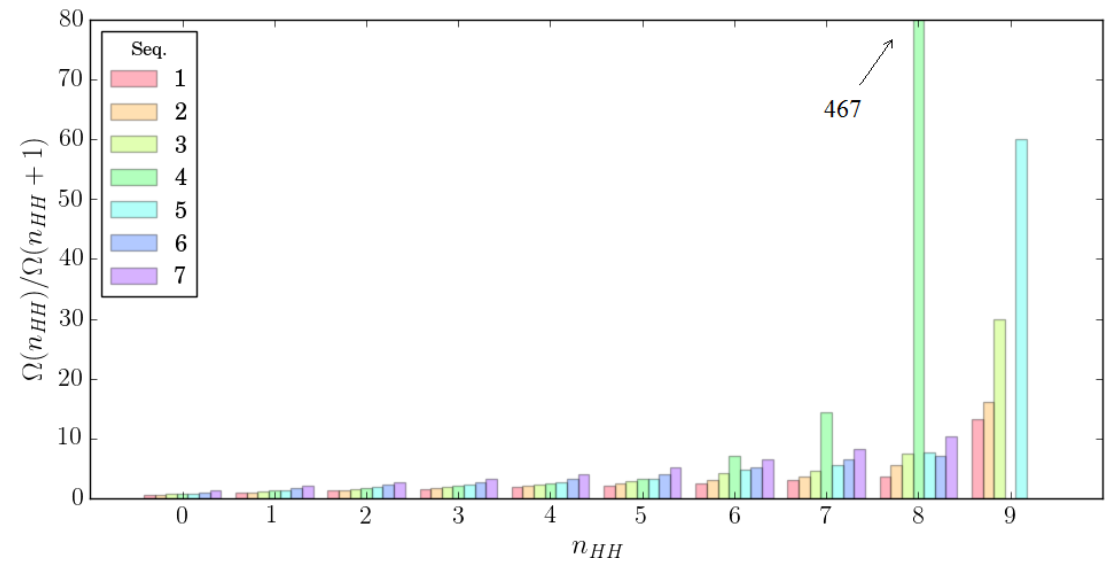

Figura 2.26: Razão entre $\Omega\left(n_{H H}\right)$ sucessivos para algumas sequências HP na rede quadrada.

Na rede triangular escolhemos quatro sequências (tabela 2.4), sendo a Seq.1 a cadeia com configuração nativa mostrada na figura 2.23. As sequências 2 e 3 foram escolhidas de tal modo a tentar preservar a estrutura do núcleo hidrofóbico da primeira cadeia, em forma de hexágono, mas aumentando o número de monômeros polares. A última sequência é aleatória.

Tabela 2.4: Sequências HP na rede triangular.

\begin{tabular}{cl}
\hline \hline Número & Sequência \\
\hline 1 & HHPHPHPHPHPH \\
2 & HHPPHHPPPHPHH \\
3 & HPHHHHPPHPPPPH \\
4 & HPPPPHPPHPPHPP
\end{tabular}



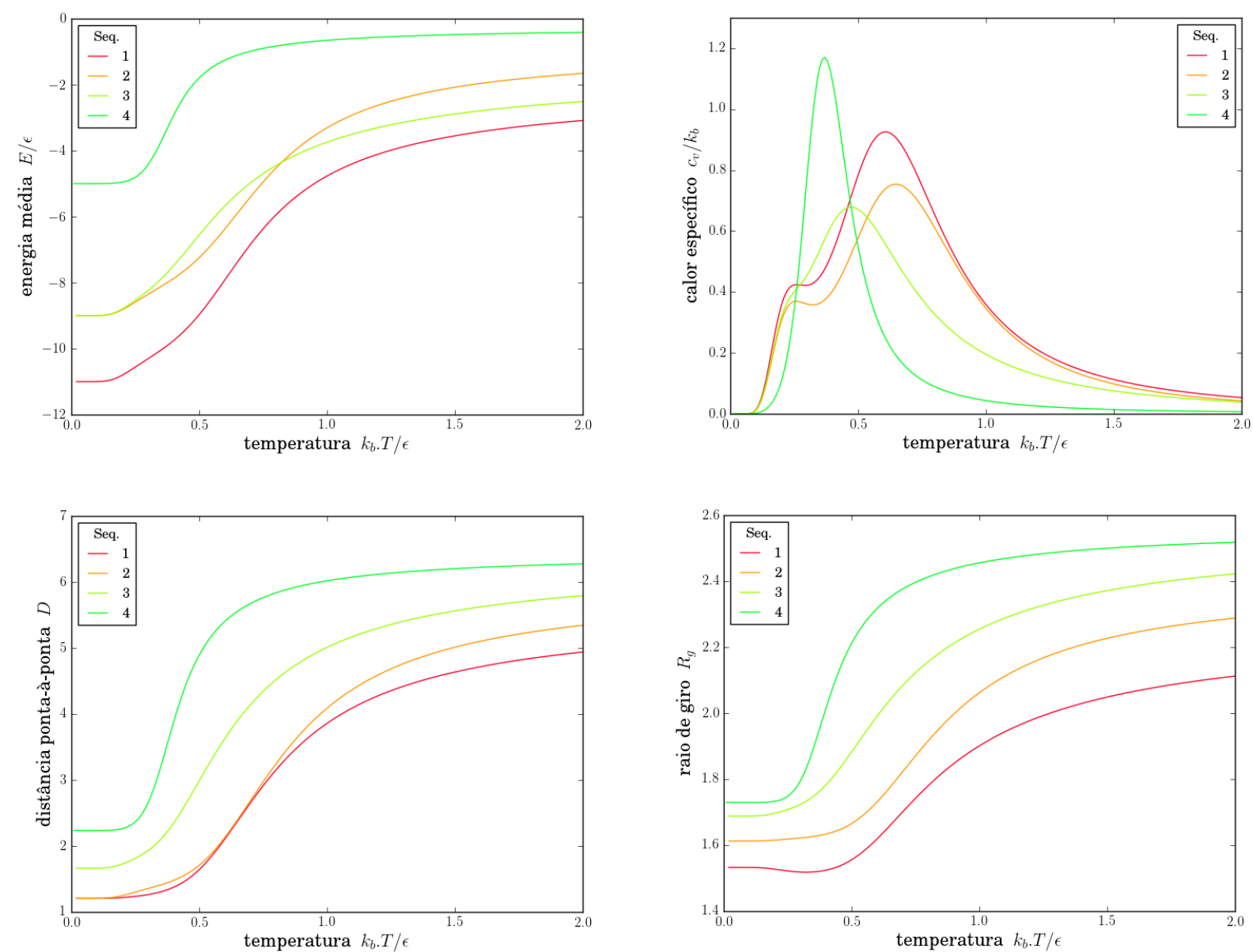

Figura 2.27: $E, c_{v}, D$ e $R_{g}$ em função da temperatura para quatro heteropolímeros na rede triangular.

Como se pode ver, as cadeias 1 e 2 apresentam dois picos nítidos no calor específico, e razões $\Omega\left(n_{m a ́ x-1}\right) / \Omega\left(n_{m a ́ x}\right)$ bastante elevadas (figura 2.27 ). No entanto, a cadeia 3 também apresenta este último parâmetro bastante elevado, maior até do que todas as sequências, mas não possui o segundo pico tão distinto quanto às primeiras. Isso mostra que o critério para a ocorrência do segundo pico baseado apenas no valor de $\Omega\left(n_{m a ́ x-1}\right) / \Omega\left(n_{m a ́ x}\right)$ não é suficiente. Observando-se a distribuição de razões na figura 2.27, vê-se que as cadeias 2 e 3 possuem distribuições relativamente parecidas, com exceção em $n_{H H}=6$, onde a cadeia 3 tem uma elevação mais pronunciada. Poderíamos 
supor que a elevação neste ponto, ou em algum outro valor intermediário de $n_{H H}$, talvez tenha uma influência sobre a distinção dos dois picos, mas isso necessitaria de uma investigação mais atenta do que a que estamos propondo neste momento. Por fim, a sequência 4, a qual apresenta claramente um único pico, não possui uma razão elevada para $n_{m a ́ x}$ e também apresenta elevações em valores de $n_{H H}$ intermediários bastante pronunciadas.

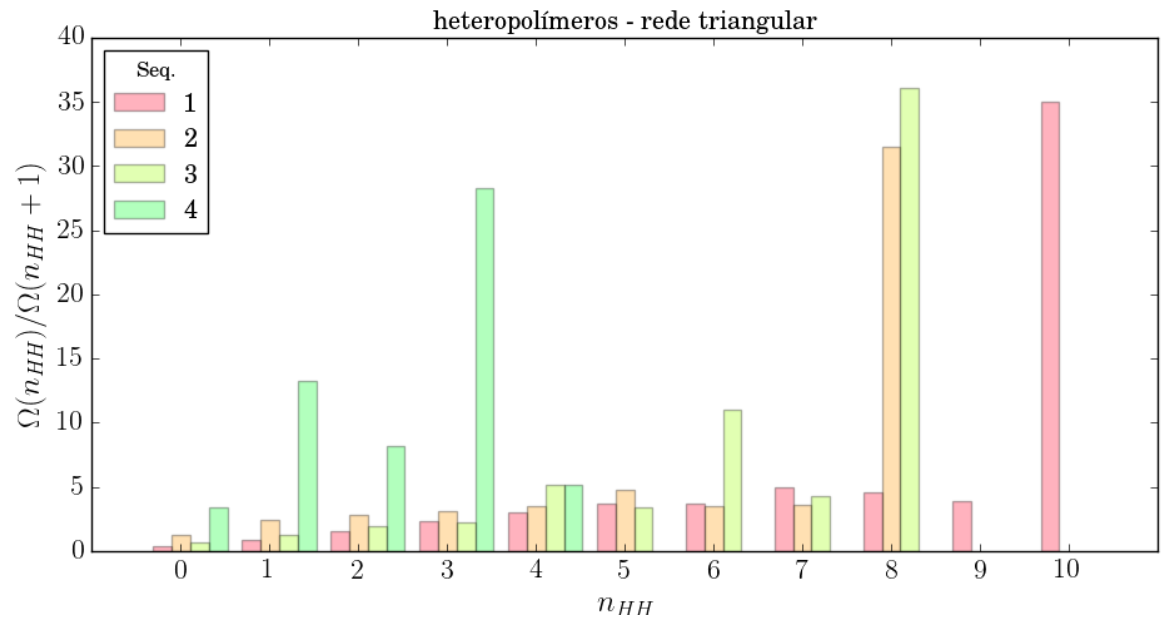

Figura 2.28: Razão entre $\Omega\left(n_{H H}\right)$ sucessivos para algumas sequências HP na rede triangular.

Algumas configurações de menor energia para essas cadeias são apresentadas abaixo:

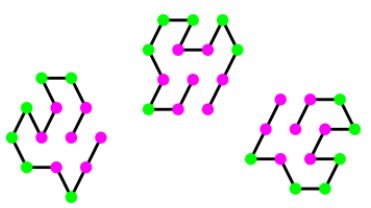

Seq. 2

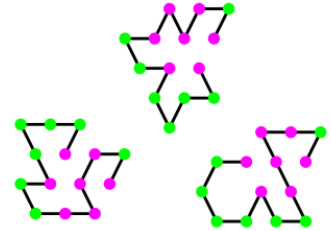

Seq. 3
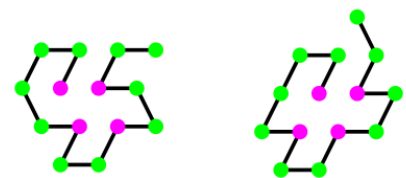

Seq. 4

Figura 2.29: Algumas conformações de menor energia das sequências 2, 3 e 4, cujas degenerescências são iguais a 32,112 e 443, respectivamente. 


\subsection{Monte Carlo}

\section{Metodologia}

Para podermos estudar cadeias de tamanho maiores do que aquelas que conseguimos através da enumeração exata, temos que fazer uso de métodos de amostragem que nos permitam analisar as propriedades do sistema sem precisar gerar todas as suas conformações. Nesse sentido, o método de Monte Carlo tem sido um dos mais amplamente empregados, sendo particularmente bem sucedido para o estudo de sistemas no equilíbrio termodinâmico. Descreveremos de maneira sucinta, a seguir, o método e alguns detalhes de sua implementação.

Dado um sistema com um espaço de configurações $C$ e uma distribuição de probabilidades $\pi$ associada a elas, o método de Monte Carlo busca produzir uma amostragem $\left\{C_{i}\right\}$ reduzida, porém representativa, de $C$ de acordo com a distribuição conhecida $\pi$ no nosso caso é a distribuição de Boltzmman. Essa amostragem pode ser feita de modo que as configurações $C_{i}$ são geradas de forma independente umas das outras (Monte Carlo estático), ou então, quando não for possível gerar configurações independentes respeitando a distribuição de probabilidades, ela é feita segundo alguma dinâmica que correlaciona as configurações sucessivas (Monte Carlo dinâmico). No caso do modelo HP, devemos recorrer ao segundo caso.

No Monte Carlo dinâmico, cria-se um algoritmo numérico para a evolução temporal do sistema, não necessariamente correspondendo a uma dinâmica física real. O processo, dito estocástico, tem como objetivo produzir uma sequência de configurações que, embora sejam localmente correlacionadas, nos permita selecionar um subconjunto delas suficientemente distantes na cadeia temporal para serem consideradas independentes entre si. Além disso, as configurações devem ser geradas de tal modo a satisfazer a distribuição de equilíbrio e garantir que todas as configurações tenham a possibilidade de serem acessadas pelo processo, ou seja, o algoritmo deve ser estacionário e ergódico. 
Quanto à primeira condição, a estacionaridade, ela significa que a probabilidade $\pi_{i}$ de uma configuração qualquer $C_{i}$ não deve variar com o tempo:

$$
\frac{\Delta \pi_{i}}{\Delta t}=0
$$

Mas, de acordo com a equação mestra, que descreve a evolução temporal da distribuição de probabilidades, isso implica que:

$$
\frac{\Delta \pi_{i}}{\Delta t}=\sum_{j}\left[w(i \mid j) \pi_{j}-w(j \mid i) \pi_{i}\right]=0
$$

onde $w(i \mid j)$ representa a taxa de troca da configuração $C_{j}$ para a configuração $C_{i}$; e o contrário para $w(j \mid i)$. Assim, se encontrarmos $w(i \mid j)$ e $w(j \mid i)$ que satisfaçam a equação anterior, teremos garantido a condição de equilíbrio. Uma das possíveis soluções é aquela que satisfaz o chamado balanceamento detalhado, no qual impomos que cada termo da somatória seja nulo:

$$
w(i \mid j) \pi_{j}-w(j \mid i) \pi_{i}=0 \quad \forall i, j
$$

Como conhecemos a distribuição $\pi$ no ensemble canônico (Boltzmann), teremos:

$$
\pi_{i}=\frac{e^{-\beta E_{i}}}{Z} \rightarrow \frac{w(i \mid j)}{w(j \mid i)}=e^{-\beta\left(E_{i}-E_{j}\right)}
$$

A equação anterior ainda não determina as taxas de transição de maneira unívoca. Uma das soluções possíveis foi proposta por Metropolis (Metropolis et al., 1953), na qual se estabelece o seguinte critério para as taxas:

$$
w(i \mid j)=\left\{\begin{array}{rrr}
e^{-\beta\left(E_{i}-E_{j}\right)} & \text { se } & E_{i}>E_{j} \\
1 & \text { se } & E_{i} \leq E_{j}
\end{array}\right.
$$

assim, dado que o sistema esteja numa configuração $C_{j}$ e o algoritmo produza uma 
nova configuração $C_{i}$ a partir dela, caso a energia do sistema não aumente $\left(E_{i} \leq E_{j}\right)$ então a transição é aceita sempre; se a energia aumentar $\left(E_{i}>E_{j}\right)$, então a transição ocorrerá com probabilidade $e^{-\beta\left(E_{i}-E_{j}\right)}<1$.

Com relação à ergodicidade, trata-se de assegurar que os movimentos utilizados para gerar as novas configurações permitam o acesso a qualquer estado $C_{i}$ do sistema. Provar que um algoritmo é ergódico não costuma ser uma tarefa fácil, porém, foi demonstrado por Sokal e colaboradores (Madras e Sokal, 1988) que o algoritmo Pivot, originalmente criado por Lal (Lal, 1969), de fato satisfaz esse critério na rede quadrada. No algoritmo, a cada novo passo é sorteado um monômero $m_{i}$ da cadeia, denominado pivot, o qual servirá provisoriamente como origem do sistema de coordenadas. Então, aplica-se uma operação de simetria $g \in G$ sobre a metade da cadeia formada pelos monômeros $\left\{m_{i+1}, m_{i+2}, \ldots, m_{N}\right\}$. O conjunto $G$ de operações pode incluir: rotações de $180^{\circ},+90^{\circ},-90^{\circ}$, as reflexões na vertical, na horizontal e nas duas diagonais, além das possíveis combinações entre elas (ver figura 2.29).
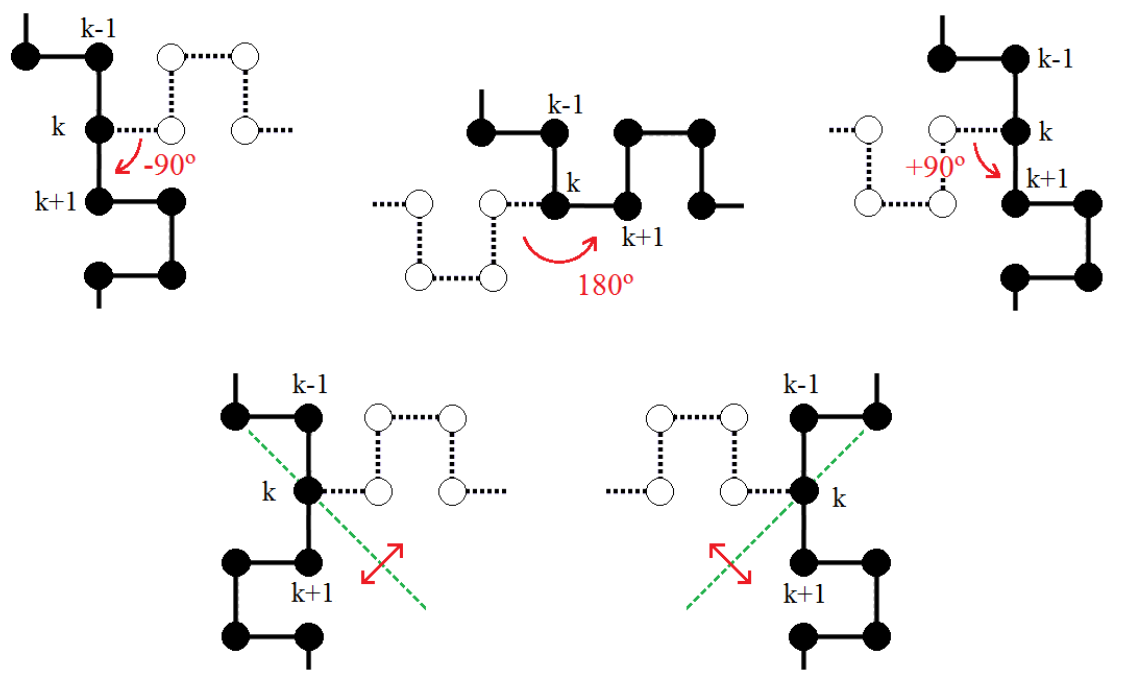

Figura 2.30: Algumas operações do grupo de simetria $G$ usado no algoritmo de Pivot. O monômero $k$ representa o pivot dos movimentos.

Segundo a prova apresentada no trabalho de Madras e Sokal, temos: 
Teorema 2. O algoritmo pivot para caminhadas auto-excludentes no $\mathbb{Z}^{2}$ é ergódico se as probabilidades de rotação de $180^{\circ}$ e $\pm 90^{\circ}$, ou a rotação de $180^{\circ}$ e as reflexões na diagonal, forem não nulas. ${ }^{2}$

Portanto, se fixarmos somente as probabilidades de rotação de $180^{\circ}$ e as reflexões na diagonal como maiores do que zero, então teremos garantido a ergodicidade do processo.

No entanto, os movimentos do algoritmo Pivot geralmente envolvem mudanças muito grandes na estrutura do polímero, o que pode resultar numa taxa de aceitação muito baixa pelo critério de Metropolis devido às altas variações positivas e frequentes na energia. Assim, para melhorar a eficiência computacional do programa, recomenda-se a inclusão de alguns movimentos locais que resultem em variações de energia menos bruscas. Dentre esses movimentos locais, selecionamos três para complementar nosso código: rotações nos monômeros das extremidades (end-flip), movimento de apenas um monômero no interior da cadeia (corner-flip) e um movimento de dobradiça de dois monômeros internos da cadeia (crankshaft), todos ilustrados na figura abaixo:

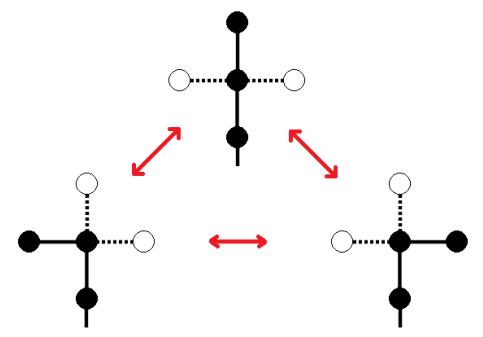

I. end-flip

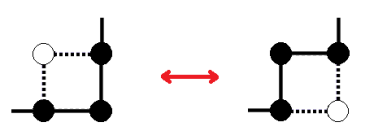

II. corner-flip

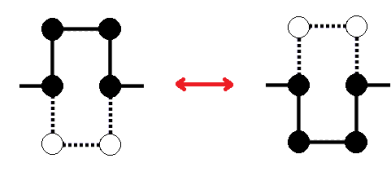

III. crankshaft

Figura 2.31: Movimentos locais na rede quadrada.

Sendo assim, a dinâmica de Monte Carlo na rede quadrada ficou do seguinte modo: Sorteia-se com igual probabilidade a aplicação de um dos quatro movimentos (pivot, end-flip, corner-flip e crankshaft) - no caso do end-flip, se ele for escolhido devemos também sortear em qual extremidade ocorrerá o movimento; no caso do pivot, também sorteamos com igual probabilidade qual dos três movimentos descritos anteriormente

\footnotetext{
${ }^{2}$ Madras e Sokal, op. cit., pg. 138.
} 
(rotação de $180^{\circ}$ e reflexões nas diagonais) será aplicado. Se o movimento escolhido for proibitivo por razões estéricas, repete-se a configuração original e inicia-se o próximo passo de Monte Carlo; se o movimento escolhido resultar em uma nova configuração, aplica-se o teste de Metropolis. Além disso, testes prévios de termalização também são realizados para assegurar que o sistema realmente se encontre no equilíbrio quando formos retirar a amostragem de configurações. O valor esperado das grandezas de interesse é então calculado por média simples sobre as configurações geradas após o intervalo de termalização.

Para a rede triangular, não sabemos dizer se o algoritmo de Pivot é ergódico, uma vez que a demonstração de Madras e Sokal se refere apenas à rede quadrada. Porém, na falta de uma demonstração rigorosa, escolhemos aplicar os mesmos tipos de movimentos usados na rede quadrada para a triangular. Como a rede triangular possui mais conexões, os movimentos anteriores também ganham um pouco mais de diversidade. Por exemplo, no corner-flip o monômero interno pode se mover através de um ângulo mais aberto e de outro mais fechado, figura 2.32.

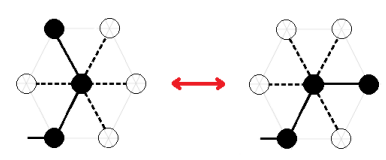

I. end-flip
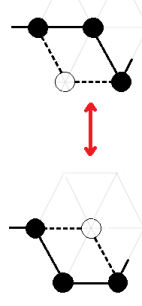

II. corner-flip
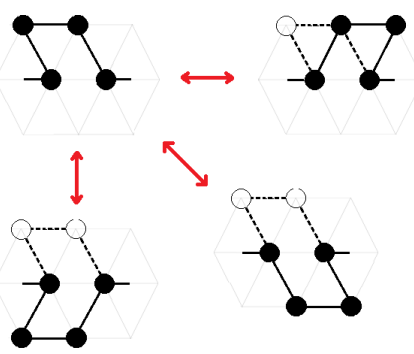

III. crankshaft
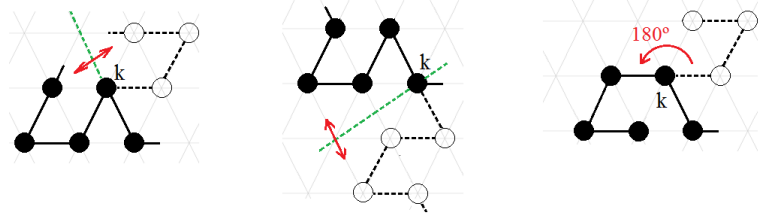

IV. pivot

Figura 2.32: Conjunto dos movimentos na rede triangular. 


\subsubsection{Resultados para cadeias maiores}

A princípio, realizamos testes preliminares com sequências curtas para verificar se o nosso algoritmo de Monte Carlo era capaz de reproduzir os resultados de enumeração exata. De fato, obtivemos uma boa concordância entre os dois métodos, como podemos observar, por exemplo, nos gráficos abaixo para o homopolímero $(H)_{12}$. Eventualmente, entretanto, encontramos algumas discrepâncias em algumas grandezas a baixas temperaturas - no caso abaixo, nas curvas da distância entre as pontas $D$ - as quais podemos relacionar com limitações do algoritmo em gerar novas configurações nesse intervalo de temperaturas, uma vez que o sistema pode ficar preso em certos estados e não visitar outros igualmente representativos, devido ao custo energético envolvido nas transições. Por conta disso, os resultados que apresentaremos a seguir foram calculados tirando-se a média entre sete corridas que utilizam o mesmo conjunto de parâmetros.
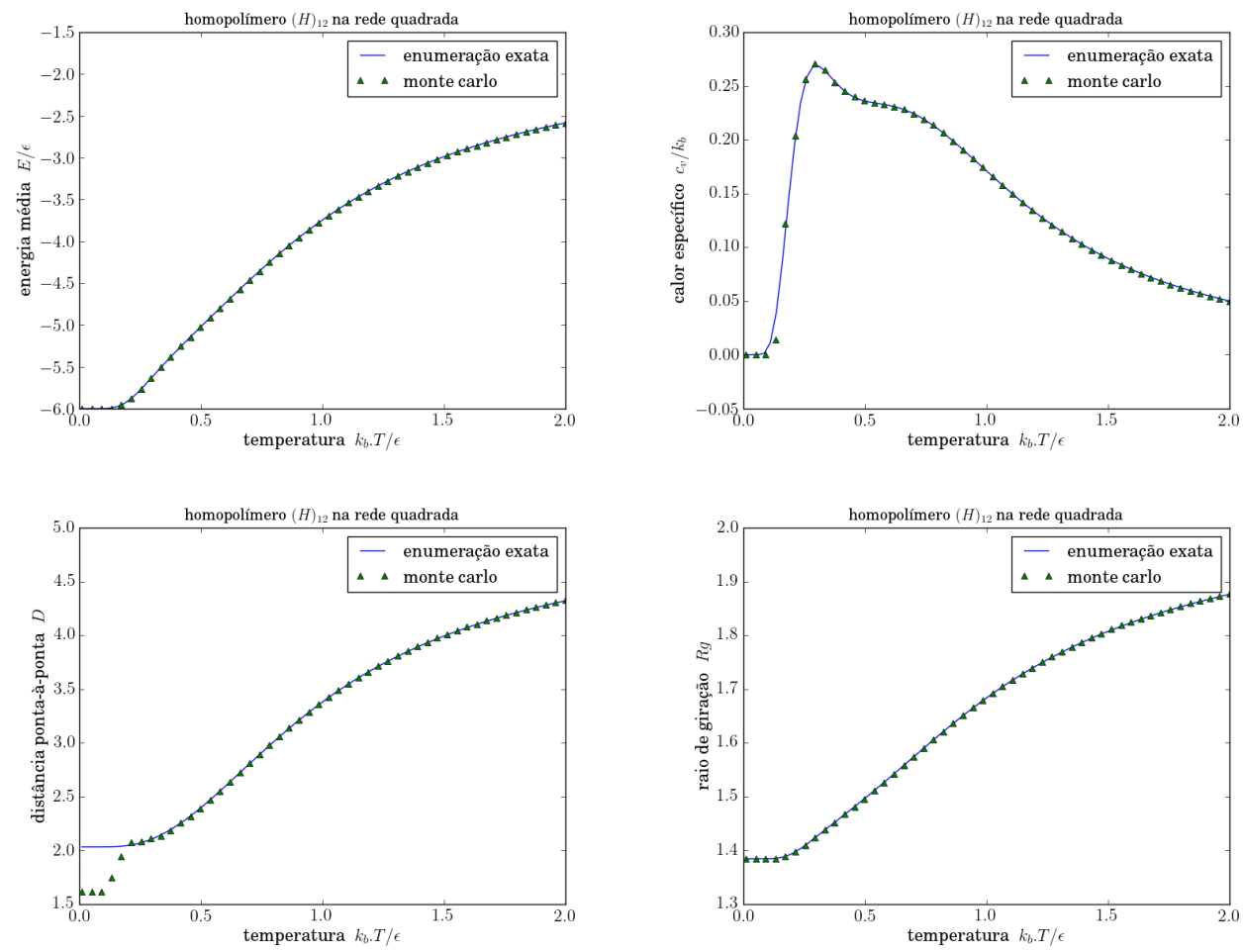

Figura 2.33: Comparação entre os métodos de Monte Carlo e enumeração exata. 


\section{Homopolímeros}

Para as sequências totalmente hidrofóbicas, $(H)_{N}$, realizamos simulações para cadeias de tamanhos $N=20,25,30$ e 50. De maneira geral, não encontramos diferenças significativas no comportamento das grandezas avaliadas para essas cadeias maiores com relação às sequências curtas estudadas por enumeração exata.

\section{Rede Quadrada:}
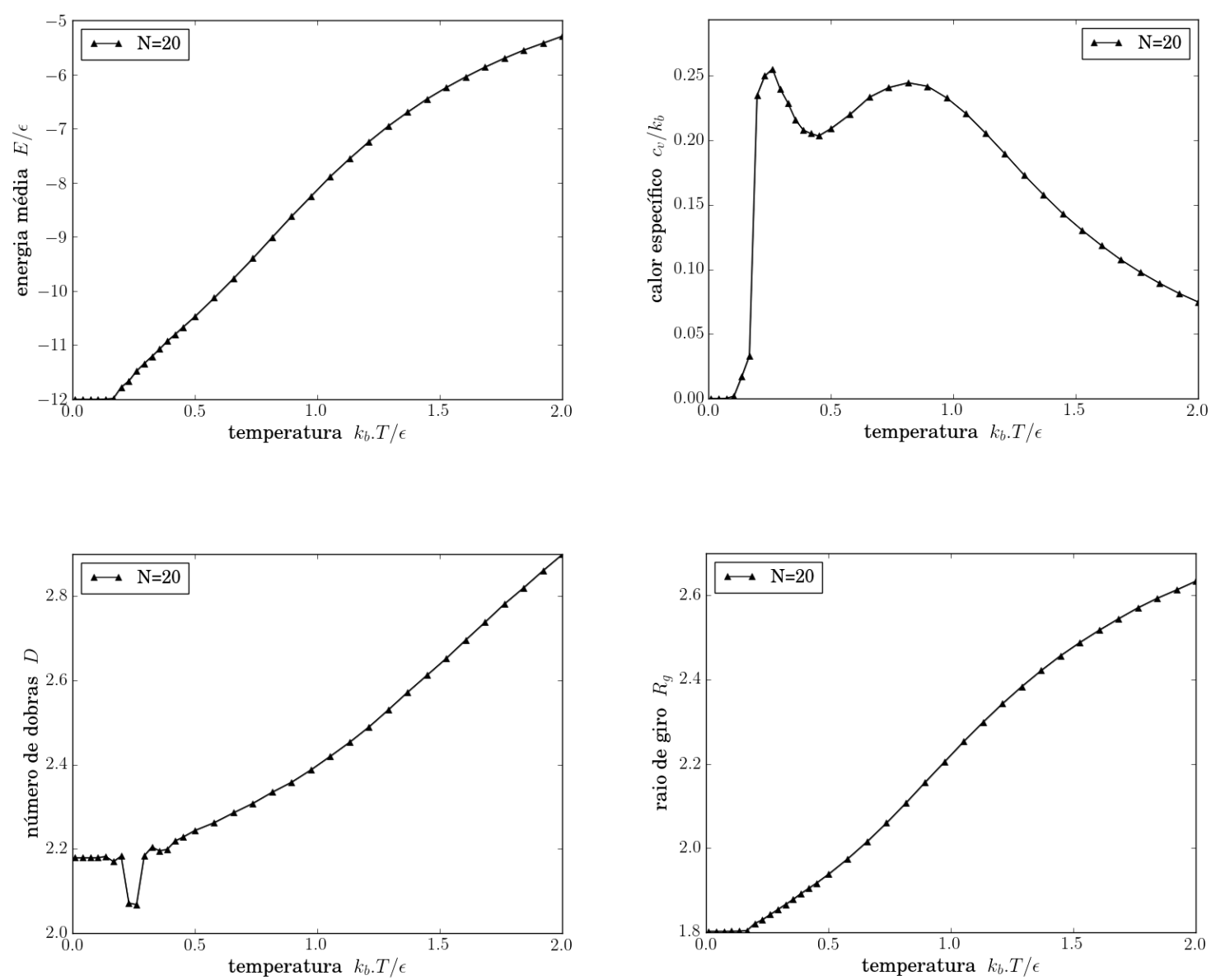

Figura 2.34: Resultados de Monte Carlo para o homopolímero $H_{20}$ na rede quadrada. 

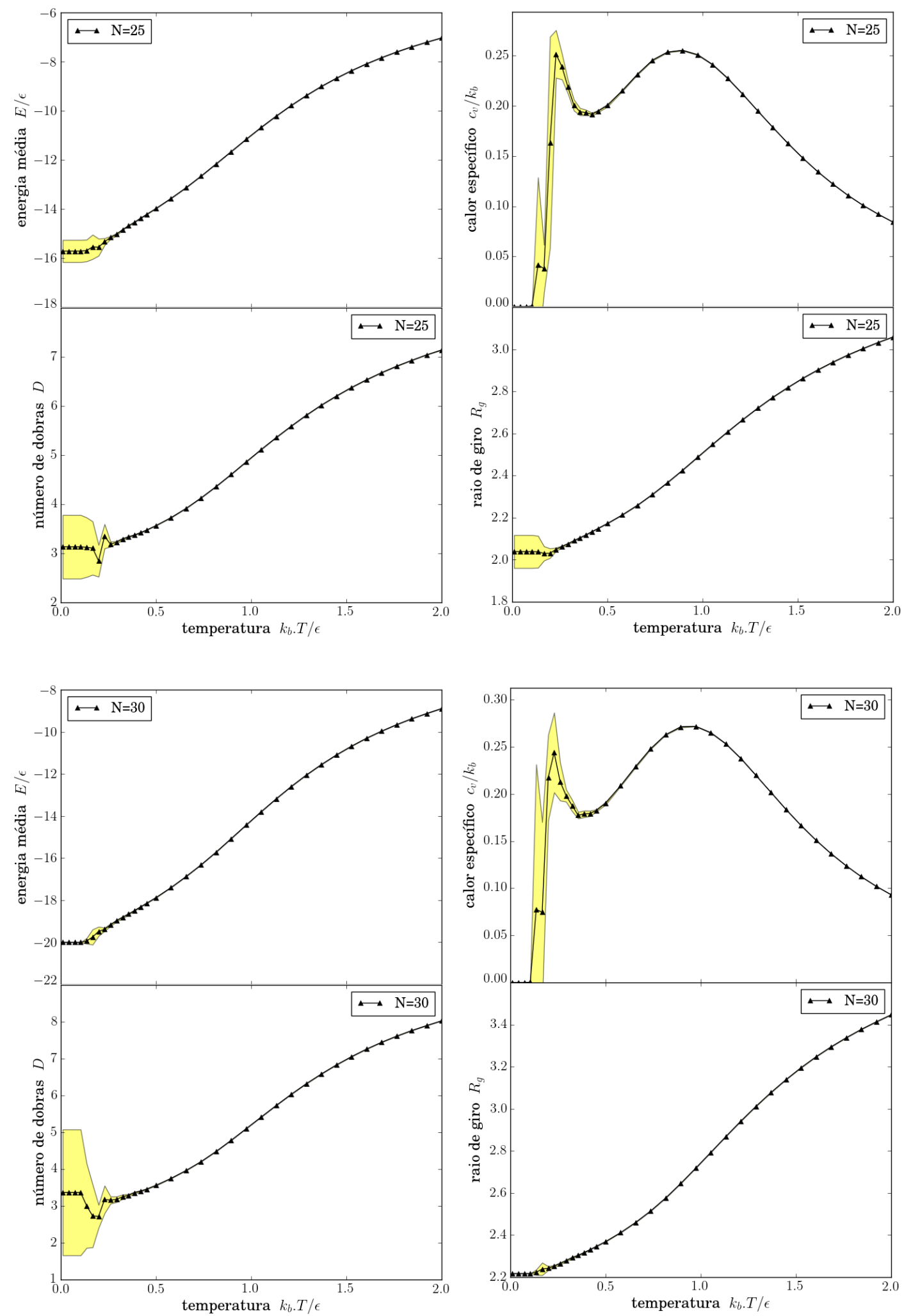

Figura 2.35: Resultados de Monte Carlo para os homopolímeros $H_{25}$ e $H_{30}$ na rede quadrada. Faixas em amarelo representam os desvios padrão. 

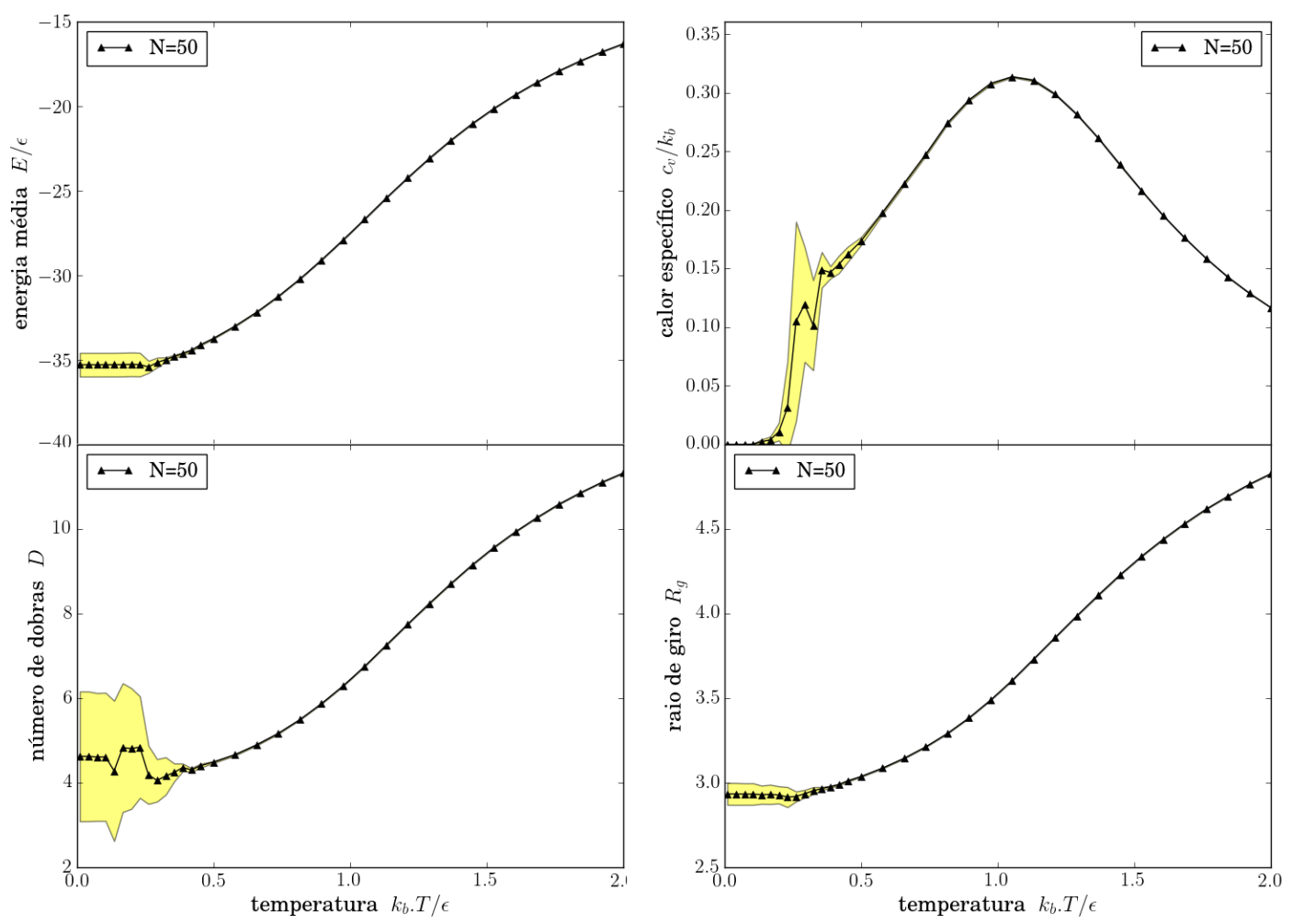

Figura 2.36: Resultados de Monte Carlo para o homopolímero $H_{50}$ na rede quadrada. 


\section{Rede Triangular:}
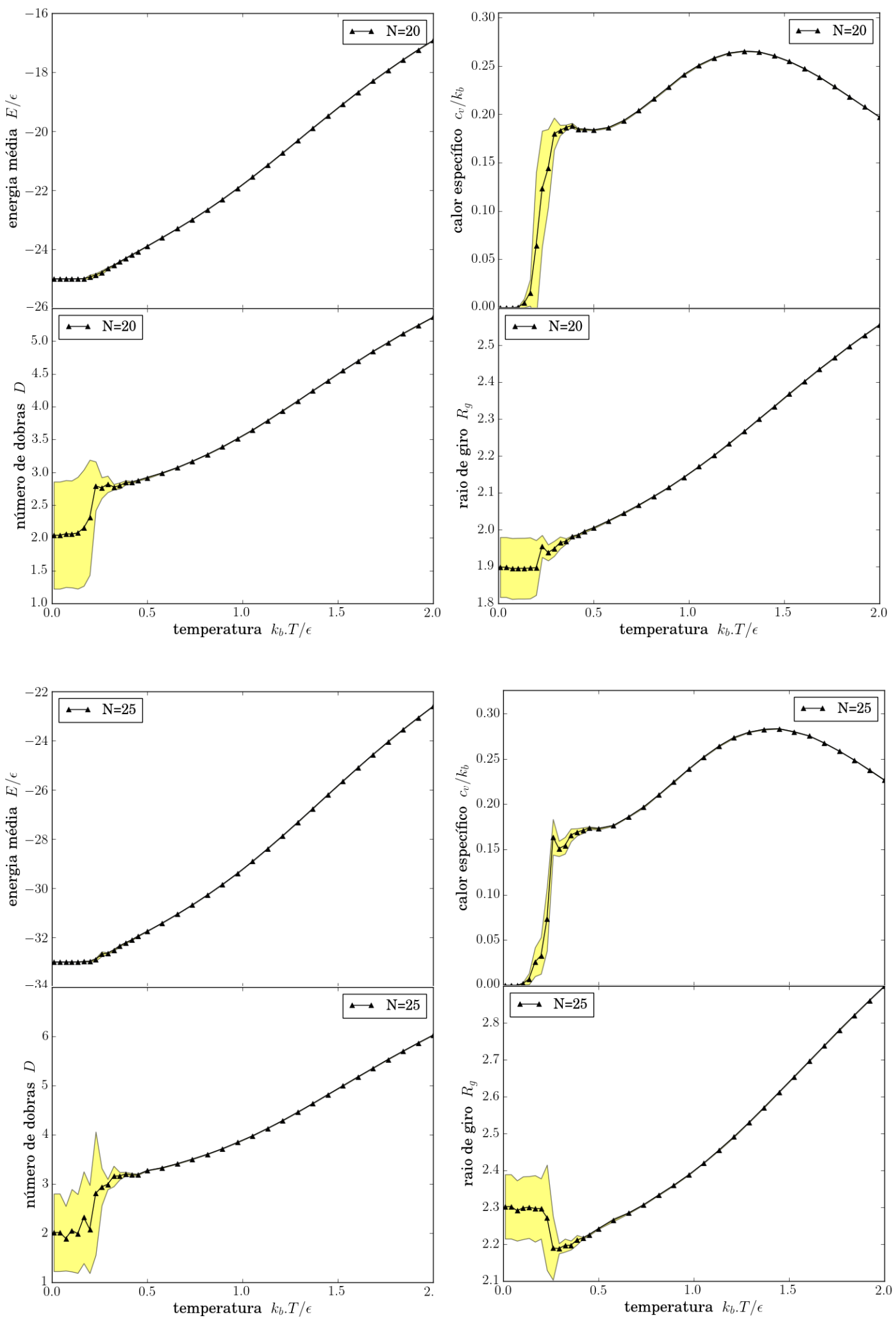

Figura 2.37: Resultados de Monte Carlo para os homopolímeros $H_{20}$ e $H_{25}$ na rede triangular. 

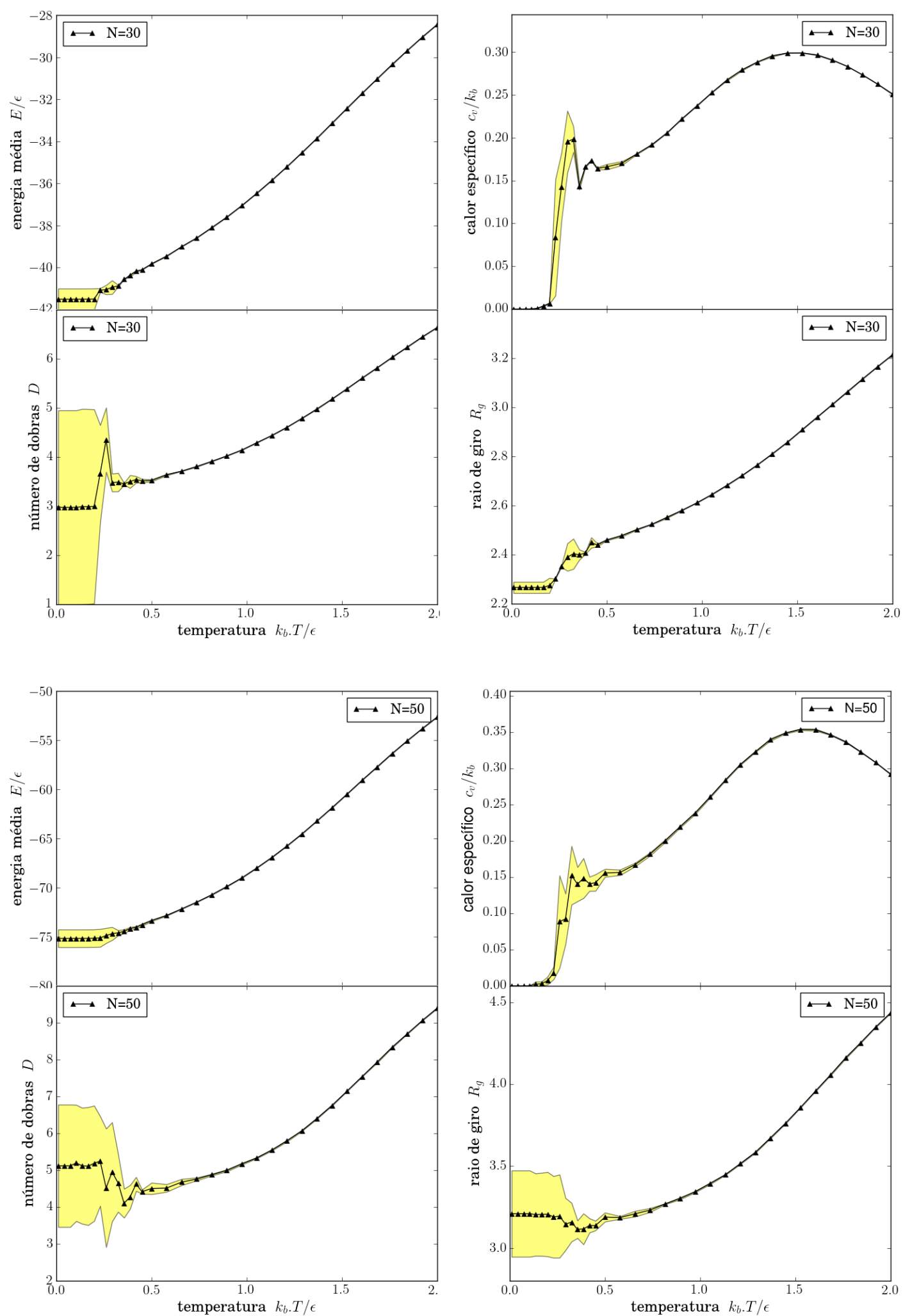

Figura 2.38: Resultados de Monte Carlo para os homopolímeros $H_{30}$ e $H_{50}$ na rede triangular. 


\section{Heteropolímeros}

Quando analisamos os heteropolímeros por enumeração exata foi possível encontrar sequências consideradas adequadas para representar proteínas, ou seja, aquelas possuindo um estado de menor energia minimamente degenerado. No entanto, conforme lidamos com cadeias cada vez maiores, para além da capacidade computacional de contar todos os estados possíveis, encontrar sequências nativas se torna uma tarefa complexa, de modo que não existe um método geral que nos permita obtê-las. A necessidade de se encontrar sequências mais representativas levou a uma abordagem comumente chamada de design de sequências (Shakhnovich, 1994) dada uma configuração compacta da cadeia, qual sequência, ou conjunto de sequências, poderia minimizar a energia livre de tal configuração? Em geral, porém, não se pode assegurar que a sequência selecionada irá realmente se enovelar para uma estrutura-alvo específica.

Como estaremos interessados, daqui para frente, unicamente em cadeias na rede triangular, onde se dará o acoplamento com o solvente (capítulos 3 e 4), não daremos atenção às cadeias HP na rede quadrada, já extensamente estudadas na literatura. Diferentemente destas, até onde pudemos pesquisar, não encontramos estudos que fornecessem boas sequências modelo na rede triangular que pudéssemos aproveitar em nossas simulações. Assim, decidimos nos guiar por um procedimento intuitivo, de tentativa e erro, para a escolha das sequências estudadas. O procedimento adotado é explicado a seguir.

Verifica-se, através da enumeração exata do homopolímero $H_{10}$ na rede triangular, que todos os seus 390 estados correspondentes a menor energia possível $(-10 \epsilon)$ assumem o mesmo formato "hexagonal"(figura 2.39), descontadas as conexões específicas entre os monômeros.

Assim, parece razoável pensar que esse formato constitui um bom núcleo hidrofóbico, no sentido de permitir a maximização do número de contatos HH. Desse modo, como um primeiro critério para a construção de uma estrutura-alvo (possível candidata à 


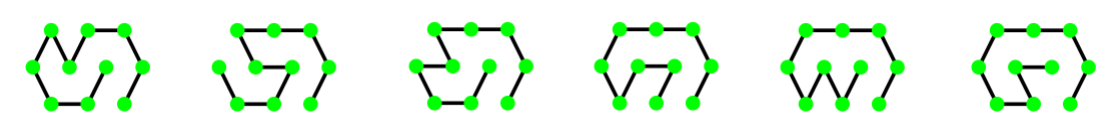

Figura 2.39: Alguns estados nativos do homopolímero triangular $H_{10}$.

estrutura nativa), estaremos fixando este núcleo de 10 resíduos apolares. Em seguida, preenchemos o seu contorno com monômeros polares $\mathrm{P}$ e definimos uma sequência com base numa possível maneira de ligar todos os monômeros. Esse procedimento está esquematizado na figura abaixo, onde mostramos a construção de duas sequências HP capazes de se dobrar na estrutura-alvo. Contudo, como já indicamos, não podemos garantir de antemão que as sequências assim desenhadas são, de fato, sequências nativas, nem dizer qual a sua degenerescência.
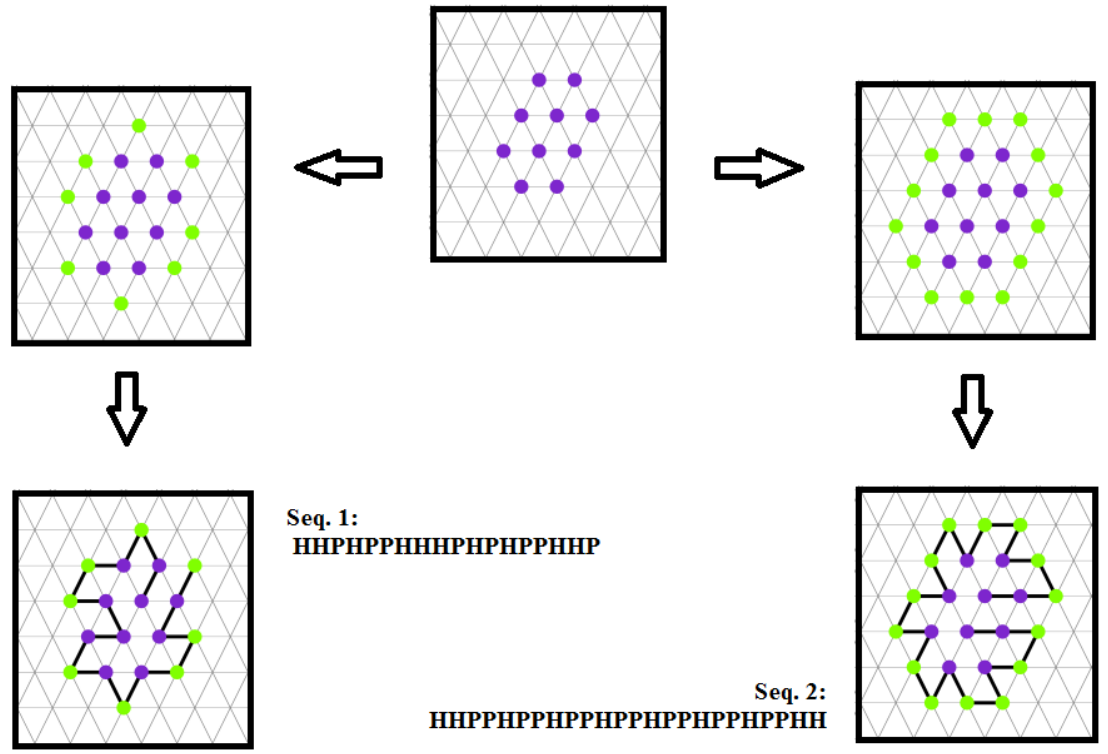

Seq. 1: НHРНРPНHНРНРНРPHНP
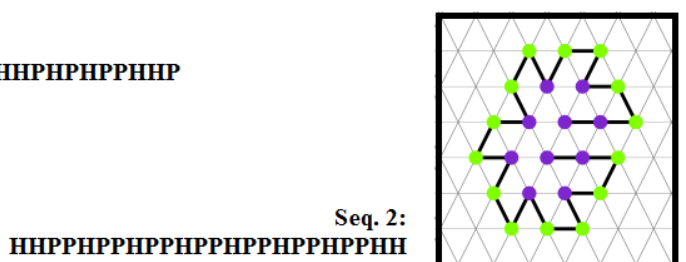

Figura 2.40: Procedimento esquemático da seleção de sequências HP.

Escolhemos, então, utilizar as duas sequências mostradas acima para nossas simulações de heteropolímeros, a saber: (Seq.1) HHPHPPHHHPHPHPPHHP com $N=18$ e (Seq.2): HHPPHPPHPPHPPHPPHPPHPPHH com $N=24$ monômeros. 


\section{Resultados:}
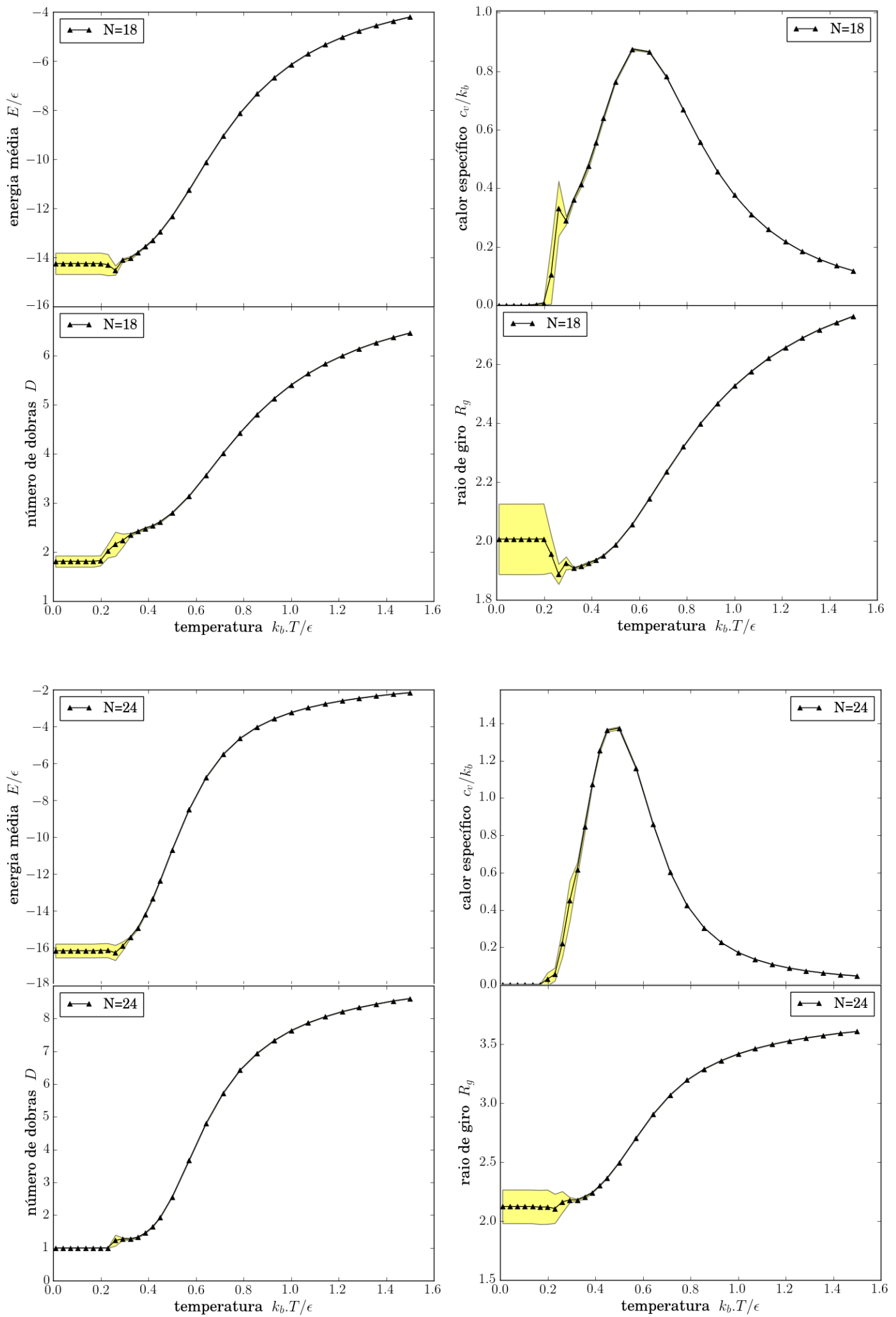

Figura 2.41: Resultados de Monte Carlo para os heteropolímeros, sequências 1 e 2, na rede triangular. 

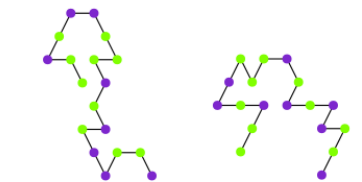

$t=1.5$

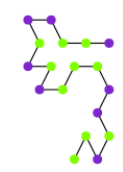

$t=0.57$
1.36

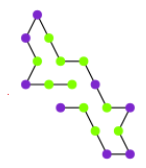

0.50

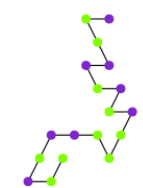

1.14

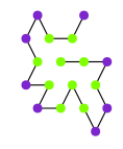

0.39

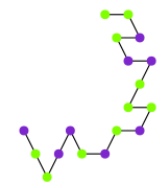

1.00

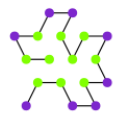

0.29

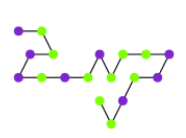

0.93

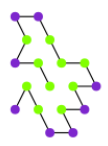

0.20

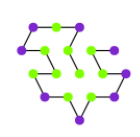

0.10

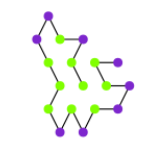

0.01

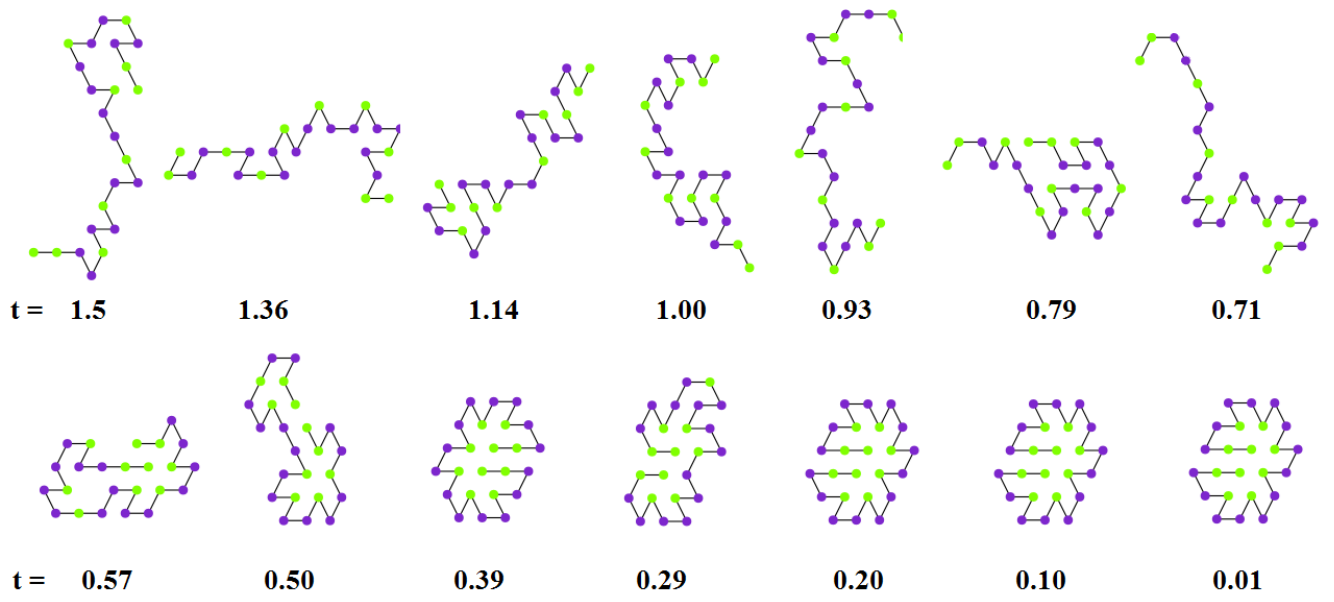

Figura 2.42: Algumas configurações geradas durante as simulações em diferentes temperaturas. Acima para a sequência 1 e abaixo para a sequência 2.

As simulações indicam que as sequências que escolhemos são capazes de se dobrar para as estruturas-alvo (comparar figuras 1.40 e 1.42 acima: em $t=0.29$ para a sequência 1 e $t=0.39,0.2,0.1$ e 0.01 para a sequência 2.). Porém, verificamos que nem sempre essas estruturas permanecem conforme reduzimos demais a temperatura. Aliás, a partir de um determinado ponto, as conformações das cadeias ficam presas em estados não necessariamente de menor energia, e que variam para cada simulação, um problema recorrente em simulações de Monte Carlo em regiões de temperaturas muito baixas. Observamos também que a sequência 1 pôde encontrar configurações tão estáveis quanto 
a estrutura-alvo que desenhamos (ver estados em $t=0.39$ e $t=0.29$ ), o que mostra a falta de garantia de unicidade quando se busca projetar uma conformação nativa para cadeias grandes. 


\section{Capítulo 3}

\section{Água: Modelo de Bell-Lavis}

A composição da molécula de água é relativamente simples: um átomo de oxigênio ligado covalentemente a dois outros de hidrogênio, formando um arranjo tetraédrico em virtude de sua estrutura eletrônica. Essa simplicidade, porém, é aparente quando tratamos de sua substância correspondente, a qual apresenta um comportamento bastante rico e complexo. Ela, que cobre a maior parte da superfície terrestre, define o nosso ambiente e os fenômenos atmosféricos, indispensável para a existência e a manutenção da vida, atuando decisivamente nos processos biomoleculares, é, ainda assim, uma total desconhecida em muitos de seus aspectos. De fato, ao contrário do que se possa imaginar, a água está longe de ser uma substância bem caracterizada. Quanto mais profundamente se investigam as suas propriedades por meio de novas técnicas, mais os problemas se acumulam, revelando uma diversidade de comportamentos e estruturas que ainda estão por serem estudados.

O que é consenso com relação a água é que as propriedades físico-químicas que a distinguem dos demais líquidos são, de alguma maneira, determinadas pela sua coesão interna decorrente da capacidade de realizar ligações de hidrogênio. Essas associações intermoleculares são direcionadas de modo que um hidrogênio de uma ligação O-H se volte para a nuvem eletrônica de um par de elétrons não compartilhado do oxigênio de 


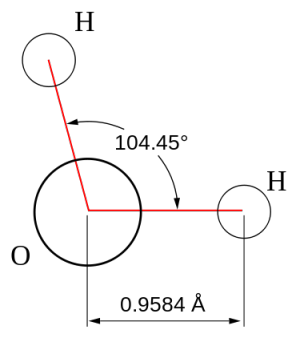

Figura 3.1: A geometria da molécula de água é tal que as ligações $\mathrm{O}-\mathrm{H}$ possuem um comprimento de $0,958 \AA$ e uma abertura angular $\mathrm{H}-\mathrm{O}-\mathrm{H}$ de $104,45^{\circ}$. A grande diferença de eletronegatividade entre os átomos confere à molécula uma alta polaridade, com um momento de dipolo de 1,85 Debye.

outra molécula ${ }^{1}$. Por serem mais fracas $(\sim 20 \mathrm{~kJ} / \mathrm{mol}$ no caso da água) do que ligações covalentes, elas não são muito estáveis em estado líquido e estão constantemente se quebrando e se reconfigurando. Porém, esta rede flutuante de conexões ainda conferiria ao líquido um certo grau de estrutura (ver figura 3.2).

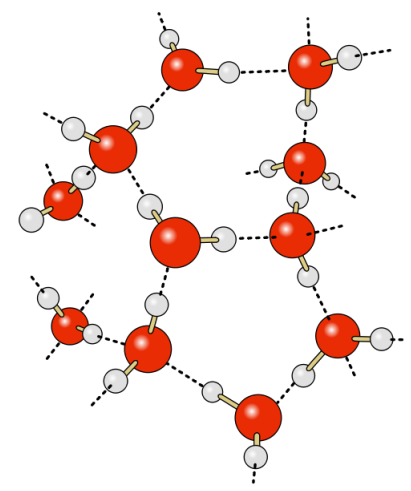

Figura 3.2: Arquitetura fugaz das interações aquosas.

No entanto, esse lugar comum nem sempre é suficiente para explicar as dezenas de anomalias apresentadas pela água², embora nos dê elementos para racionalizá-las.

\footnotetext{
${ }^{1}$ Em 2011, uma definição atualizada de ligação de hidrogênio foi proposta pela IUPAC (Arunan et al., 2011), segundo a qual: "A ligação de hidrogênio é uma interação atrativa entre um átomo de hidrogênio de uma molécula ou fragmento molecular $X-H$ no qual $X$ é mais eletronegativo que $H$, e um átomo ou grupo de átomos na mesma ou em outra molécula, na qual existe evidência da formação de ligação". Na publicação consta ainda uma lista de critérios que corroborariam uma caracterização da evidência mencionada.

${ }^{2}$ Uma compilação das diversas propriedades anômalas da água pode ser conferida em http://www1.lsbu.ac.uk/water/water_anomalies.html.
} 
Talvez a mais conhecida delas seja a expansão do volume, ou, a diminuição de sua densidade, quando passa para o estado sólido, o que faz com que observemos os cubos de gelo flutuarem em nossas bebidas. Em condições normais, a densidade da água cresce conforme a temperatura aumenta até aproximadamente $4^{\circ}$, onde atinge a sua máxima densidade. Desse ponto em diante, passa a se comportar nesse aspecto aos demais líquidos, ou seja, reduzindo sua densidade conforme a temperatura se eleva. Esse comportamento anômalo da água abaixo dos $4^{\circ}$ geralmente é entendido pela desorganização da estrutura tetraédrica das ligações que, ao serem rompidas pelo fornecimento de calor, liberariam espaço para que as moléculas se aproximassem mais umas das outras e, consequentemente, levando a um aumento da densidade. Porém, no que diz respeito às diversas anomalias, não é nada clara a relação entre o comportamento microscópico e a sua tradução no comportamento da substância em escala macroscópica.

Além disso, muitas outras questões também estão em debate atualmente, por exemplo, se a água formaria duas fases distintas a baixas temperaturas e pressões, ou ainda, incluindo outros tipos de moléculas, como que a água se organizaria próxima a superfícies e solutos? Sua estrutura numa célula seria semelhante à do meio líquido puro? Que papel ela desempenharia em certos processos ou estruturas biomoleculares? Alguma dessas questões se relacionam diretamente com o problema do enovelamento protéico, uma vez que a proteína só assume sua forma funcional em razão de estar em um ambiente aquoso. Além do que, sua própria atividade pode depender de algumas poucas moléculas de água presentes nas proximidades do sítio ativo, atuando por exemplo como pontes para moléculas ligantes, ou ainda participando das reações químicas.

Talvez, o papel mais destacado da água para a forma da proteína, assim como para várias outras estruturas moleculares, seja como responsável pela força atrativa que surge entre elementos apolares em meio aquoso, o chamado efeito hidrofóbico, postulada há décadas como a principal força condutora do enovelamento protéico (Kauzmann, 1959). O argumento se resume em dizer que as moléculas de água se tornam altamente estru- 
turadas ao redor de solutos apolares e que a liberação para o bulk de algumas dessas moléculas, através da agregação desses solutos e a consequente diminuição da superfície exposta, levaria a um aumento favorável da entropia total. Como as proteínas possuem em sua composição aminoácidos com cadeias laterais hidrofóbicas, esses tenderiam a se aproximar e então colapsar para o interior da macromolécula, reduzindo significativamente sua área exposta. Outra analogia evocada é a do processo de enovelamento como uma transferência favorável de solutos apolares de um meio polar (água) para um meio hidrofóbico (núcleo), assim como a transferência de um metano da água para um solvente orgânico, a qual apresentaria uma variação da energia livre de Gibbs negativa, indicando a espontaneidade do processo.

No entanto, é razoável imaginar que o processo de enovelamento não se resume a uma descrição simplista por efeito hidrofóbico, da mesma forma como as várias propriedades da água não se explicam apenas em dizer que há ligações de hidrogênio orientando a sua estrutura. Dependendo do grau de entendimento que exigimos para um fenômeno, é claro que será necessário um detalhamento cada vez maior das forças e mecanismos relevantes que estejam ali atuando. Felizmente, não precisamos para cada caso específico conhecer a fundo as sutilezas do sistema, como se fosse um pré-requisito para podermos avançar numa determinada direção. Há, porém, de se estar atento às limitações de abordagens reducionistas e aos perigos de se abstrair detalhes cruciais em se tratando de sistemas tão complexos quanto a água ou uma proteína.

Em relação aos modelos estatísticos já desenvolvidos para a água, podemos dividí-los em dois grupos: os modelos isotrópicos, ou seja, que não distinguem uma direção privilegiada para as interações intermoleculares, as quais geralmente são estabelecidas como uma competição entre potenciais atrativos e repulsivos; e os modelos orientacionais, que levam em conta os estados (orientações) específicos das moléculas para que elas possam interagir entre si via ligações de hidrogênio. Nessa última categoria se incluem os modelos do tipo Potts, onde as orientações são representadas por variáveis de ligação, 
a qual se dá quando partículas vizinhas estão em estados de Potts específicos, e os modelos tipo-gelo (ice-like models), que enfatizam uma orientação fixa para a ocorrência das ligações.

Nesse sentido, discutiremos a seguir um modelo tipo-gelo simplificado para a água introduzido originalmente em 1970 por David Lavis e George M. Bell (Bell e Lavis, 1970), tentando explorar brevemente algumas de suas propriedades e as informações úteis que podemos extrair dele para o entendimento dessa substância. Posteriormente, exibiremos alguns resultados de simulação numérica comparando-os com aqueles obtidos recentemente por (Fiore et al., 2009).

\subsection{Modelo de Bell-Lavis}

O modelo de Bell-Lavis em duas dimensões é basicamente um gás de dois estados numa rede triangular, no qual as partículas de água, representadas através de três braços simétricos (figura $3.3 \mathrm{a}$ ), podem interagir via um potencial de primeiros vizinhos tipo van der Waals $\left(-\epsilon_{v}\right)$ e/ou ligações de hidrogênio $\left(-\epsilon_{h}\right)$ quando seus braços estiverem apontando um em direção ao outro.

(a)

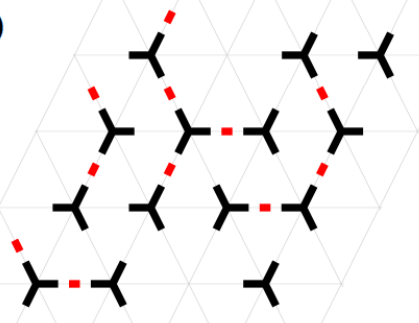

(b)

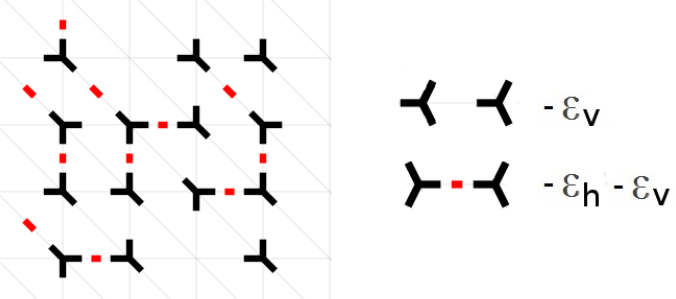

Figura 3.3: (a) Moléculas de água, representadas em forma de "Y", dentro de uma rede triangular. Os traços em vermelho indicam as ligações de hidrogênio. (b) Rede equivalente usada nas simulações.

Em termos mais formais, a rede pode ser tratada como uma matriz quadrada onde cada sítio $(i, j)$ - localizado na linha $i$ e na coluna $j$ - está conectado a seis vizinhos: 
dois na vertical, dois na horizontal e dois em uma das diagonais. Para cada um desses sítios associamos então uma variável ocupacional/orientacional $\sigma_{i, j}$, que pode assumir o valor 0 , caso o sítio se encontre vazio, 1 , se tiver uma molécula orientada com um dos braços para a direita e -1 se ele estiver para a esquerda (figura $3.3 \mathrm{~b}$ ). Assim, a energia total de uma configuração do sistema poderá ser escrita como:

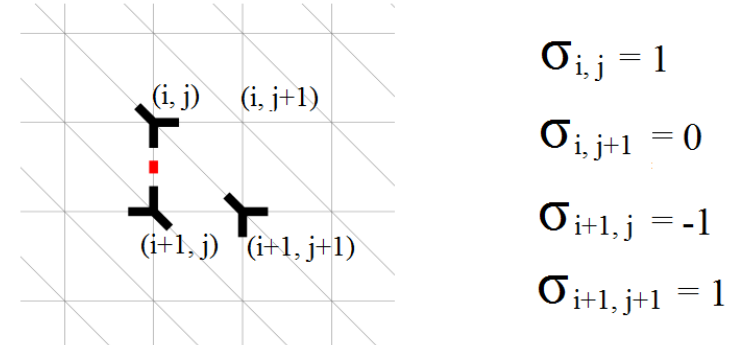

Figura 3.4: Variáveis da rede.

$E=\sum_{(i, j)} \sigma_{i, j}^{2} \cdot \epsilon_{h}\left[\frac{\left(\sigma_{i, j}+1\right)\left(\sigma_{i+1, j}-1\right)}{4}+\frac{\left(\sigma_{i, j}+1\right)\left(\sigma_{i, j+1}-1\right)}{4}+\frac{\left(\sigma_{i, j}-1\right)\left(\sigma_{i+1, j+1}+1\right)}{4}\right]$

$$
-\sigma_{i, j}^{2} \cdot \epsilon_{v} \cdot\left[\sigma_{i+1, j}^{2}+\sigma_{i, j+1}^{2}+\sigma_{i+1, j+1}^{2}\right]
$$

onde a soma se estende sobre todos os sítios da rede e as interações contadas somente entre três vizinhos: o de baixo $\left(\sigma_{i+1, j}\right)$, o da direita $\left(\sigma_{i, j+1}\right)$ e da diagonal inferior $\left(\sigma_{i+1, j+1}\right)$, de modo a garantir que não contaremos os mesmos pares duas vezes. O primeiro termo entre colchetes verifica se os pares estão orientados de maneira apropriada para formar uma ligação de hidrogênio, por exemplo, o par $\sigma_{i, j}$ e $\sigma_{i+1, j}$ fará ligação somente se o primeiro for igual a 1 e o segundo -1 . O outro termo em colchetes, por sua vez, verifica apenas se há ou não partículas nos sítios vizinhos e, caso houver, uma interação do tipo van der Waals é contabilizada.

Uma particularidade geométrica do modelo é a possibilidade dele se ordenar de tal modo a formar uma estrutura tipo colméia, onde a rede de ligações de hidrogênio 
repete um padrão hexagonal. Essa estrutura pode ser fechada se considerarmos o sistema com condições periódicas de contorno e tamanhos múltiplos de 3. Por essa razão, as simulações que apresentaremos foram realizadas em redes satisfazendo essas duas condições.

\subsection{Breve exploração do modelo}

O modelo proposto foi então estudado através de simulações numéricas realizadas no ensemble canônico, $N, V$ e $T$ fixos, utilizando o método de Monte Carlo e o algoritmo de Metropolis, já discutidos anteriormente (Seção 2.3). Neste caso, a dinâmica das partículas de água é feita através do sorteio entre dois movimentos, com igual probabilidade: ou trocamos a orientação de uma molécula escolhida aleatoriamente $(+1 \leftrightarrow-1)$, ou trocamos sua posição com um sítio desocupado. Apresentamos, a seguir, as grandezas que decidimos explorar e as técnicas usadas para a obtenção de algumas delas (potencial químico e a pressão).

\subsubsection{Energia média e calor específico}
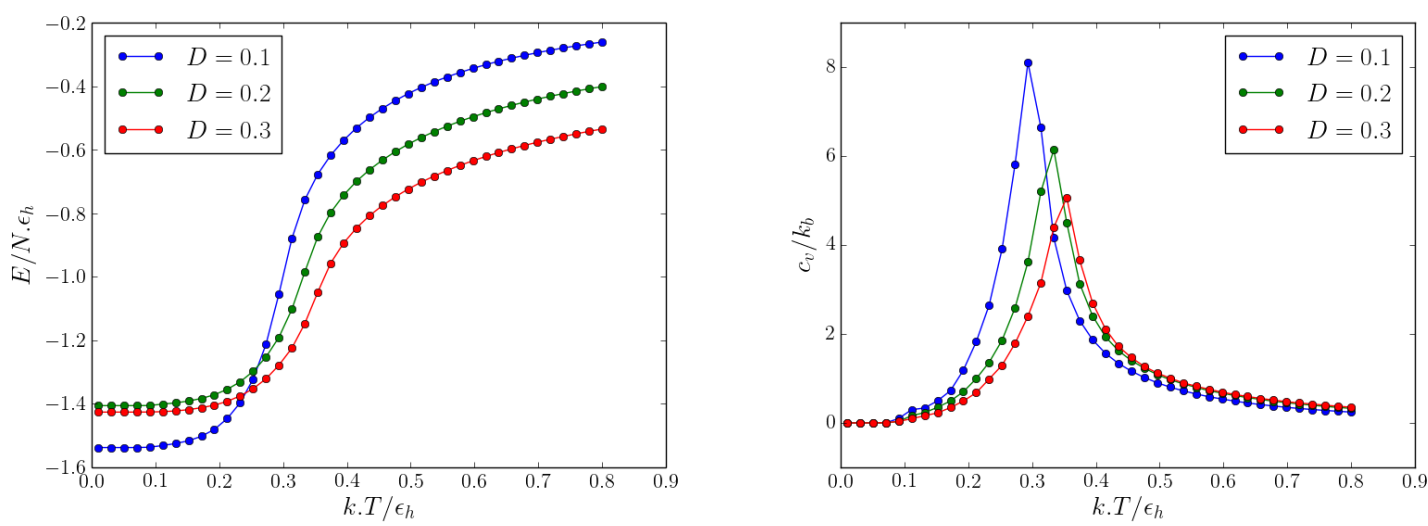

Figura 3.5: Energia média por partícula $\left(E / N . \epsilon_{h}\right)$ e calor específico x temperatura, para algumas densidades D. Rede com volume $V=30 \times 30$ e interações $\epsilon_{v} / \epsilon_{h}=1 / 9$. 


\subsubsection{Cálculo do potencial químico: o método de Widom}

Benjamin Widom publicou em 1963 a derivação de um método estatístico para o cálculo do potencial químico no ensemble canônico (Widom, 1963), o qual tem sido amplamente utilizado em simulações moleculares. Sua abordagem tem a vantagem de centralizar os cálculos em uma única molécula, que é inserida virtualmente no sistema (daí o nome método de inserção), fazendo-a percorrer todos os espaços disponíveis de uma dada configuração acessada durante a simulação. As variações de energia provocadas por essa partícula nas várias posições em que é colocada é então diretamente relacionada com o potencial químico. Vejamos, a seguir, uma demonstração do método e como ele se adapta ao modelo de água que estamos tratando.

Das relações termodinâmicas básicas, podemos expressar o potencial químico de um fluido simples como derivada parcial da energia livre de Helmholtz:

$$
d F=-p d V+\mu d N-S d T \rightarrow \mu=\frac{\partial F}{\partial N}
$$

$\mathrm{Na}$ física estatística, $F(N, V, T)$ está relacionada com a função de partição $Z$ do sistema:

$$
F=-\ln (Z) / \beta
$$

a qual podemos usar para aproximar a derivada parcial em (2.1):

$$
\begin{aligned}
\mu(N, V, T) & \approx \frac{F(N+\delta N, V, T)-F(N, V, T)}{\delta N}=\frac{F(N+1, V, T)-F(N, V, T)}{1} \\
& =-\frac{1}{\beta} \cdot \ln Z(N+1, V, T)+\frac{1}{\beta} \cdot \ln Z(N, V, T)=-\frac{1}{\beta} \cdot \ln \frac{Z(N+1, V, T)}{Z(N, V, T)}
\end{aligned}
$$

ou ainda,

$$
e^{-\beta \mu}=\frac{Z(N+1, V, T)}{Z(N, V, T)}
$$


onde usamos $\delta N=1 \ll N$. Agora iremos desenvolver o numerador da equação anterior usando a definição da função de partição, ou seja, uma soma sobre todas as configurações $\nu$ do sistema, assumindo que um estado seja completamente descrito pelas posições $\vec{r}_{1}, \vec{r}_{2}, \ldots \vec{r}_{N+1}$ das $N+1$ partículas:

$$
Z(N+1, V, T)=\sum_{\nu\left(\vec{r}_{1}, \vec{r}_{2} \ldots \vec{r}_{N+1}\right)} e^{-\beta E_{\nu}}
$$

Ora, podemos substituir a somatória sobre $\nu$ por $N+1$ somatórias, cada uma percorrendo todo o espaço de posições de uma partícula, sem nos preocuparmos em contar configurações com sobreposição de partículas - quando isto ocorre a energia é definida como sendo infinita e a exponencial $e^{-\beta E}$ se anula. Como as partículas são indistinguíveis entre si, fazer essa substituição também exige que se descontem todas as permutações resultantes. Assim, teremos:

$$
Z(N+1, V, T)=\frac{1}{(N+1) !} \sum_{\vec{r}_{N+1}} \sum_{\vec{r}_{N}} \ldots \sum_{\vec{r}_{1}} e^{-\beta E\left(\vec{r}_{1}, \ldots, \vec{r}_{N+1}\right)}
$$

e, analogamente,

$$
Z(N, V, T)=\frac{1}{N !} \sum_{\vec{r}_{N}} \ldots \sum_{\vec{r}_{1}} e^{-\beta E\left(\vec{r}_{1}, \ldots, \vec{r}_{N}\right)}
$$

Convém aqui introduzir algumas definições: chamaremos de $E_{N}$ a energia de interação entre as partículas rotuladas de 1 até $\mathrm{N}$; e $\delta E$ será a energia de interação da partícula restante com as demais. Logo, $E\left(\vec{r}_{1}, \ldots, \vec{r}_{N+1}\right)=E_{N}+\delta E$, onde $E_{N}$ é função das distâncias $\left|\vec{r}_{i}-\vec{r}_{j}\right|$ de cada par $(i, j)$ com $i, j=1,2, \ldots, N$; e $\delta E$ é função de $\left|\vec{r}_{i}-\vec{r}_{N+1}\right|$ com $i=1,2, . ., N$. Se dividirmos a equação (2.5) por (2.6), obtemos:

$$
\begin{aligned}
\frac{Z(N+1, V, T)}{Z(N, V, T)}= & \frac{N !}{(N+1) !} \frac{\sum_{\vec{r}_{N+1}} \sum_{\vec{r}_{N}} \cdots \sum_{\vec{r}_{1}} e^{-\beta E_{N}} e^{-\beta \delta E}}{\sum_{\vec{r}_{N}} \cdots \sum_{\vec{r}_{1}} e^{-\beta E_{N}}} \\
& =\frac{1}{N+1} \sum_{\vec{r}_{N+1}}\left\langle e^{-\beta \delta E}\right\rangle .
\end{aligned}
$$


onde a média acima, representada pelo símbolo \langle\rangle , fica evidente quando identificamos o fator de Boltzmann na equação. O ensemble no qual ela é calculada é claramente o $(N, V, T)$. Assim, igualando (2.7) com (2.3) ficamos com:

$$
e^{-\beta \mu}=\frac{1}{N+1} \sum_{\vec{r}_{N+1}}\left\langle e^{-\beta \delta E}\right\rangle=\frac{\left\langle\sum_{\vec{r}_{N+1}} e^{-\beta \delta E}\right\rangle}{N+1}
$$

e finalmente,

$$
\mu=-\frac{1}{\beta} \cdot \ln \left(\frac{\left\langle\sum_{\vec{r}_{N+1}} e^{-\beta \delta E}\right\rangle}{N+1}\right) .
$$

Podemos pensar na última média da seguinte maneira, numa dada configuração do sistema no $(N, V, T)$ uma partícula a mais é introduzida e feita passear por cada posição disponível do volume, em cada posição mede-se a interação $\delta E$ dela com as restantes e calcula-se $e^{-\beta \delta E}$; em seguida, somamos todas as exponenciais de cada posição. A média dessa soma pode então ser facilmente calculada numa simulação de Monte Carlo, na qual acessamos apenas as configurações mais representativas do sistema.

Repare que a demonstração anterior considerou partículas unicamente definidas pelas suas posições $\vec{r}_{i}$, porém, como vimos, o modelo de Bell-Lavis também as distingue pela orientação: $\overrightarrow{o_{i}}= \pm 1 \mathrm{com} i=1,2, \ldots, N$. Neste caso, a dedução seria essencialmente a mesma, com exceção de que as somatórias também se estenderiam para as orientações. Assim, a fórmula resultante adaptada ao modelo de Bell-Lavis seria:

$$
\mu=-\frac{1}{\beta} \cdot \ln \left(\frac{\left\langle\sum_{\vec{o}_{N+1}} \sum_{\vec{r}_{N+1}} e^{-\beta \delta E}\right\rangle}{N+1}\right)
$$

ou seja, além da partícula "virtual"ter de percorrer todas as posições da rede, ela também deve assumir cada uma das orientações possíveis no modelo. 


\section{Resultados:}

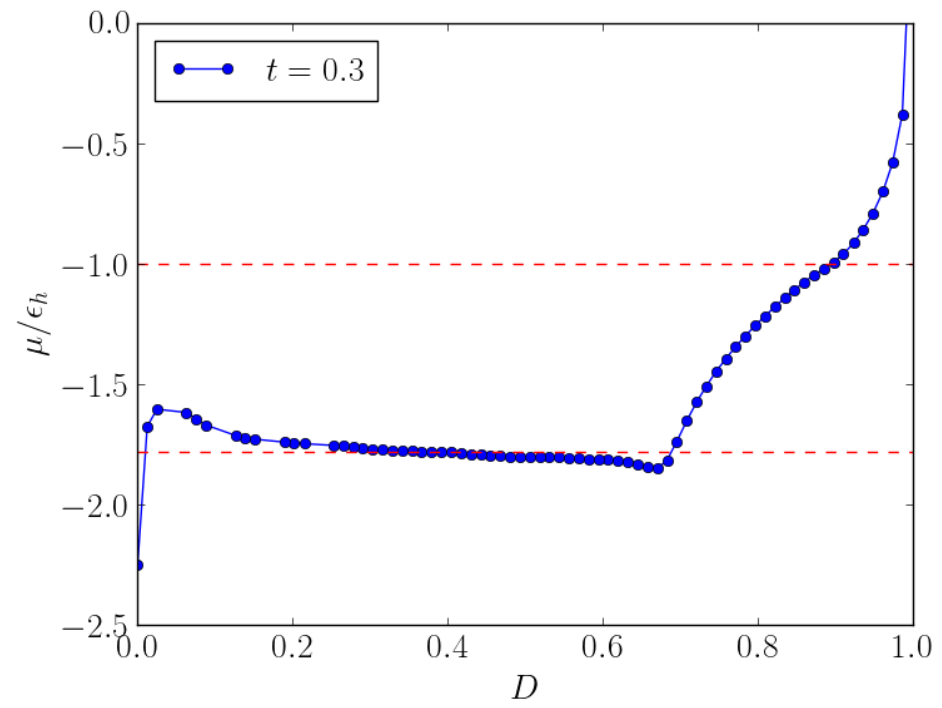

Figura 3.6: Potencial químico $\mathrm{x}$ Densidade, para a rede de volume $V=42 \mathrm{x} 42$ à temperatura adimensional $t=0.3$ e interações $\epsilon_{v} / \epsilon_{h}=1 / 9$. As linhas pontilhadas indicam as regiões de transição de primeira (abaixo) e segunda ordem (acima).

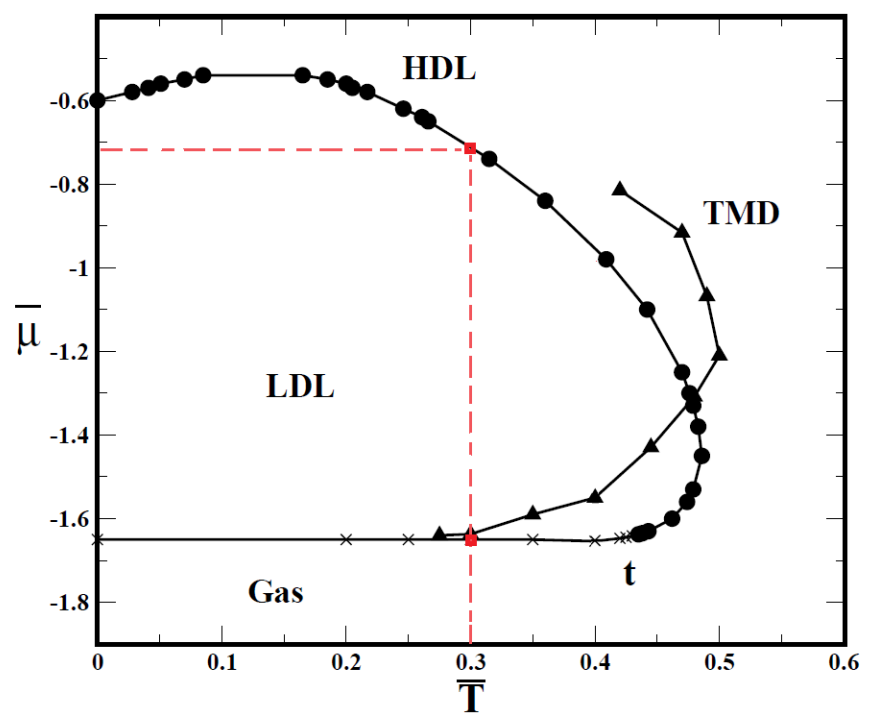

Figura 3.7: Diagrama de fase: potencial químico x temperatura, volume $V=42 \times 42$ e interações $\epsilon_{v} / \epsilon_{h}=0.1$. Fonte: adaptado de (Fiore et al., 2009). A linha tracejada vermelha indica a isoterma $t=0.3$ (comparar com a figura anterior). 
No estudo de (Fiore et al., 2009), os autores distinguem duas transições de fase no modelo de Bell-Lavis: uma de primeira ordem, entre as fases gasosa e líquida de baixa densidade (LDL) e outra de segunda ordem entre as fases líquidas de baixa densidade (LDL) e alta densidade (HDL). Na figura 3.7, exibimos o diagrama de fase $\mu \mathrm{x} t$ obtido pelos autores para uma rede $42 \times 42$ e interações $\epsilon_{v} / \epsilon_{h}=0.1$. Para verificarmos a concordância entre as nossas simulações e o diagrama da literatura, tomamos uma rede de mesmo tamanho à temperatura fixa de $t=0.3$, abaixo da temperatura crítica, variando-se a densidade do sistema. Utilizamos, no entanto, uma proporção entre as interações de $\epsilon_{v} / \epsilon_{h}=1 / 9 \approx 0,111 \ldots$, levemente diferente do estudo citado.

Na curva que obtivemos do potencial químico em função da densidade, figura 3.6, observamos uma larga região de patamar em torno de $\mu / \epsilon_{h} \approx-1.7$, indicando a transição de primeira ordem e o intervalo de coexistência gás-LDL. Este valor do potencial químico também está próximo do valor encontrado no diagrama de fase - ver a intersecção da isoterma (linha vermelha pontilhada) e a linha de transição inferior no diagrama. Quanto à transição de segunda ordem, não encontramos um patamar, mas uma mudança de concavidade na curva do potencial químico próximo a $\mu / \epsilon_{h} \approx-1$, o que corresponderia, no diagrama de fase, à segunda intersecção da isoterma na curva que separa as fases LDL e HDL. No caso do diagrama, o potencial em que ocorre essa mudança fica em torno de $\mu / \epsilon_{h} \approx-0.7$. A diferença entre esses valores pode ser atribuída às diferentes interações adotadas entre os estudos comparados. O comportamento qualitativo, entretanto, permanece o mesmo ao longo da isoterma.

Além do mais, é interessante notar a presença de "laços"na curva do potencial químico, localizados nas extremidades do patamar de coexistência. Tal característica, aparentemente proibitiva pelas leis termodinâmicas, pode ser equacionada em termos dos efeitos da tensão superficial e da área de contato entre as duas fases do sistema. A demonstração para esta afirmação tem sido desenvolvida pelo doutorando Jozismar R. Alves juntamente com a Prof. Vera B. Henriques e preparada para futura publicação. 


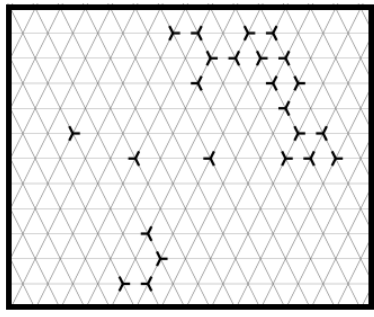

$\mathbf{D}=\mathbf{0 . 1 1}$

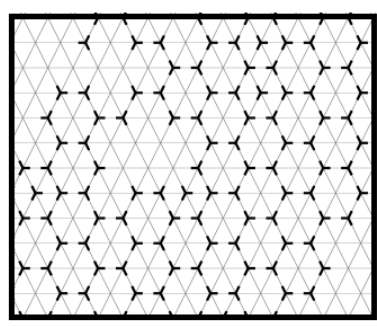

$\mathrm{D}=\mathbf{0 . 6 6}$

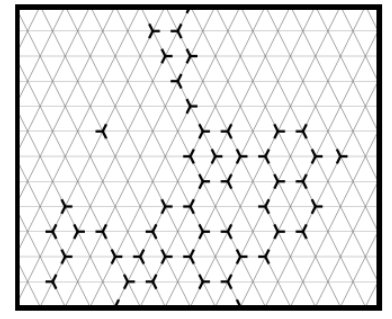

$\mathbf{D}=\mathbf{0 . 2 2}$

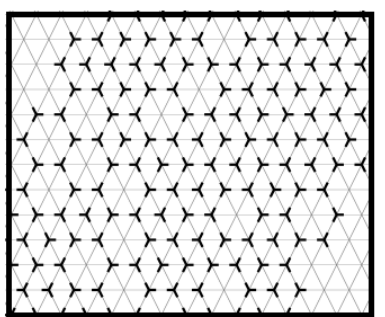

$\mathrm{D}=\mathbf{0 . 8 8}$

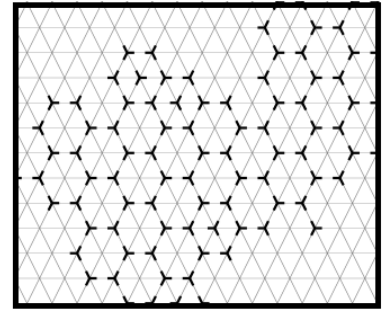

$\mathrm{D}=\mathbf{0 . 4 4}$

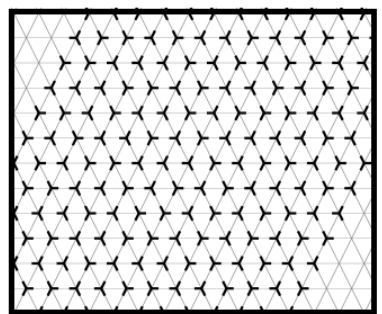

$\mathbf{D}=\mathbf{0 . 9 9}$

Figura 3.8: Mudanças de fase em função da densidade para $T<T_{\text {crítico. }}$ Para densidades muito baixas predomina a fase gasosa. A fase LDL corresponde à ordenação das moléculas em forma de colméia (sub-rede de hexágonos); ela coexiste com a fase gasosa num certo intervalo de densidades, apresenta uma região onde é a única fase e, com o aumento progressivo da densidade, passa continuamente para a fase HDL. Nesta última, a ordenação hexagonal regular é quebrada, embora o sistema ainda apresente diversos conjuntos de moléculas unidos por ligações de hidrogênio. 


\subsubsection{Cálculo da pressão: proposta de uma nova metodologia}

Apresentamos no apêndice algumas novas abordagens computacionais e teóricas para o problema da obtenção da pressão no ensemble canônico. Essas propostas, em boa medida inspiradas pelo método de Widom, foram desenvolvidas paralelamente à realização do projeto original das proteínas e acabaram por tomar um rumo próprio. Assim, deixaremos as demonstrações e as discussões mais detalhadas para o apêndice, indicando aqui apenas as fórmulas pelas quais obtivemos os nossos resultados. Vale ressaltar que trata-se de uma proposta exploratória e que ainda está em fase de desenvolvimento, de forma que apresentaremos somente alguns testes preliminares.

Para o gráfico pressão x temperatura, usamos a fórmula (A.18):

$$
p(N, V, T)=\frac{1}{\beta L} \ln \left(\frac{\left\langle e^{\beta \delta E}\right\rangle}{p_{0}^{*}}\right)
$$

própria para redes com contorno periódico, que é o nosso caso. Aqui, $L$ representa o tamanho de um dos lados da rede, $\delta E$ a energia de interação entre duas linhas ou colunas adjacentes (o símbolo \langle\rangle indicando o valor médio) e $p_{0}^{*}$ é a probabilidade de encontrar uma linha (ou coluna) da rede vazia. Para densidades altas, essa probabilidade é difícil de ser estimada, uma vez que a rede se ordena de tal modo a baixas temperaturas que encontrar uma linha totalmente vazia se torna muito improvável. Assim, escolhemos uma densidade reduzida para poder aplicar a fórmula com maior facilidade.

Já para o gráfico pressão x densidade, como queremos cobrir toda faixa de densidades, escolhemos usar a fórmula (A.109):

$$
p(N, V, T)=p_{1 D}(\mu, T)-\frac{\ln \left\langle e^{\beta\left(E_{i}-E_{c}\right)}\right\rangle}{\beta L}
$$

onde o primeiro termo à direita representa a pressão do modelo de Bell-Lavis em uma dimensão, com o potencial químico do sistema bidimensional. Essa pressão pode ser 
calculada através da resolução da equação cúbica (A.80). O significado dos outros termos da fórmula pode ser encontrado na seção A.4.2 do apêndice.

\section{Resultados:}

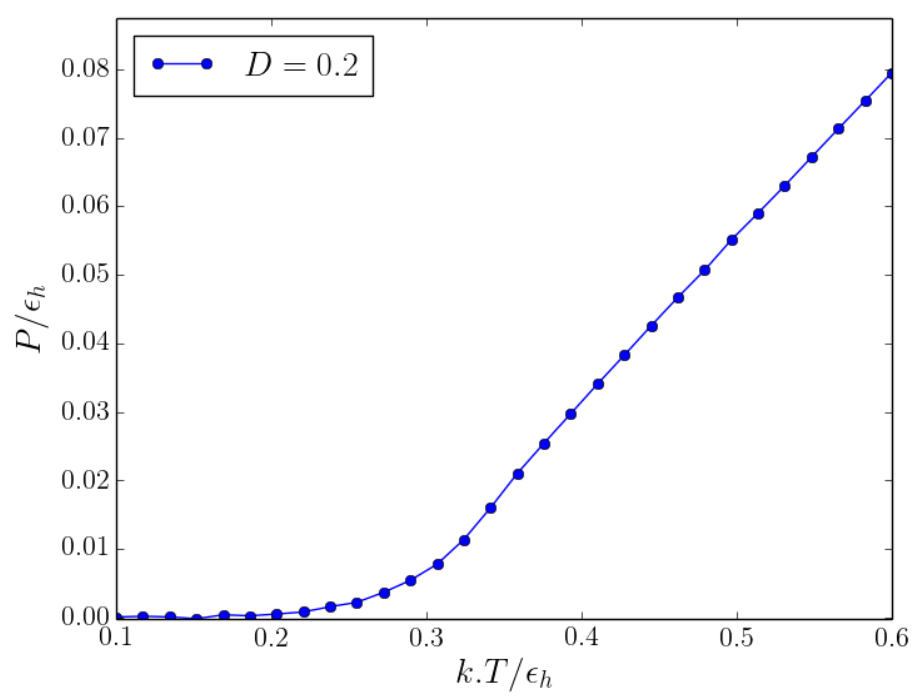

Figura 3.9: Pressão x Temperatura, para uma rede $V=30 \times 30$ e densidade $D=0.2$.

De maneira análoga à análise que fizemos do potencial químico, calculamos a pressão em função da densidade para a isoterma $t=0.3$. As curvas, em ambos os casos, possuem um comportamento bastante similar - contendo uma região de patamar e outra de inflexão -, assim como o formato dos diagramas de fase. As pressões de transição encontradas foram $P_{\text {gas }-L D L} \approx 0$ e $P_{L D L-H D L} \approx 0.75$, figura 3.9 , as quais estão de bom acordo com o diagrama $P x T$ encontrado da literatura, fig. 3.10.

Assim, até onde pudemos analisar, as fórmulas propostas para o cálculo da pressão têm produzido resultados coerentes com aqueles já obtidos para o modelo de Bell-Lavis. Outros testes, usando o gás de rede como sistema modelo, estão contidos no apêndice. 


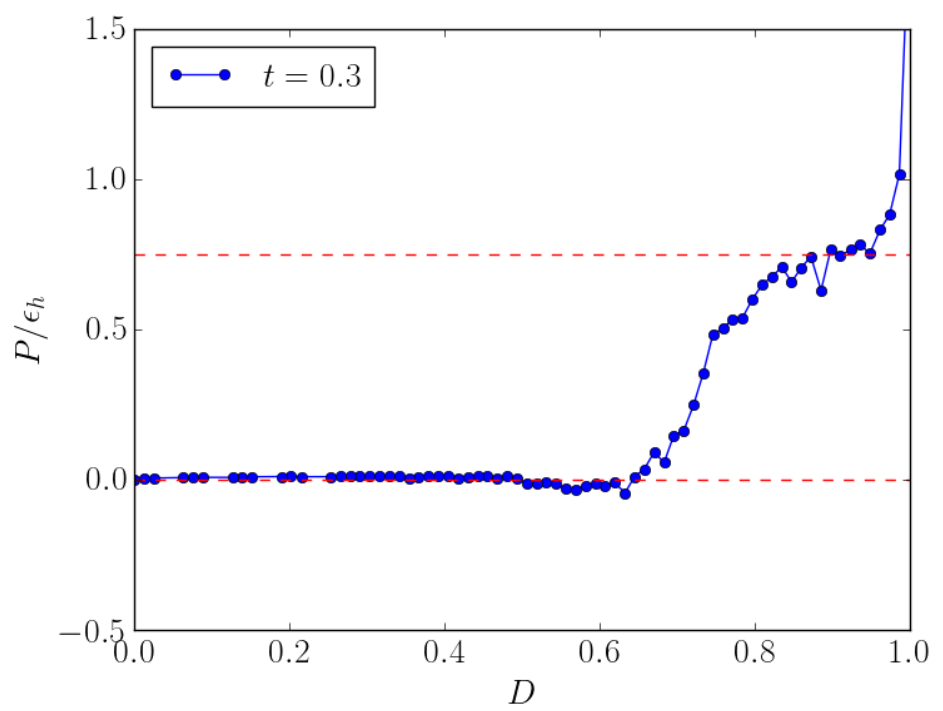

Figura 3.10: Pressão x Densidade, para uma rede de volume $V=42 \times 42$ e interações $\epsilon_{v} / \epsilon_{h}=1 / 9$ à temperatura adimensional $t=0.3$. As linhas tracejadas indicam, aproximadamente, as pressões de transição: abaixo está a transição de primeira ordem (patamar) e acima a de segunda ordem.

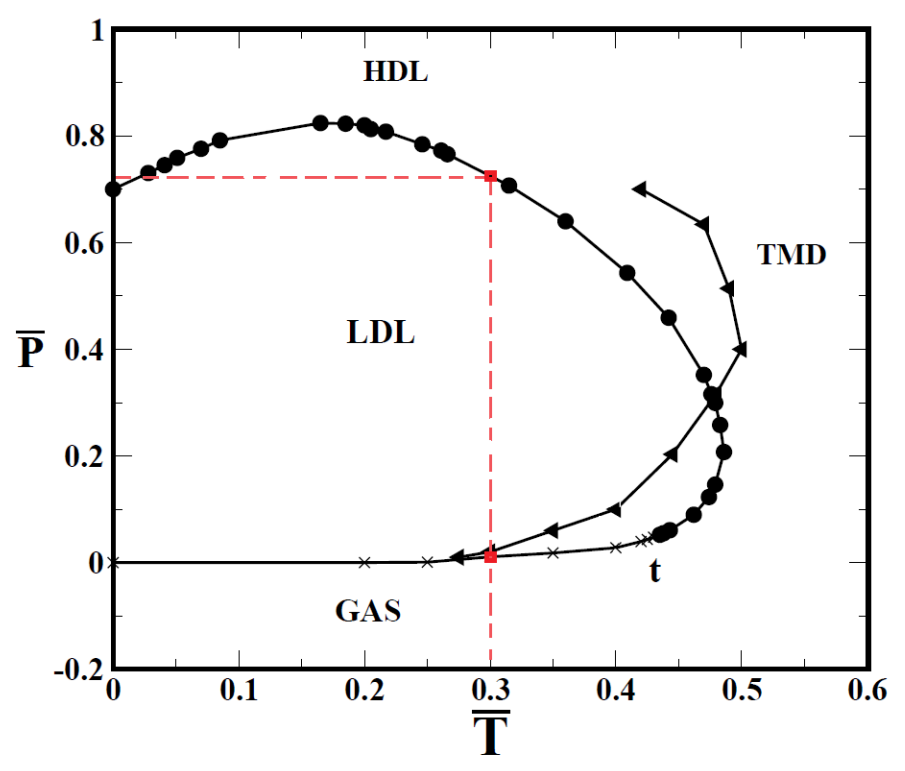

Figura 3.11: Diagrama de fase: pressão x temperatura, para um volume $V=42 \mathrm{x} 42$ e interações $\epsilon_{v} / \epsilon_{h}=0.1$. Fonte: adaptado de (Fiore et al., 2009). A linha tracejada vermelha indica os pontos de coexistência ao longo da isoterma $t=0.3$ (comparar com a figura anterior). 


\section{Capítulo 4}

\section{Proteína HP no solvente de}

\section{Bell-Lavis}

Nesta seção, propomos um novo modelo de rede para representar uma cadeia protéica imersa em um solvente aquoso através do acoplamento entre o modelo HP e o modelo orientacional de Bell-Lavis para a água, ambos na rede bidimensional triangular. O objetivo principal será o de estudar o comportamento das ligações de hidrogênio envolvidas num evento de enovelamento.

\subsection{Inclusão do solvente}

A omissão das partículas do solvente no modelo HP, ou em outros modelos que consideram apenas a cadeia protéica, torna a análise do enovelamento bastante restrita em certos aspectos. Além da necessidade de se incluir um potencial atrativo entre os monômeros apolares para se mimetizar o efeito hidrofóbico, não é possível tratar de propriedades que dependam intrinsecamente da organização das partículas de água em torno da proteína e em solução (bulk), como, por exemplo, a estruturação das ligações de hidrogênio e a competição entre elas na presença de um soluto interagente. Evidências 
experimentais de que as proteínas podem sofrer desnaturação a baixas temperaturas também não conseguem ser capturadas pelo modelo HP tradicional, uma vez que o potencial constante e atrativo torna as conformações nativas cada vez mais estáveis para $T \rightarrow 0$.

Nas últimas duas décadas diversos modelos foram propostos com a intenção de lidar diretamente com os efeitos do solvente. Dentre os modelos analíticos, podemos citar os trabalhos de (Hansen et al., 1997), que partem de um Hamiltoniano abstrato onde as variáveis que representam a água levam em conta a ordenação das moléculas em contato com estados desenovelados; (De Los Rios e Caldarelli, 2000, 2001), que utilizam o modelo HP na rede quadrada junto com o modelo de água MLG (MullerLee-Graziano), no qual se considera que todos os sítios sem proteína são ocupados por moléculas de água, representadas por variáveis de q estados, e somente consideram interações entre monômeros $\mathrm{H}$ em contato com a água: interação favorável para um único estado e desfavorável para os demais q-1 estados; (Bruscolini e Casetti, 1999, 2001) que estudam homopolímeros HH na rede triangular com partículas de água com três braços no estilo do modelo de Bell-Lavis, embora difiram bastante nas interações. Via de regra, esses trabalhos envolvem grandes simplificações na forma das interações para facilitar a manipulação analítica.

Dentre os modelos que utilizam o método de Monte Carlo dinâmico, temos por exemplo o estudo na rede de (Buzano et al., 2007), o qual se aproxima muito do sistema que iremos propor a seguir, onde os autores inserem um homopolímero HH inerte na rede triangular com o solvente representado como no modelo de Bell-Lavis, com a diferença de que eles adicionam um termo repulsivo quando uma molécula de água é vizinha de outras duas que estejam realizando ligação de hidrogênio ${ }^{1}$. Há ainda outros modelos fora da rede (Polson e Zuckermann, 2000) que utilizam um potencial contínuo

\footnotetext{
1"The weakening term is an effective three-body interaction, which makes the bond formation dependent both on orientation and local density and mimics the fact that HBs may be perturbed when water molecules are too close to one another."(Buzano et al., 2007).
} 
tipo Lennard-Jones para as interações aquosas e nos quais as águas são constituídas por bolinhas interagentes.

Em geral, tanto os estudos analíticos quanto os computacionais têm se focado principalmente na modelagem da desnaturação térmica por meio do aumento ou diminuição da temperatura. No entanto, nosso interesse aqui está em analisar o comportamento das ligações de hidrogênio em função da temperatura na presença de uma proteína HP. Para isso, diferentemente dos trabalhos citados antes, desejamos incluir contribuições para as ligações de hidrogênio provenientes tanto de pares água-água quanto por pares aminoácido-aminoácido ou aminoácido-água. A razão desta escolha se baseia no fato de que os grupos amida $(-\mathrm{NH}-\mathrm{CO}-)$ presentes no esqueleto protéico, resultantes da ligação peptídica, podem atuar como aceptores e doadores de ligação de hidrogênio, ver figura 1.4; da mesma forma, alguns grupos (aminas, hidroxilas, carboxilas) presentes sobretudo nas cadeias laterais de aminoácidos polares também podem realizar esse tipo de ligação. A ideia central, portanto, será avaliar a competição decorrente dessas diversas contribuições.

\subsection{Descrição do modelo}

As moléculas de água serão descritas como no modelo de Bell-Lavis, preservando-se o esquema de interações original: partículas vizinhas contribuem com um termo atrativo $-\epsilon_{v}$, tipo van der Waals, e, se seus braços estiverem orientados um na direção do outro, então dizemos que elas realizam uma ligação de hidrogênio, com potencial $-\epsilon_{h}$. Estaremos usando uma proporção entre as energias de um para dez: $\epsilon_{v} / \epsilon_{h}=0.1$. $\mathrm{Na}$ mesma rede inserimos uma única proteína HP, cujos monômeros interagem via ligação de hidrogênio se forem primeiros vizinhos, independentemente do tipo $(\mathrm{H}$ ou P). Conforme observamos, todos os grupos amida do esqueleto podem fazer ligações de hidrogênio, mesmo se as cadeias laterais dos aminoácidos que os originaram forem 
polares ou apolares - basta olhar, por exemplo, as ligações que definem as hélices- $\alpha$ e as folhas- $\beta$. Quanto às interações proteína-água, consideraremos que monômeros vizinhos de partículas de água se atraem com potencial de van der Waals $-\epsilon_{v}$, mas, se um dos braços da água estiver apontado para um monômero polar $\mathrm{P}$, diremos que há entre eles uma ligação de hidrogênio $-\epsilon_{h}$. Monômeros H não fazem ligação com o solvente. A justificativa para essa convenção é que, como as cadeias laterais estão mais expostas ao solvente do que o esqueleto, consideramos apenas a capacidade particular delas em formar ou não ligações com a água, daí a distinção entre os monômeros P e H. Em suma, as interações ficam como segue:
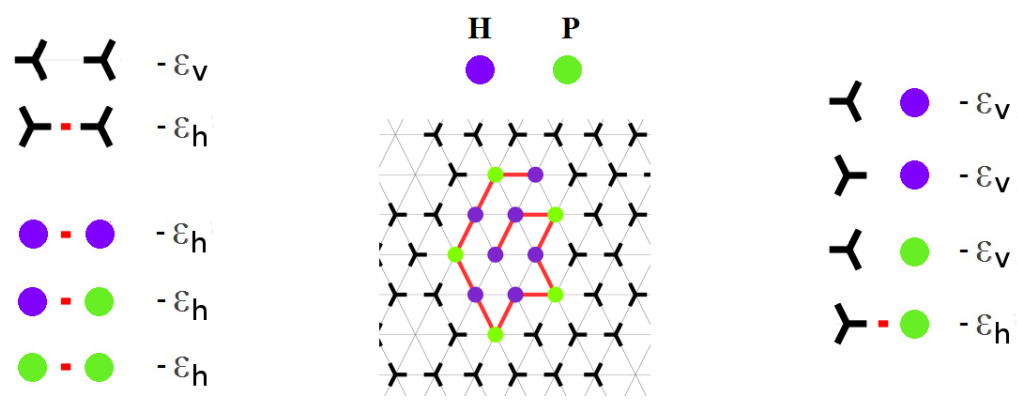

Figura 4.1: Esquema de interações água-água, água-proteína e proteína-proteína. Os monômeros hidrofóbicos estão em roxo e os polares em verde.

\subsubsection{Dinâmica de Monte Carlo}

O algoritmo aplicado para simular o modelo será uma combinação daqueles já detalhados nos capítulos 2 e 3 . A princípio, para cada passo novo da dinâmica, sorteamos com igual probabilidade se iremos movimentar a proteína ou o solvente. No primeiro caso, ainda sorteamos qual dos movimentos (end-flip, corner-flip, crankshaft ou pivot) a cadeia irá realizar, com a diferença que, se houver moléculas de água nos sítios envolvidos no movimento, elas simplesmente trocam de lugar com o monômero que foi para a sua posição. No segundo caso, sorteamos se iremos trocar a posição de uma molécula de água ou se iremos trocar sua orientação, assim como é feito no modelo de Bell- 
Lavis. Dado que um movimento é possível de ser realizado, ele é então submetido ao critério de Metropolis. Todas as simulações foram realizadas em uma rede de volume $V=15 \times 15$, com $N=160$ partículas de água e uma da proteína, dentro de um intervalo de temperaturas $t=0-0.8$. Cada simulação foi feita com $1,5.10^{6}$ passos de Monte Carlo e um intervalo de termalização de $4 \cdot 10^{5}$. Repetimos cada simulação sete vezes e tiramos a média e o desvio padrão entre elas.

\subsubsection{Sequências}

As sequências mais simples que podemos usar para testar o nosso modelo são os homopolímeros $(H)_{N}$. Através delas podemos verificar se o sistema realmente está reproduzindo o efeito hidrofóbico. Nesse caso, a sequência que decidimos estudar foi a de um homopolímero com $N=15$ monômeros:

Seq.1: homopolímero $(H)_{15}$.

Para heteropolímeros, diferentemente do modelo HP tradicional, não sabemos se existe alguma sequência capaz de se enovelar para um estado nativo na presença de um solvente explícito, nem mesmo para cadeias curtas. Diante dessa dificuldade, foi necessário estabelecer algum critério para selecionar as sequências que iríamos analisar. Um critério interessante consiste em usar uma sequência nativa no modelo HP com o objetivo de verificar seu comportamento na presença do solvente e com o novo esquema de interações que acabamos de fixar. Assim, segundo esse critério, escolhemos comparar a sequência nativa de 12 monômeros estudada por enumeração exata no capítulo 2 (ver figura 2.24):

Seq.2: sequência nativa no modelo HP triangular, $H H P H P H P H P H P H ~(N=$ $12)$.

As outras duas sequências estudadas foram aquelas utilizadas no capítulo 2 pelo método de Monte Carlo: 
Seq.3: ННРНРРНHНРНРНРРНHР $(N=18)$

Seq.4: ННРРНРРНРРНРРНРРНРРНРРНН $(N=24)$

\subsection{Resultados}

Organizamos os dados das simulações em duas colunas de quatro gráficos cada (figuras $4.2,4,6,8)$ com a intenção de facilitar uma visão global do comportamento das grandezas estudadas em função da temperatura. Os gráficos na coluna da esquerda dizem respeito, respectivamente, à: (1) energia média, (2) calor específico por molécula da mistura proteína-água, da água pura com a mesma densidade da mistura e da proteína pura, (3) raio de giro e (4) número de dobras. Na coluna da direita, dispomos de cima para baixo: (5) o número de ligações de hidrogênio proteína-proteína (PP) por monômero, água-proteína (AP) por monômero, água-água (AA) por molécula de água, e as ligações na primeira camada de solvatação (1 camada) por molécula de água; (6) as derivadas das curvas anteriores pela temperatura calculadas pelo método five-point stencil ${ }^{2}$, ou seja, usando cinco pontos sucessivos; (7) e (8), as mesmas variáveis anteriores ajustadas pelo método de Savitzky-Golay (Savitzky e Golay, 1964), o qual realiza sucessivas aproximações polinomiais locais, para eliminar os ruídos de alta frequência de nossos dados e facilitar sua visualização.

Em seguida, figuras 4.3,5,7,9, exibimos algumas configurações geradas durante as simulações em diferentes temperaturas, de onde podemos ter uma ideia das mudanças estruturas sofridas pelo polímero e o solvente. Monômeros polares estão coloridos de roxo e os apolares de verde.

\footnotetext{
${ }^{2} f^{\prime}(x) \approx-f(x+2 h)+8 \cdot f(x+h)-8 f(x-h)+f(x-2 h) / 12 h$.
} 
Seq.1: Homopolímero $(H)_{15}$
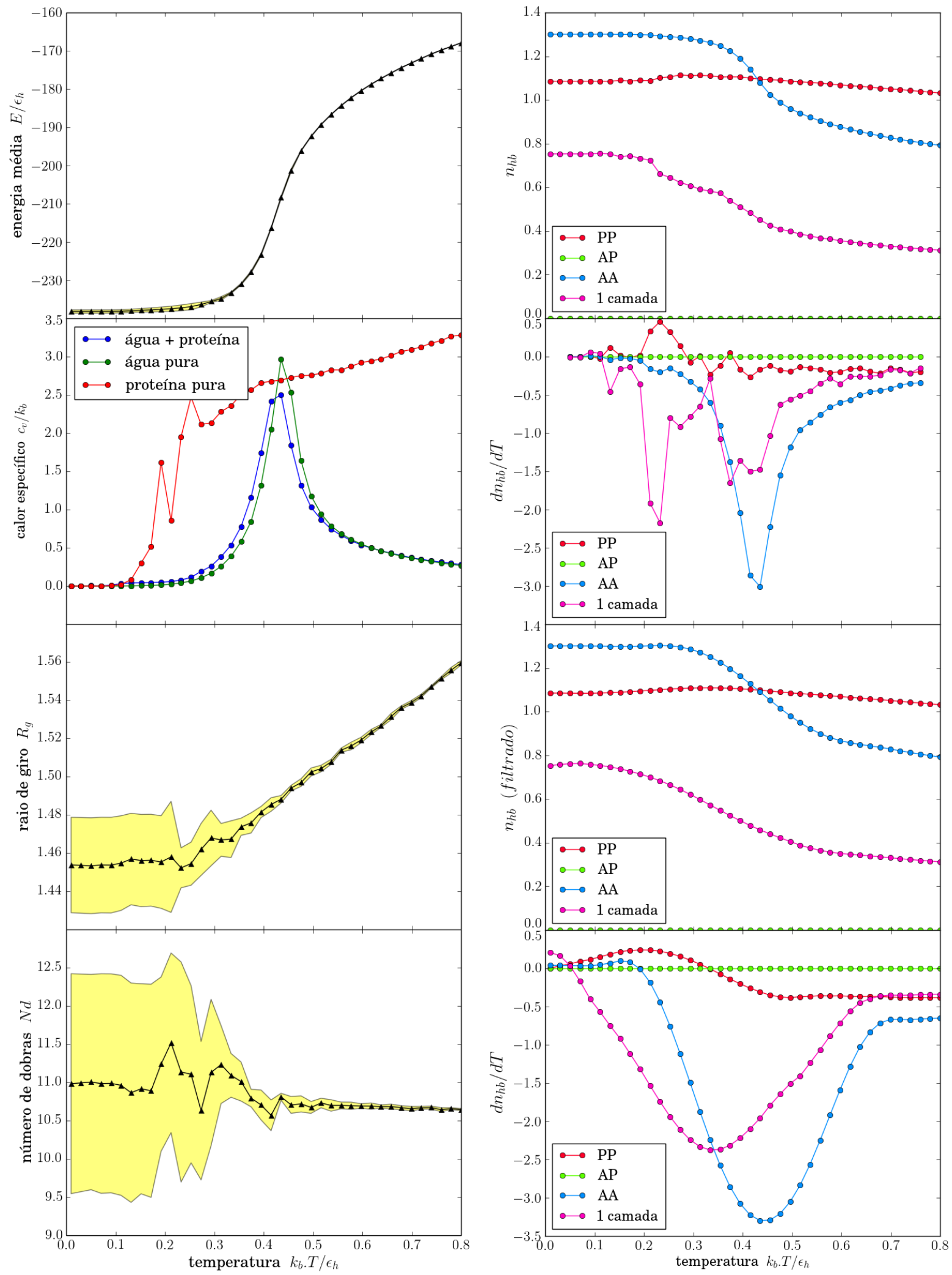

Figura 4.2: Resultados para a sequência 1. 

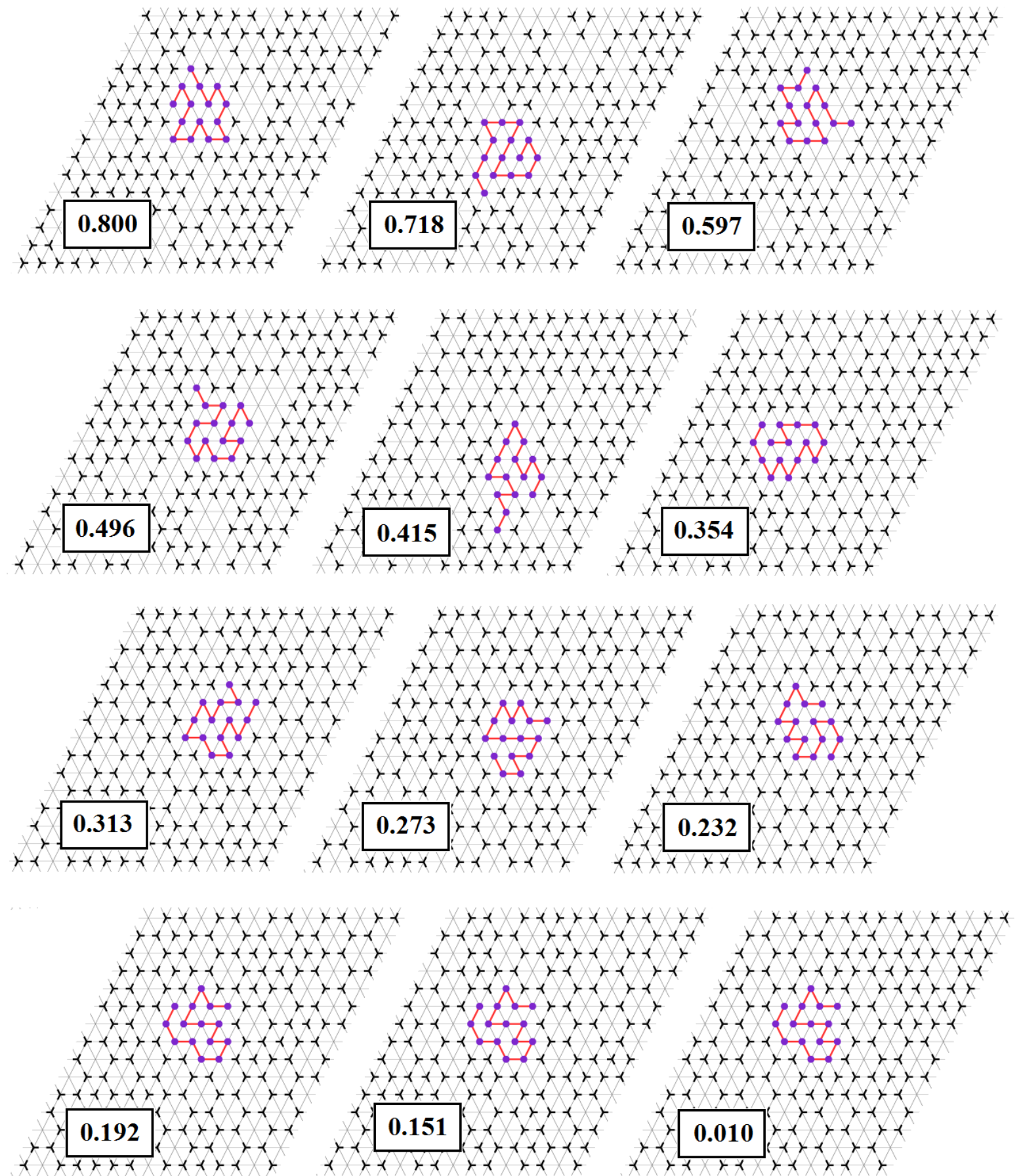

Figura 4.3: Algumas configurações da sequência 1. 
Seq.2: HHРHРНРНРНPH $(N=12)$
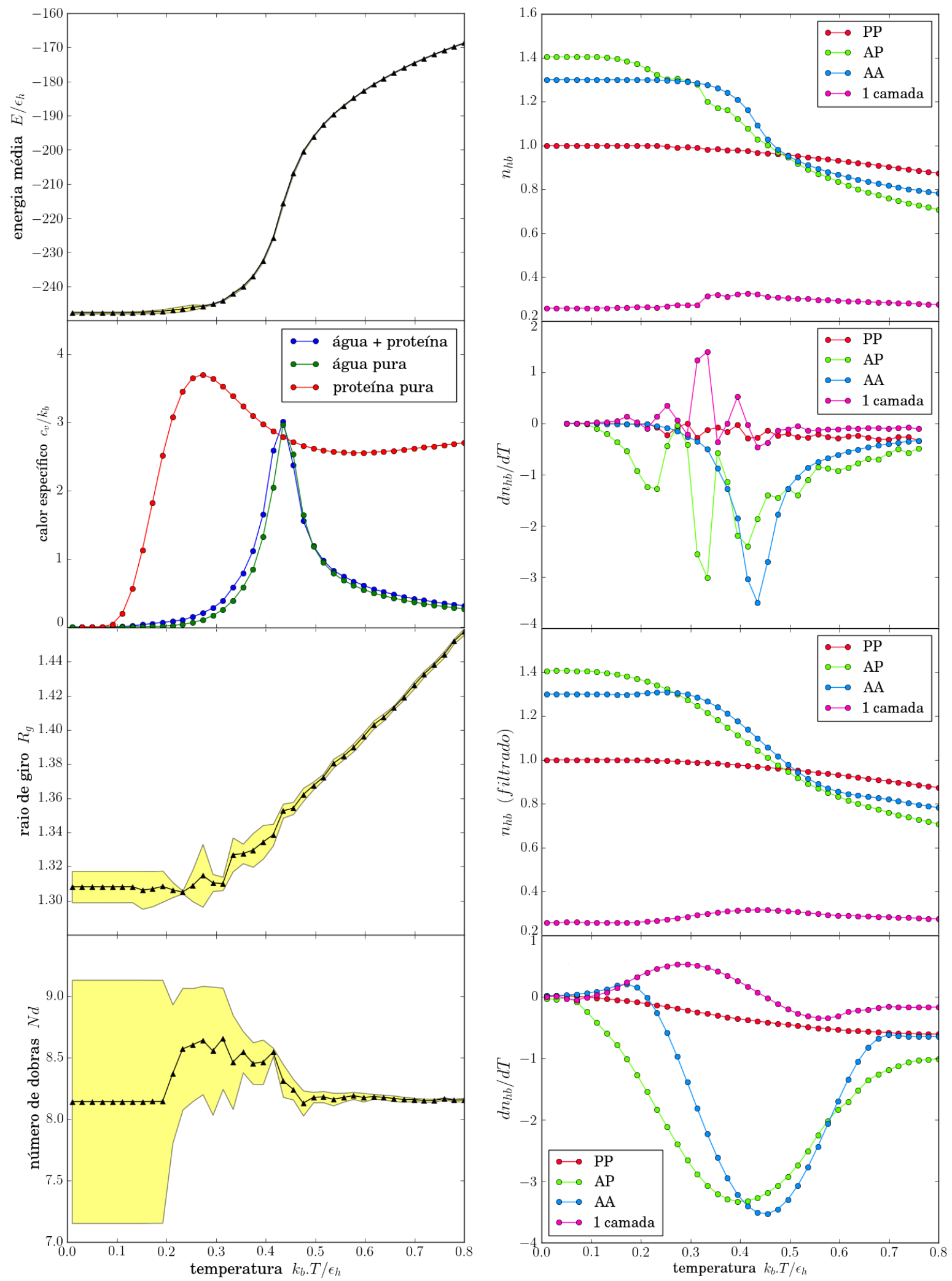

Figura 4.4: Resultados para a sequência 2. 


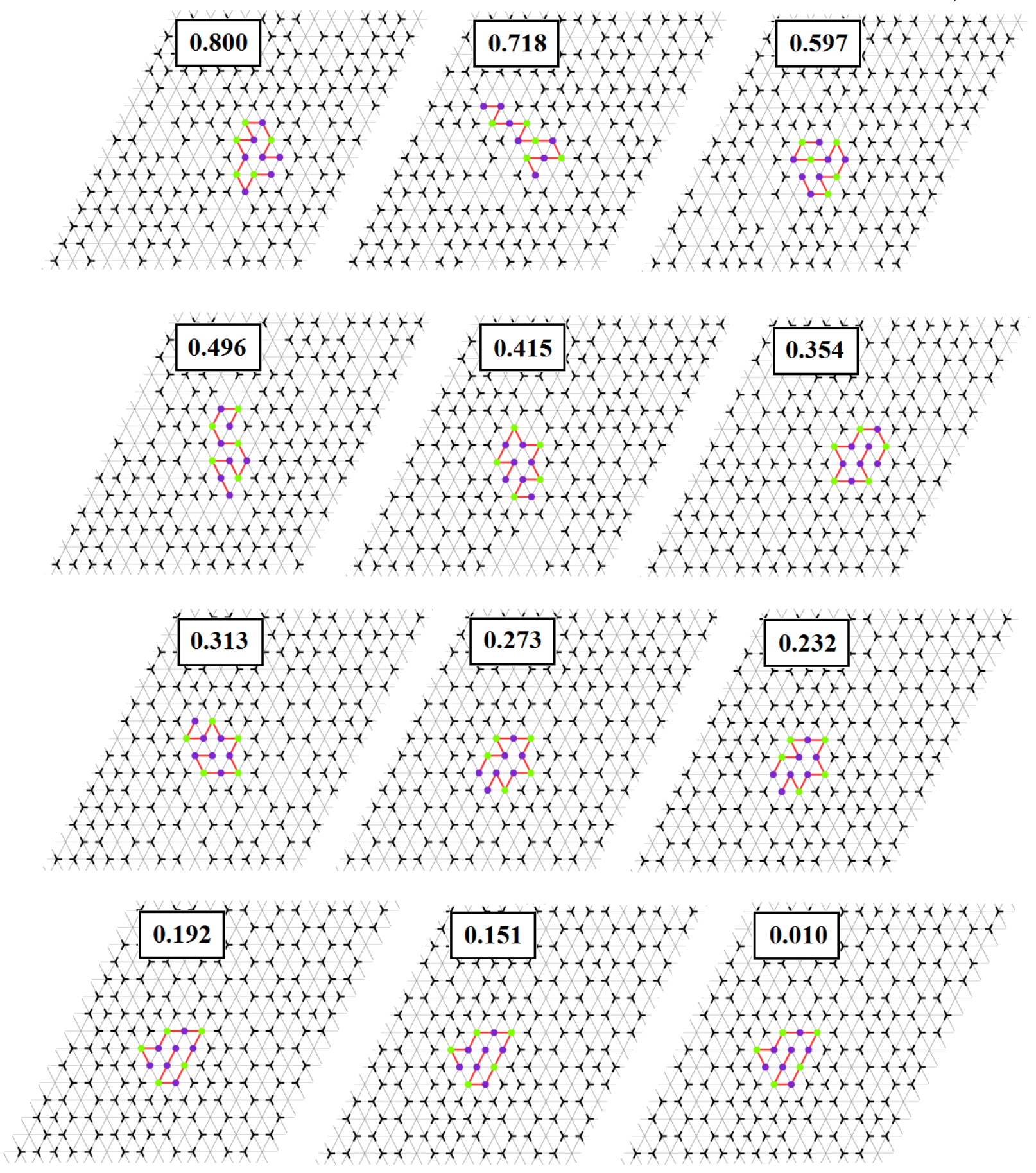

Figura 4.5: Algumas configurações da sequência 2. 
Seq.3: НHРНРРНHНРНРНРРНHР $(N=18)$
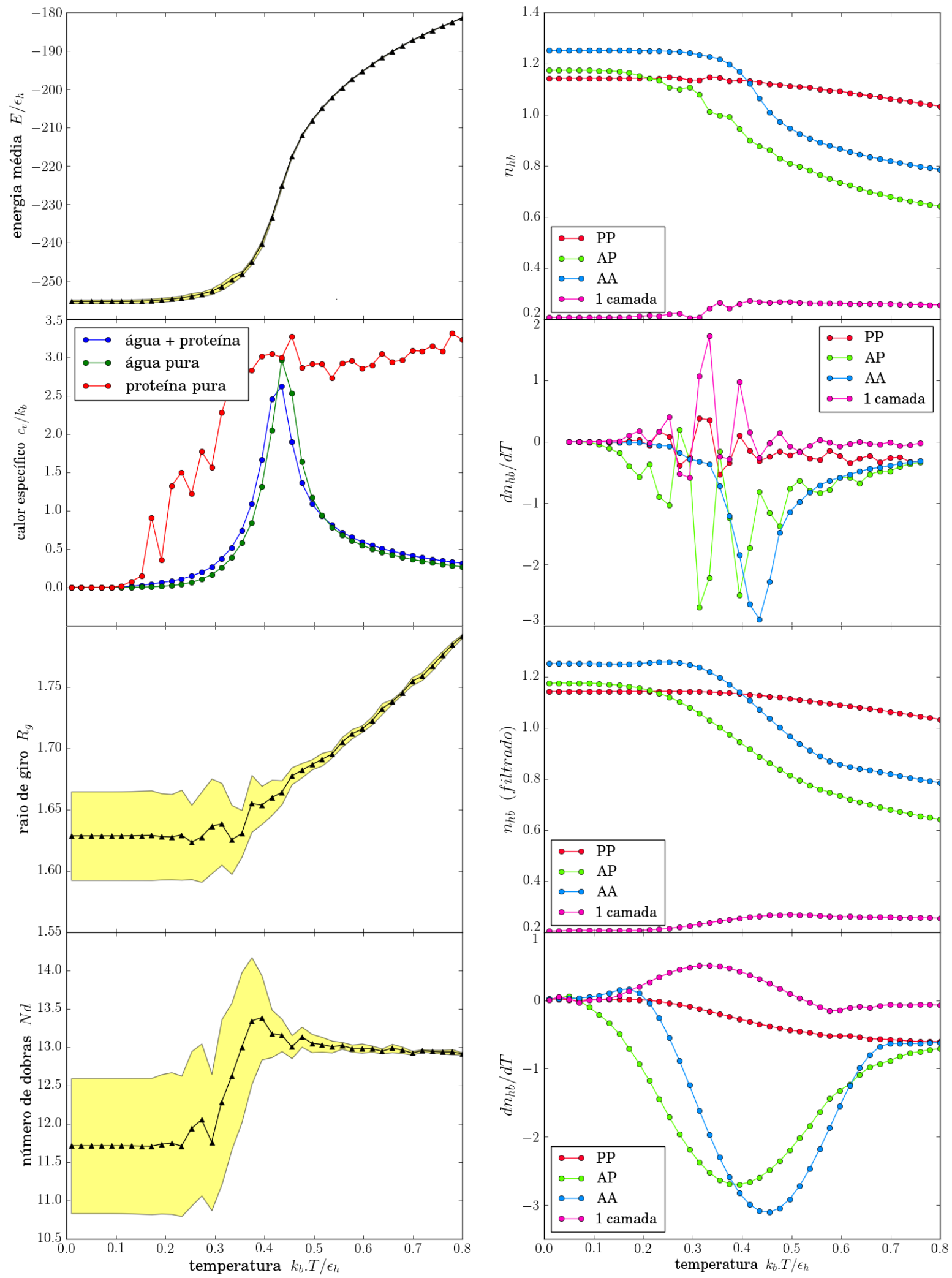

Figura 4.6: Resultados para a sequência 3. 

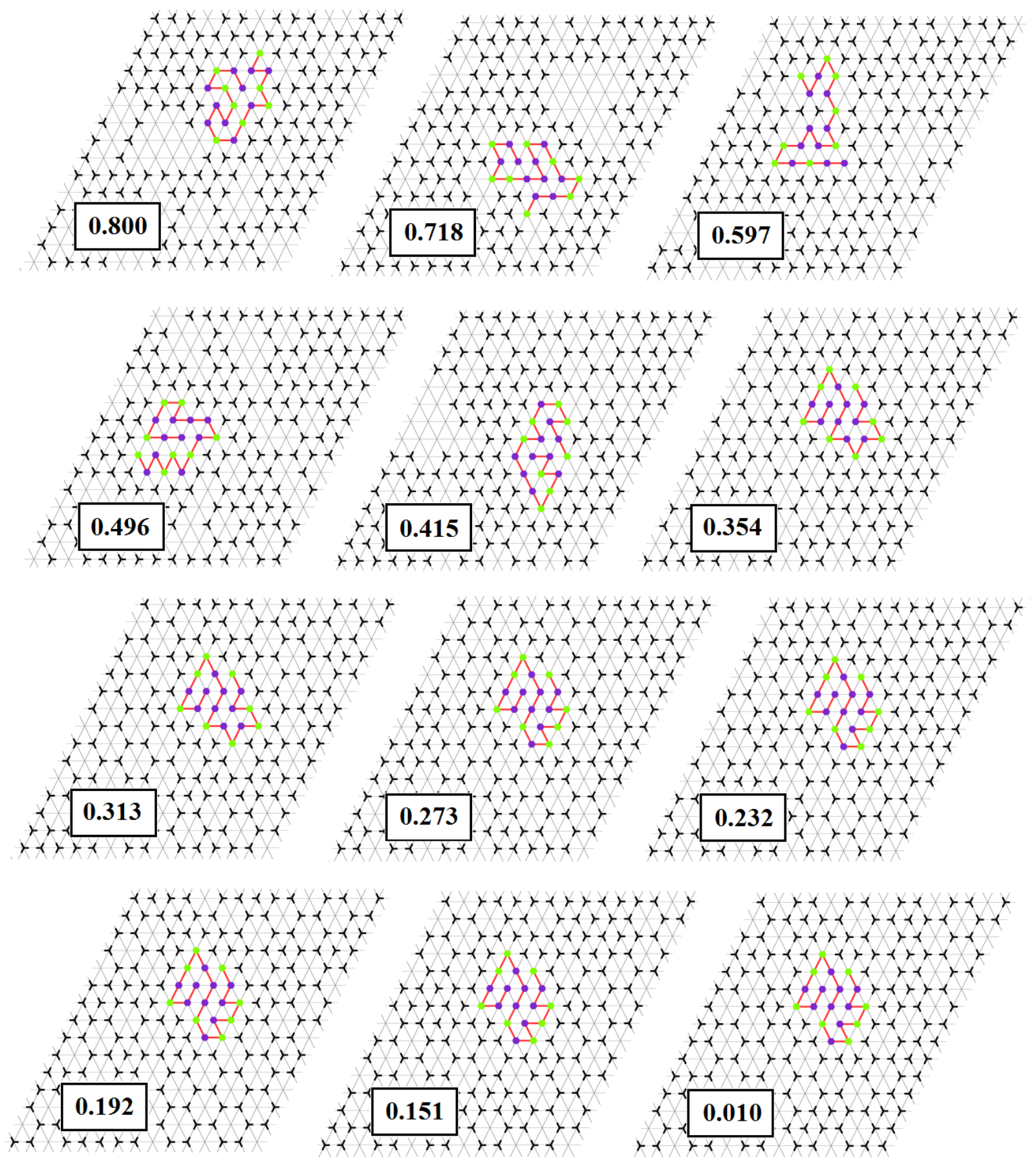

Figura 4.7: Algumas configurações da sequência 3. 
Seq.4: НHРРНРРНРРНРРНРРНРРНРРНН $(N=24)$
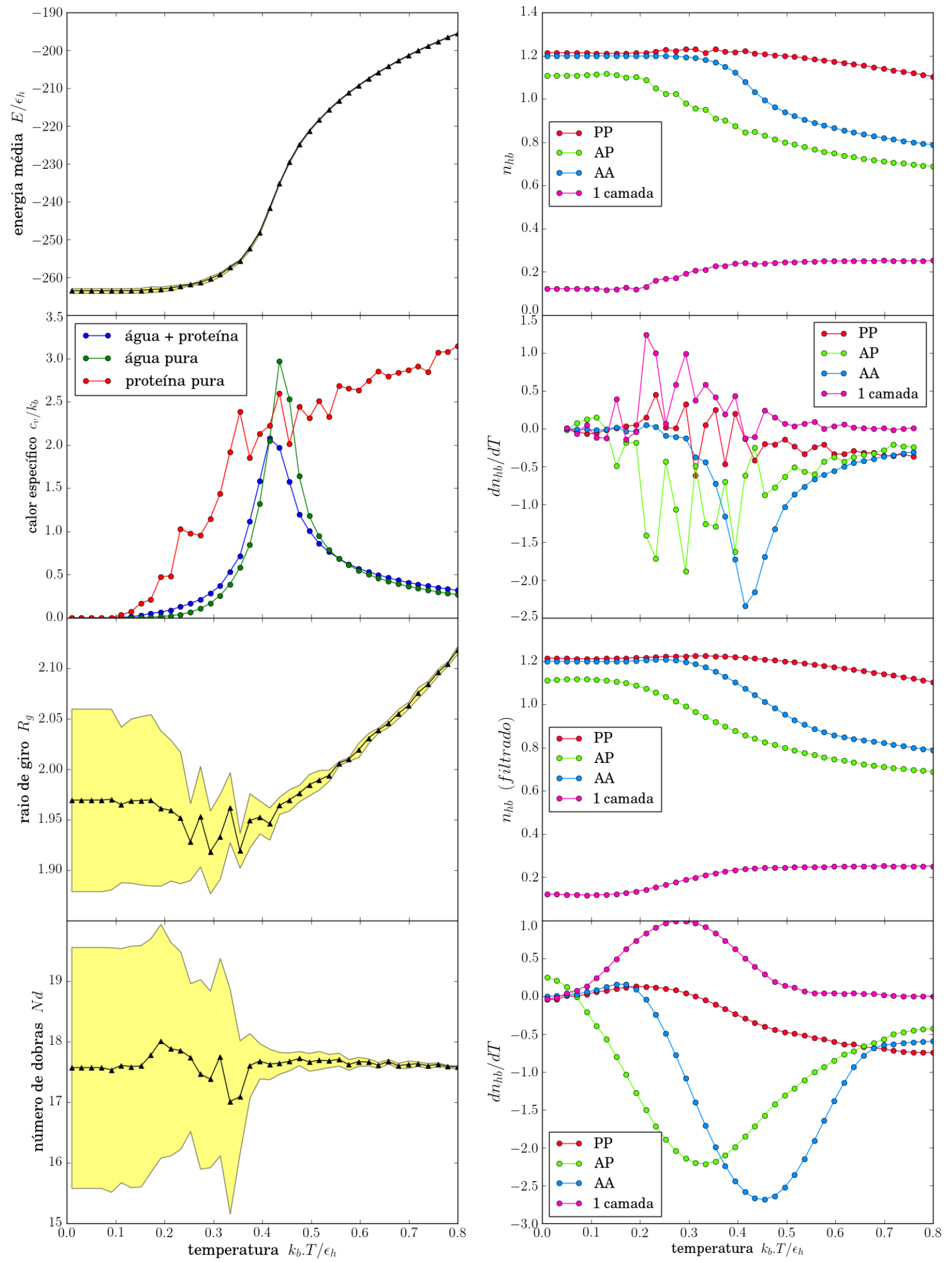

Figura 4.8: Resultados para a sequência 4. 

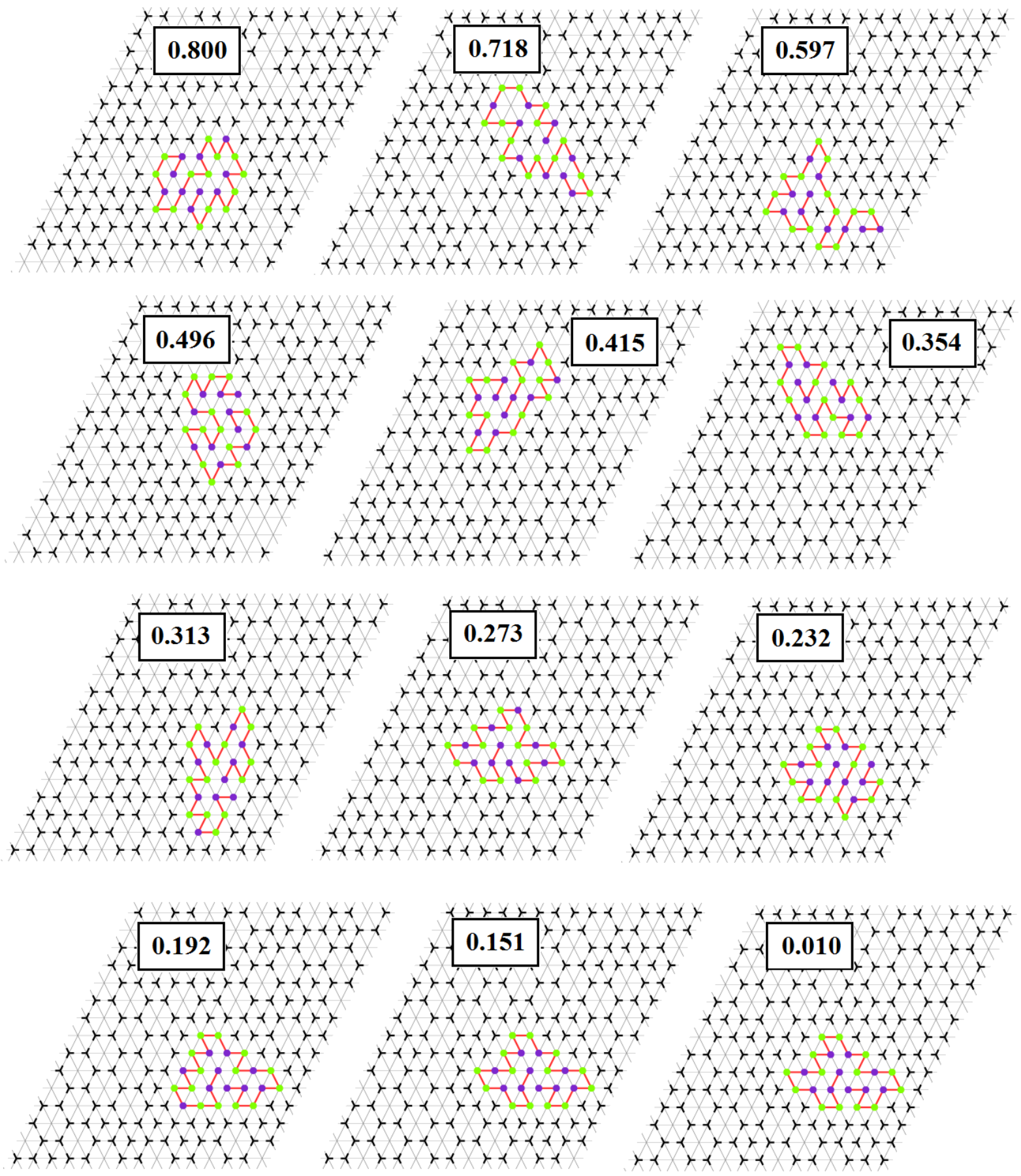

Figura 4.9: Algumas configurações da sequência 4. 
Uma primeira característica que podemos notar no modelo é o colapso das cadeias estudadas em estruturas compactas, nas quais se observa a formação de um núcleo predominantemente hidrofóbico e um exterior mais hidrofílico no caso dos heteropolímeros. Os monômeros apolares tenderam a ficar próximos entre si e afastados do solvente, embora ainda encontremos uma fração deles na superfície da proteína (figuras $4.3,5,7,9)$. Assim, até onde pudemos verificar, o modelo é capaz de reproduzir o efeito hidrofóbico. Isso pode ser explicado, em parte, pelo esquema de energias que adotamos: as moléculas de água podem realizar ligações de hidrogênio com monômeros polares, mas não com os apolares, de modo que há uma preferência para aqueles ficarem na superfície da proteína. O ordenamento rígido da fase LDL do solvente em baixas temperaturas também pode ter favorecido o colapso das cadeias, uma vez que a presença de monômeros apolares expostos impediriam que interações mais favoráveis pudessem ser formadas.

Não verificamos o chamado desenovelamento a frio, isto é, o afrouxamento da forma compacta em temperaturas muito baixas, pelo contrário, observa-se que nessas regiões a estrutura protéica tende a ficar presa em alguma configuração. Ao que parece, nenhum movimento na proteína é aceito nessas regiões, pois isso levaria à quebra de várias ligações de hidrogênio, implicando num custo energético elevado e uma baixa taxa de aceite. Além do que, nem poderíamos falar propriamente em desenovelamento para as sequências que selecionamos, uma vez que não se verifica a formação de um estado nativo ou preferencial em todas as simulações. Mesmo a cadeia curta de 12 monômeros (seq. 2), a qual apresenta um estado nativo no modelo HP tradicional, não se dobra nele, preferindo assumir uma diversidade de outros estados. Temos aqui o mesmo problema que enfrentamos antes para cadeias longas no modelo HP, a dificuldade em achar uma sequência nativa.

Em cada simulação, as cadeias se dobram de maneiras diversas, de onde não somos capazes de distinguir um estado nativo característico. Disso, podemos dizer que as 
poucas sequências estudadas não seriam boas candidatas a proteínas no nosso modelo. Nem saberíamos de um critério para escolher sequências mais apropriadas. A inclusão de um solvente explícito, portanto, coloca uma dificuldade neste aspecto. Talvez uma solução fosse alterar o potencial de interação entre os aminoácidos para que favorecêssemos uma única estrutura, como acontece com os potenciais do tipo Go (conta-se uma interação somente quando pares específicos de monômeros são primeiros vizinhos), embora a interpretação física dos resultados neste caso seja mais problemática.

Comparamos o calor específico por molécula dos sistemas: proteína-água (mistura), do solvente puro (apenas as moléculas de água, mas com a mesma densidade da mistura) e da proteína pura - ver o segundo gráfico das figuras 4.2, 4.4, 4.6 e 4.8 nas colunas da esquerda. Analisando os gráficos, observamos que as curvas correspondentes à mistura se encontram sempre um pouco deslocadas para a esquerda em relação às curvas do solvente puro. Isso nos indica que a introdução da molécula de proteína no solvente tem o efeito de facilitar o desordenamento da rede (o pico do calor específico da água corresponde à transição do fluido desordenado para a fase líquida de baixa densidade LDL, como podemos ver nos diagramas de fase apresentados no capítulo 3). Assim, temos que a presença da proteína reduz a temperatura necessária para romper a estrutura de colmeia do meio, agindo como uma perturbação no bom ordenamento do solvente. Além disso, como temos muito mais moléculas de água (160) do que de proteína (1), o calor específico da mistura tem uma forma muito próxima daquela do solvente puro, sendo difícil enxergar alguma transição do polímero analisando somente o gráfico desta função.

O raio de giro das cadeias indica o colapso sofrido à medida que reduzimos a temperatura. A queda nessa grandeza se dá até aproximadamente $t \approx 0.3$, ficando quase constante para temperaturas mais baixas, o que reflete o congelamento da estrutura nessas regiões, onde também se nota o aumento considerável do desvio padrão. Como cada simulação congela em uma estrutura diferente, com diferentes raios de giro, a 
estatística não é tão boa nessa região. No número de dobras encontramos um comportamento menos claro. Ao que parece, a grandeza não varia muito na faixa entre $t \approx 0.8-0.5$, sofre algumas perturbações entre $t \approx 0.5-0.2$ e depois volta a estabilizar (de novo, devido ao congelamento das estruturas). Talvez possamos dizer, pela comparação entre a localização do pico do calor específico da mistura e as mudanças nas duas últimas variáveis, que algo significativo deve ocorrer na estrutura da proteína devido ao ordenamento da rede aquosa.

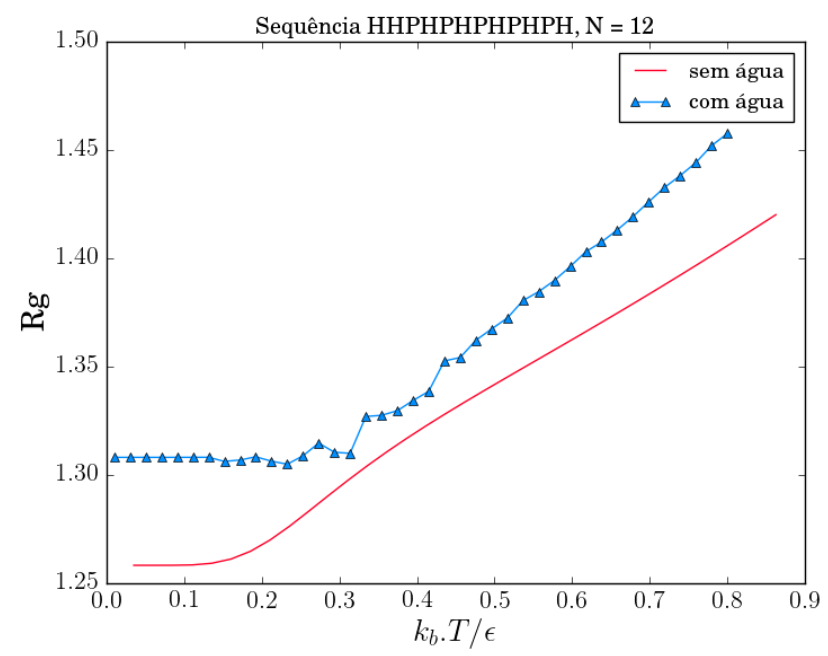

Figura 4.10: Comparação dos raios de giro nas situações com e sem água.

Na figura 4.10, comparamos o raio de giro da sequência 2, nas situaçõoes em que o polímero está em meio aquoso (curva azul) e num meio sem moléculas de água, ou seja, apenas a cadeia como no modelo HP. Como as interações são mantidas constantes, o polímero puro no nosso modelo é equivalente ao homopolímero $H_{12}$ no modelo HP (visto que todos os monômeros podem interagir entre si). O que observamos é que a cadeia em água se encontra mais aberta, ou, menos compacta, do que quando está sozinha na rede. Podemos entender este comportamento novamente devido à característica dos monômeros polares de interagirem via ligação de hidrogênio com a água, de modo que as estruturas mais compactas para as quais a cadeia se dobra sem a presença do solvente 
seriam menos favoráveis para a ocorrência dessas interações em água. Quer dizer, há uma preferência da cadeia ficar menos compacta na água desde que ela possa interagir melhor com o meio. Estruturas muito compactas poderiam esconder os resíduos polares e evitar essas ligações.

Para analisarmos as mudanças sofridas nas interações de hidrogênio, dividimos as contribuições relativas ao solvente (AA), à proteína (PP), às interações água-proteína (AP) e olhamos também para as interações água-água na primeira camada de hidratação (contorno formado pelos primeiros vizinhos dos monômeros). Obtivemos as seguintes conclusões a partir da análise comparativa das cadeias selecionadas:

(1) As curvas das interações AA permanecem, em todos os casos, com uma taxa máxima de variação em torno de $t \approx 0.4-0.5$, de modo que a transição da água parece ser indiferente à presença de um homopolímero ou heteropolímero. No entanto, o número máximo de ligações por molécula é reduzido conforme aumentamos o tamanho do polímero, o que é esperado, uma vez que há mais monômeros para as águas interagirem enquanto que o número delas continua o mesmo.

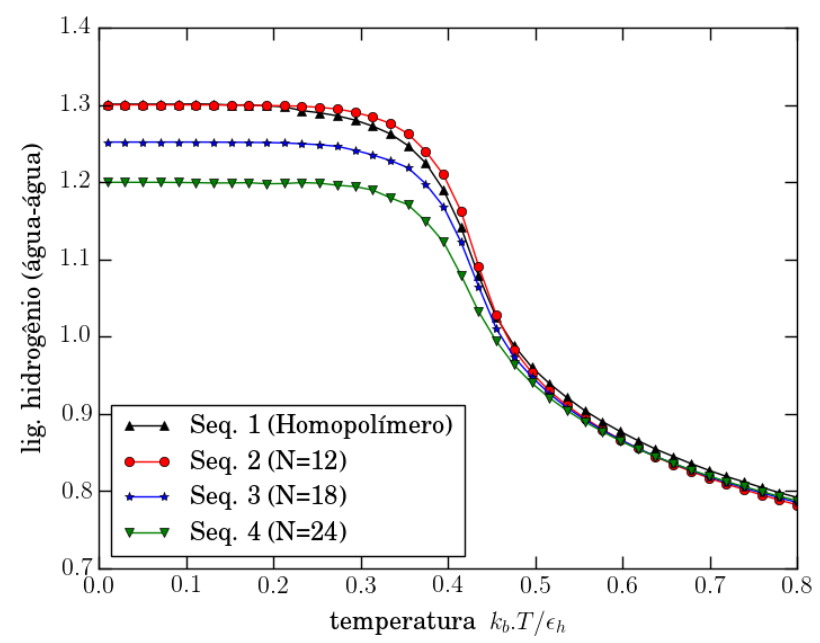

Figura 4.11: Ligações de hidrogênio água-água por molécula de água.

(2) O número de interações por molécula na primeira camada não variam de forma 
significativa para os heteropolímeros, sofrendo apenas uma leva queda em baixas temperaturas. Para o homopolímero $H_{15}$, ao contrário, há um aumento considerável nessas interações, comparável à variação das ligações água-água, quando reduzimos a temperatura, o que indica que a rede de ligações de hidrogênio tende a contornar o exterior da molécula hidrofóbica - como é possível observar na figura 4.3. Se observarmos o contorno da primeira camada nos heteropolímeros, veremos que muitas moléculas de água estão realizando ligações com os monômeros polares, em detrimento de moléculas vizinhas do solvente. Aliás, nota-se em geral que o solvente na superfície tende a contornar os monômeros apolares e se ligar aos polares.

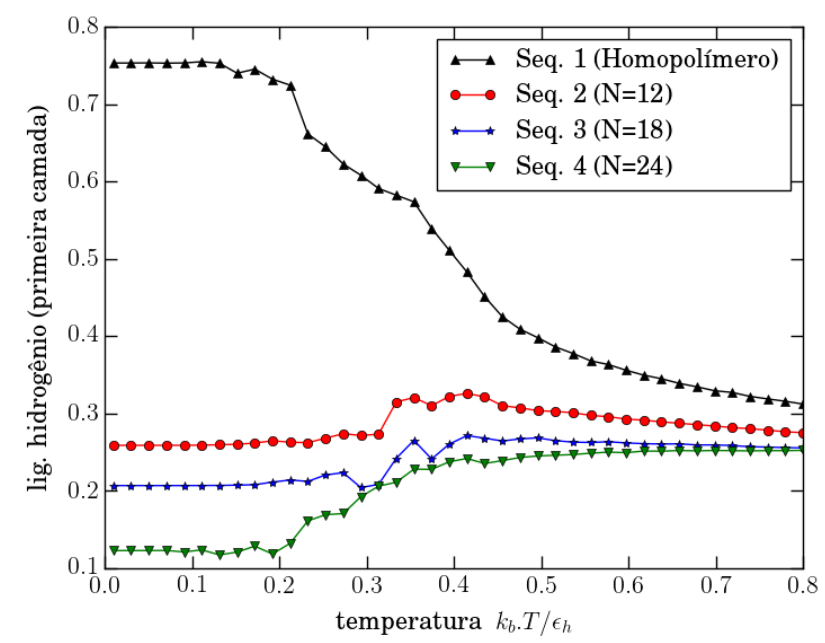

Figura 4.12: Ligações de hidrogênio água-água na primeira camada de solvatação por molécula de água na camada.

(3) A densidade de moléculas de água próxima ao heteropolímero parece ser maior do que nas proximidades do homopolímero. Isso se deve à tendência do sistema em maximizar as ligações de hidrogênio: se há um monômero polar exposto, uma molécula de água que não esteja realizando pontes no solvente irá preferir se ligar ao monômero (é mais favorável do que realizar 6 interações de van der Waals com o solvente).

(4) As ligações água-proteína aumentam com a diminuição da temperatura em todos 
os heteropolímeros, em razão do que acabamos de dizer. A transição nessa variável acompanha sempre a transição de ordenamento da água, porém aparece levemente deslocada para temperaturas mais baixas. A estruturação do meio favorece que mais águas possam se ligar à proteína HP. O homopolímero não faz ligações com a água, portanto não há variação neste aspecto.

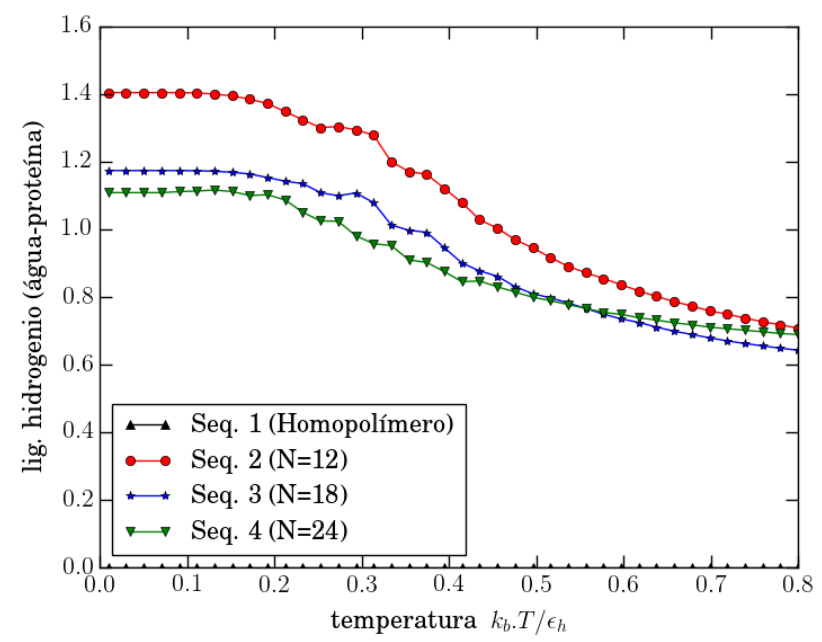

Figura 4.13: Ligações de hidrogênio água-proteína por monômero.

(5) O número de ligações proteína-proteína, PP, também não sofre variações significativas na faixa de temperaturas considerada, apenas um leve aumento é observado para todas as cadeias conforme se esfria o sistema. Se pensarmos que a cadeia protéica está imersa numa rede cheia de água, ela não tem tanta liberdade quanto no modelo HP puro para adotar conformações mais estendidas, devido à pressão que o solvente lhe impõe. Assim, entendemos que a cadeia se encontra mais comprimida na mistura e realizando um número médio de contatos entre seus monômeros que não se altera muito durante a simulação, como se ela já estivesse parcialmente colapsada na faixa de temperaturas considerada. 


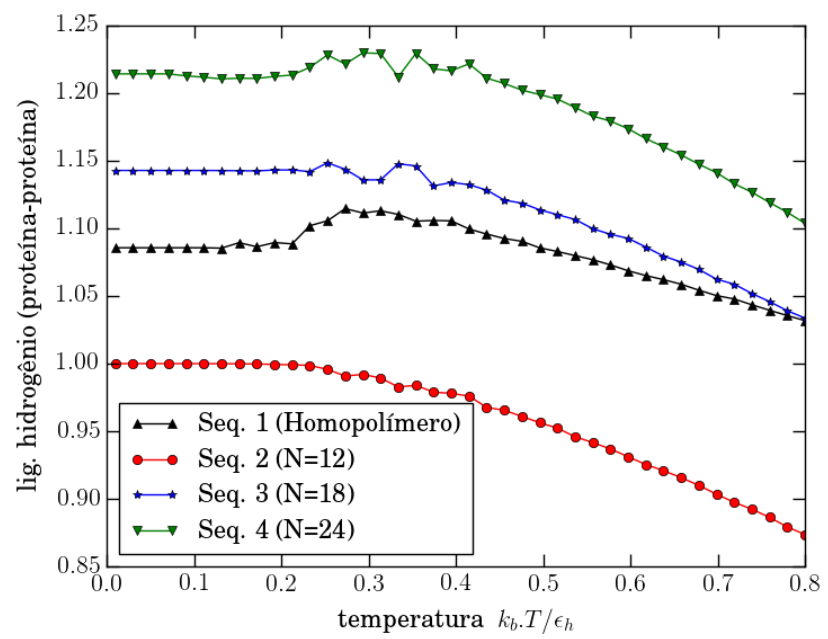

Figura 4.14: Ligações de hidrogênio proteína-proteína por monômero. 



\section{Capítulo 5}

\section{Considerações Finais}

Nossa investigação teve como objeto o processo de enovelamento protéico visto sob o enfoque de modelos termo-estatísticos mínimos. A análise foi realizada em dois momentos distintos conforme estivéssemos considerando o polímero imerso em um solvente implícito (modelo HP) ou explícito (modelo HP acoplado ao modelo de Bell-Lavis). No primeiro caso, a análise de cadeias curtas permitiu o tratamento por enumeração exata, de onde propusemos a existência de uma relação entre a ocorrência de um segundo pico no calor específico - associado na literatura à transição de congelamento - com uma drástica redução no número de configurações entre o primeiro estado excitado e o estado fundamental/nativo. Observamos, também, que esse pico pode aparecer tanto em homopolímeros quanto em heteropolímeros, para ambas as redes quadrada e triangular. Para cadeias maiores tivemos que adotar o método de Monte Carlo, o qual foi utilizado até o final do estudo. A principal dificuldade imposta por este método para nós é a de não sermos capazes de selecionar com facilidade uma sequência nativa, mais própria para representar uma proteína.

Em seguida, fizemos um breve estudo do modelo aquoso de Bell-Lavis, nos limitando a reproduzir alguns resultados da literatura para ganharmos familiaridade com este sistema. Aproveitamos a ocasião para testarmos novas metodologias de cálculo da pressão 
no ensemble canônico, as quais desenvolvemos paralelamente ao projeto original e estão descritas com maiores detalhes no apêndice. Os resultados preliminares que obtivemos com elas se mostraram bastante coerentes, de onde pretendemos nos aprofundar tendo em vista uma publicação futura.

Por fim, propomos um modelo exploratório composto por uma cadeia HP imersa no fluido tipo água de Bell-Lavis. Além de verificarmos algumas propriedades características do enovelamento de proteínas, tais como o colapso hidrofóbico e a tendência de migração dos monômeros polares em direção à superfície e dos apolares para o núcleo, pudemos acompanhar a mudança no padrão das ligações de hidrogênio de cada componente, o que é uma vantagem possibilitada pelo tratamento mínimo do sistema. Concluímos que o enovelamento, neste contexto $^{1}$, é fortemente influenciado pelo ordenamento da rede de ligações de hidrogênio do solvente (fase LDL), o qual produz aumentos significativos no número médio de ligações proteína-água (no caso dos heteropolímeros) e na primeira camada de solvatação (com maior intensidade para o homopolímero). Observamos que o ordenamento da rede aquosa também confere uma maior rigidez estrutural às cadeias, cujos movimentos ficam energeticamente mais limitados. No entanto, essa modesta constatação não explica a estabilidade do estado nativo das proteínas, visto que estudamos apenas sequências não-nativas, mas sugere um papel estabilizador para o solvente. Poderíamos questionar, entretanto, se a fase LDL da água de Bell-Lavis seria adequada para representar a estrutura de ligações altamente flutuante da água real nas condições fisiológicas em que a maioria das proteínas atua. Neste sentido, uma sugestão que poderíamos propor ao nosso modelo seria a de trabalhar com faixas de densidade mais altas, próprias da fase líquida HDL, a qual, como a água, também possui um certo grau de ordenamento, mas com ligações que podem constantemente se quebrar e se refazer.

\footnotetext{
${ }^{1}$ Incluindo o esquema de interações que definimos para o modelo.
} 


\section{Referências Bibliográficas}

Anfinsen, C. B. (1973). Principles that govern the folding of protein chains. Science (New York, N.Y.), 181(4096):223-30.

Arunan, E., Desiraju, G. R., Klein, R. a., Sadlej, J., Scheiner, S., Alkorta, I., Clary, D. C., Crabtree, R. H., Dannenberg, J. J., Hobza, P., Kjaergaard, H. G., Legon, A. C., Mennucci, B., e Nesbitt, D. J. (2011). Definition of the hydrogen bond (IUPAC Recommendations 2011). Pure and Applied Chemistry, 83(8):1637-1641.

Baldwin, R. L. e Rose, G. D. (1999). Is protein folding hierarchic? II. Folding intermediates and transition states. Trends in Biochemical Sciences, 24(2):77-83.

Bell, G. M. e Lavis, D. A. (1970). Two-dimensional bonded lattice fluids I. Interstitial model. Journal of Physics A: General Physics, 3(4):427-441.

Binder, K., Block, B. J., Virnau, P., e Troster, A. (2012). Beyond the Van Der Waals loop: What can be learned from simulating Lennard-Jones fluids inside the region of phase coexistence. American Journal of Physics, 80(12):1099.

Bruscolini, P. e Casetti, L. (1999). Lattice model for cold and warm swelling of polymers in water. Physical Review E, 61(3):5.

Bruscolini, P. e Casetti, L. (2001). Model for the hydration of nonpolar compounds and polymers. Physical Review E, 64(5):1-6. 
Buzano, C., De Stefanis, E., e Pretti, M. (2007). Low-temperature-induced swelling of a hydrophobic polymer: A lattice approach. Journal of Chemical Physics, 126(7):1-8.

Chan, H. S. e Dill, K. a. (1989a). Compact polymers. Macromolecules, 22(12):4559-4573.

Chan, H. S. e Dill, K. a. (1989b). Intrachain loops in polymers: Effects of excluded volume. The Journal of Chemical Physics, 90(1):492.

Dalal, S., Balasubramanian, S., e Regan, L. (1997). Protein alchemy: Changing $\beta$-sheet into $\alpha$-helix. Nature Structural Biology, 4(7):548-552.

De Los Rios, P. e Caldarelli, G. (2000). Putting proteins back into water. Physical Review E - Statistical Physics, Plasmas, Fluids, and Related Interdisciplinary Topics, $62(6 \mathrm{~B}): 8449-8452$.

De Los Rios, P. e Caldarelli, G. (2001). Cold and warm swelling of hydrophobic polymers. Physical Review E, 63(3):031802.

Dill, K. A., Bromberg, S., Yue, K. Z., Fiebig, K. M., Yee, D. P., Thomas, P. D., e ChanS, H. S. (1995). Principles of Protein-Folding - a Perspective From Simple Exact M Odels. Protein Sci., 4:561-602.

Fiore, C. E., Szortyka, M. M., Barbosa, M. C., e Henriques, V. B. (2009). Liquid polymorphism, order-disorder transitions and anomalous behavior: A Monte Carlo study of the Bell-Lavis model for water. Journal of Chemical Physics, 131(16):1-10.

Hansen, A., Jensen, M. H., Sneppen, K., e Zocchi, G. (1997). Statistical mechanics of warm and cold unfolding in proteins. 161:5.

Kauzmann, W. (1959). Some Factors in the Interpretation of Protein Denaturation. Advances in Protein Chemistry, 14(C):1-63.

King, J. (1989). Deciphering the rules of protein folding. Chem. Eng. News, 67(15):32$37,40-47,50-54$. 
Lal, M. (1969). 'Monte Carlo' computer simulation of chain molecules. I. Molecular Physics, 17(1):57-64.

Lau, K. F. e Dill, K. A. (1989). A lattice statistical mechanics model of the conformational and sequence spaces of proteins. Macromolecules, 22(10):3986-3997.

Levinthal, C. (1969). How to fold graciously. Mössbauer Spectroscopy in Biological Systems Proceedings, 24(41):22-24.

Madras, N. e Sokal, A. D. (1988). The pivot algorithm: A highly efficient Monte Carlo method for the self-avoiding walk. Journal of Statistical Physics, 50(1-2):109-186.

Metropolis, N., Rosenbluth, A. W., Rosenbluth, M. N., Teller, A. H., e Teller, E. (1953). Equation of state calculations by fast computing machines. Journal Chemical Physics, 21(6):1087-1092.

Orr, W. J. C. (1947). Statistical treatment of polymer solutions at infinite dilution. Transactions of the Faraday Society, 43:12.

Polson, J. M. e Zuckermann, M. J. (2000). Simulation of heteropolymer collapse with an explicit solvent in two dimensions. Journal of Chemical Physics, 113(3):1283-1293.

Ramachandran, G. N., Ramakrishnan, C., e Sasisekharan, V. (1963). Stereochemistry of polypeptide chain configurations. Journal of molecular biology, 7(1):95-99.

Sauerwein, R. e de Oliveira, M. (1995). Entropy of spin models by the Monte Carlo method.

Savitzky, A. e Golay, M. J. E. (1964). Smoothing and Differentiation of Data by Simplified Least Squares Procedures. Analytical Chemistry, 36(8):1627-1639.

Shakhnovich, E. I. (1994). Proteins with selected sequences fold into unique native conformation. Physical Review Letters, 72(24):3907-3910. 
Widom, B. (1963). Some Topics in the Theory of Fluids. The Journal of Chemical Physics, 39(11):2808. 


\section{Apêndice A}

\section{Cálculos de Pressão no Ensemble Canônico}

A pressão de um sistema termodinâmico, como um fluido por exemplo, é uma grandeza macroscópica bastante explorada na apresentação de gráficos e diagramas de fase experimentais. Daí a importância, para aqueles modelos que buscam simular tais sistemas, de se ter à mão métodos práticos de aferí-la computacionalmente. O ensemble estatístico que permite fazer essa comparação entre teoria e experimento de maneira mais imediata é o canônico, uma vez que podemos extrair dele curvas de pressão à temperatura, número de partículas e volume constantes, variáveis que geralmente estão sob controle no laboratório. Nessa direção, apresentaremos algumas propostas desenvolvidas em parceria com o então doutorando Jozismar R. Alves e a prof(a) Vera B. Henriques ao longo do período de realização do mestrado.

A ideia original que motivou essa pesquisa foi a procura de um método análogo ao de Widom para o cálculo do potencial químico no canônico (Widom, 1963), o qual se mostra bastante vantajoso sob determinados aspectos. Por exemplo, é possível definir com maior precisão as regiões de transição e coexistência (Binder et al., 2012). Isso se deve à formação de patamares nessa função, o que facilita a demarcação dessas regiões 
diferentemente das histereses observadas (no gráfico $\rho \mathrm{x} \mu$ ) em simulações realizadas no ensemble grande canônico. No caso da pressão, boa parte das simulações são feitas no grande canônico, usando por exemplo a relação de Gibbs-Duhem, porém envolvem um trabalho computacional considerável, principalmente em se tratando de misturas. Um método alternativo e mais direto nesse último ensemble pode ser visto em (Sauerwein e de Oliveira, 1995).

A primeira seção aborda a questão da pressão através da busca por segmentos vazios na rede, a qual apresentará melhor desempenho para regiões de baixa densidade. Em seguida, exploraremos a situação contrária, ou seja, buscando segmentos cheios, os quais serão mais fáceis de encontrar em regimes de altas densidades. Como modelo teste escolhemos o bem conhecido gás de rede bidimensional, cujos resultados servirão de base para a validação dos métodos. Finalmente, algumas soluções exatas em uma dimensão são demonstradas.

\section{A.1 Método I: Cálculo com segmentos vazios}

Seja um sistema definido pelas seguintes grandezas: número de partículas $N$, volume $V$ e temperatura $T$. Usando as relações fundamentais da termodinâmica, podemos escrever a pressão como a derivada negativa da energia livre de Helmholtz $F$ em relação ao volume:

\section{Relembrando:}

$1^{a}$ Lei da termodinâmica: $\quad d E=T d S-p d V+\mu d N$

Energia livre de Helmholtz: $F=E-T S$

$\Rightarrow \quad d F=-p d V+\mu d N-S d T$

ou seja,

$$
p(N, V, T)=-\frac{\partial F}{\partial V}
$$

Na física estatística, $F(N, V, T)$ está relacionada com a função de partição $Z$ do 
sistema:

$$
F=-\ln (Z) / \beta
$$

a qual podemos usar para aproximar a derivada parcial em (A.1):

$$
\begin{aligned}
p(N, V, T) & \approx-\frac{F(N, V+\delta V, T)-F(N, V, T)}{\delta V} \\
& =\frac{\frac{1}{\beta} \cdot \ln Z(N, V+\delta V, T)-\frac{1}{\beta} \cdot \ln Z(N, V, T)}{\delta V}=\frac{1}{\beta \delta V} \cdot \ln \frac{Z(N, V+\delta V, T)}{Z(N, V, T)}
\end{aligned}
$$

ou ainda,

$$
e^{p \beta \delta V}=\frac{Z(N, V+\delta V, T)}{Z(N, V, T)}
$$

válida para $\delta V \ll V$.

Considere que o volume do sistema está discretizado numa rede onde cada sítio pode ser ocupado por, no máximo, uma única partícula. A seguir, estaremos interessados na probabilidade $p_{0}$ de um dos segmentos da borda dessa rede (figura abaixo) estar vazio:
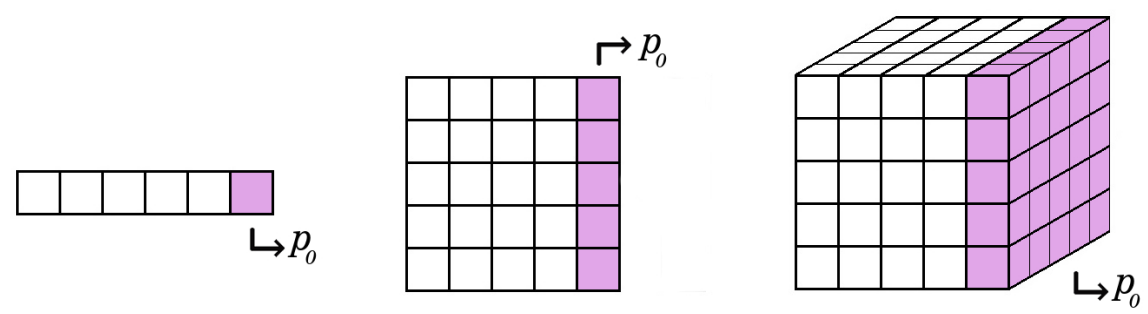

Figura A.1: Redes em 1, 2 e 3 dimensões. Em lilás segmentos da borda onde calcularemos $p_{0}$.

\section{A.1.1 redes sem contorno periódico}

Considere que no segmento da borda escolhido não se aplique condição periódica de contorno. Digamos que esse segmento contenha L sítios e o restante da rede V sítios, logo um "volume"total de V+L. Nesse ensemble, então, calcularemos a seguinte 
probabilidade:

$$
p_{0}(N, V+L, T)
$$

notação: representaremos por $\nu_{0}(\mathrm{~N}, \mathrm{~V})$ uma configuração genérica de uma rede $(\mathrm{N}, \mathrm{V})$ cujo último segmento está vazio. A probabilidade de uma dada configuração será indicada por $p_{\nu}$.

Assim, por definição,

$$
p_{0}(N, V+L, T)=\sum_{\nu_{0}(N, V+L)} p_{\nu_{0}(N, V+L)}=\sum_{\nu_{0}(N, V+L)} \frac{e^{-\beta E_{\nu_{0}(N, V+L)}}}{Z(N, V+L, T)}
$$

Ora, mas se o último segmento está sempre vazio, podemos, sem perda de generalidade, substituir a soma sobre $\nu_{0}(N, V+L)$ por uma em $\nu(N, V)$, já que só há variação das $N$ partículas entre os $V$ sítios restantes:

$$
\sum_{\nu_{0}(N, V+L)}=\sum_{\nu(N, V)}
$$

além disso, como o segmento vazio não interage com o restante da rede,

$$
E_{\nu_{0}(N, V+L)}=E_{\nu(N, V)}
$$

ou seja,

$$
p_{0}=\sum_{\nu(N, V)} \frac{e^{-\beta E_{\nu(N, V)}}}{Z(N, V+L, T)}=\frac{Z(N, V, T)}{Z(N, V+L, T)}
$$

e, usando (A.3) com $\delta V=L$, chegamos em:

$$
p_{0}=e^{-p \beta L}
$$


Se isolarmos a pressão, ficamos com:

$$
p(N, V, T)=-\frac{\ln \left(p_{0}\right)}{\beta L},
$$

onde $p_{0}$, assim como fora definido, deve ser calculado no ensemble $(N, V+L, T)$. Logo, para obtermos a pressão na rede basta adicionar um segmento a mais numa borda sem contorno periódico e medir a probabilidade do mesmo estar vazio. Tal probabilidade pode ser obtida por simples verificação em cada passo de uma simulação de Monte Carlo. Note que as bordas onde não estamos avaliando $p_{0}$ podem ser ou não periódicas, a equação (A.10) continua valendo em ambos os casos.

\section{Simulações:}

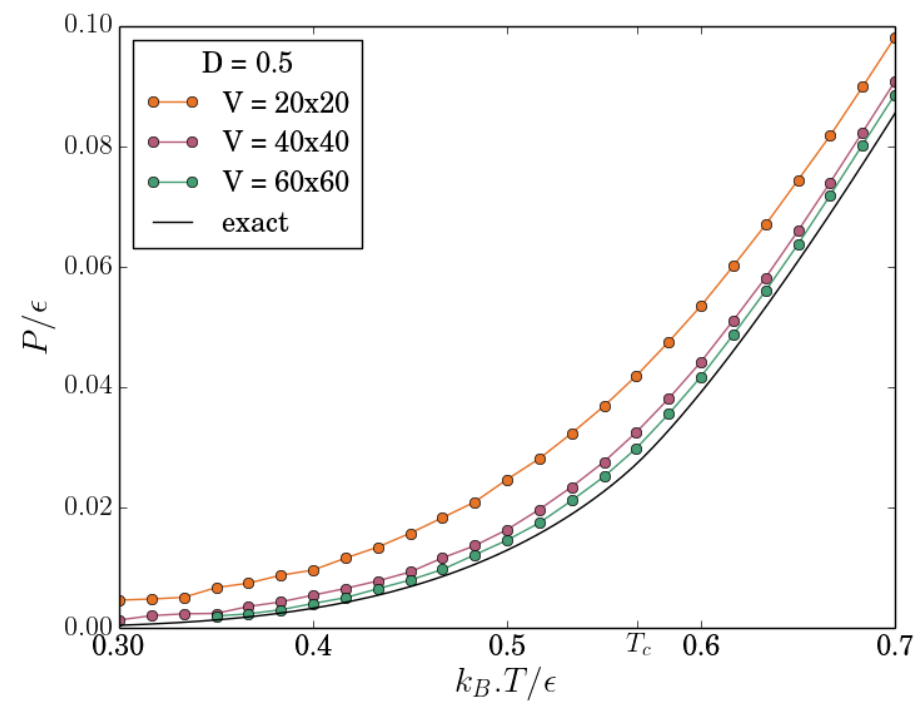

Figura A.2: Pressão em função da temperatura para diferentes tamanhos de rede e densidade $D=0.5$. A curva em preto é a solução exata devida a Onsager. 


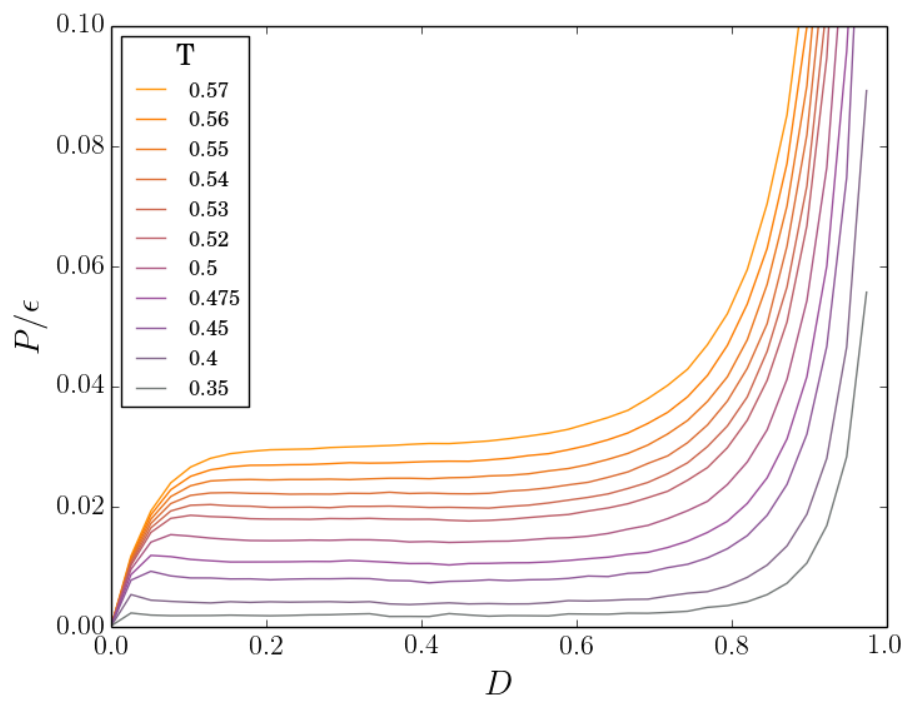

Figura A.3: Pressão em função da densidade para várias temperaturas.

\section{A.1.2 redes com contorno periódico}

Só pudemos usar a equação (A.3) no caso anterior pois as funções de partição na razão da equação (A.8) eram calculadas sem o contorno periódico, ou seja, tinham o mesmo perfil de interações. Caso tivéssemos começado com uma rede periódica, o numerador estaria sem contorno enquanto que o denominador estaria com contorno, impossibilitando a operação. Logo, algumas modificações precisam ser introduzidas para deduzirmos uma fórmula análoga em redes com contorno periódico no segmento escolhido.

notação: Usaremos um asterisco* para indicar algumas grandezas calculadas com condição de contorno periódico. Por exemplo,

$$
p_{0}^{*}(N, V+L, T)
$$


Assim como antes, tinhamos:

$$
p_{0}^{*}=\sum_{\nu_{0}(N, V+L)} \frac{e^{-\beta E_{\nu_{0}(N, V+L)}^{*}}}{Z^{*}(N, V+L, T)}
$$

A diferença aqui é que a energia de uma configuração $\nu_{0}(N, V+L)$ não pode ser prontamente igualada com a da configuração correspondente $\nu(N, V)$ se a rede é periódica:

$$
E_{\nu_{0}(N, V+L)}^{*} \neq E_{\nu(N, V)}^{*}
$$

Porém, pode-se relacionar essas duas energias se descontarmos a interação de contorno $\delta E$, ou seja, entre o segmento e a borda oposta:

$$
E_{\nu_{0}(N, V+L)}^{*}=E_{\nu(N, V)}^{*}-\delta E
$$

Sendo assim, teremos:

$$
p_{0}^{*}=\sum_{\nu(N, V)} \frac{e^{-\beta\left(E_{\nu(N, V)}^{*}-\delta E\right)}}{Z^{*}(N, V+L, T)}
$$

Se multiplicarmos e dividirmos a equação acima pela função de partição $Z^{*}(N, V, T)$, chegamos em

$$
=\frac{Z^{*}(N, V, T)}{Z^{*}(N, V+L, T)} \sum_{\nu(N, V)} \frac{e^{-\beta E_{\nu(N, V)}^{*} e^{\beta \delta E}}}{Z^{*}(N, V, T)}=e^{-p \beta L} \sum_{\nu(N, V)} p_{\nu}^{*} e^{\beta \delta E}
$$

onde a última soma representa a média da função $e^{\beta \delta E}$ no ensemble $(N, V, T)$, isto é:

$$
p_{0}^{*}=e^{-p \beta L}\left\langle e^{\beta \delta E}\right\rangle_{N, V, T}
$$

ou, isolando a pressão, 


$$
p(N, V, T)=\frac{1}{\beta L} \ln \left(\frac{\left\langle e^{\beta \delta E}\right\rangle}{p_{0}^{*}}\right)
$$

sendo $p_{0}^{*}$ calculada no ensemble $(N, V+L, T)$, como havíamos definido no início. Note inclusive que, como a rede possui contorno periódico, calcular a probabilidade do segmento da borda estar vazio é equivalente a calcular essa probabilidade para qualquer segmento, estando ele na borda ou não. O mesmo vale para a média das interações de contorno $\left\langle e^{\beta \delta E}\right\rangle$, onde $\delta E$ pode ser tomado como a energia de interação entre dois segmentos adjacentes quaisquer da rede.

\section{Simulações:}

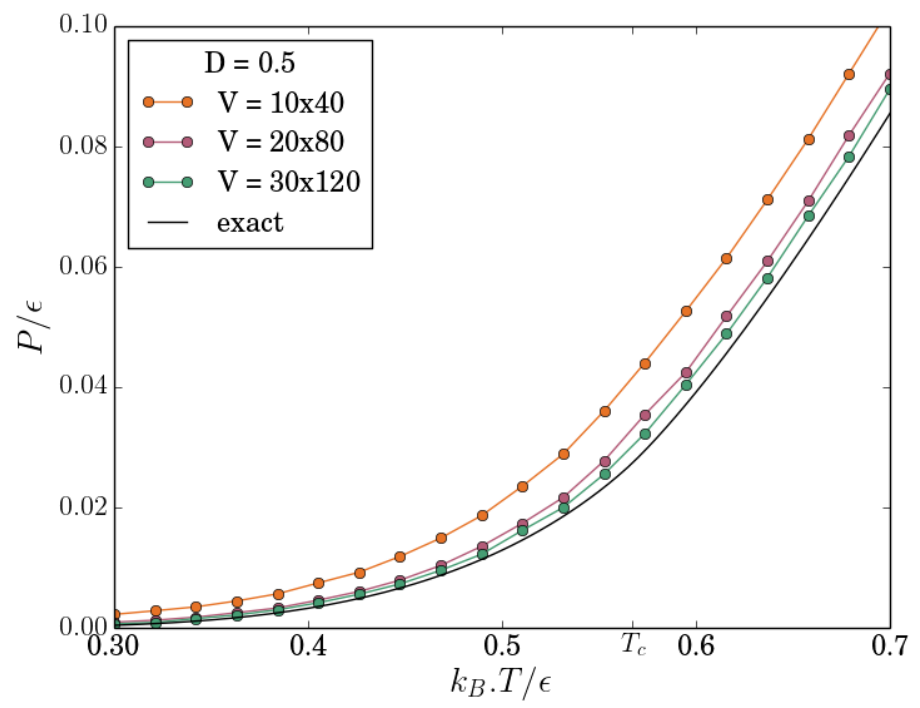

Figura A.4: Pressão em função da temperatura para vários tamanhos de rede. 


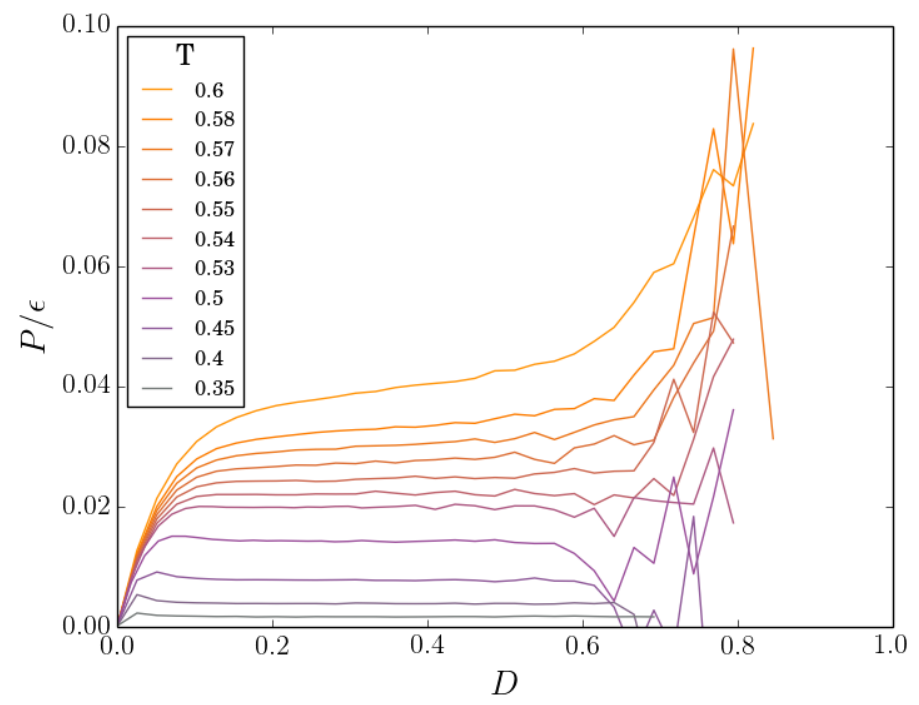

Figura A.5: Pressão em função da densidade para várias temperaturas.

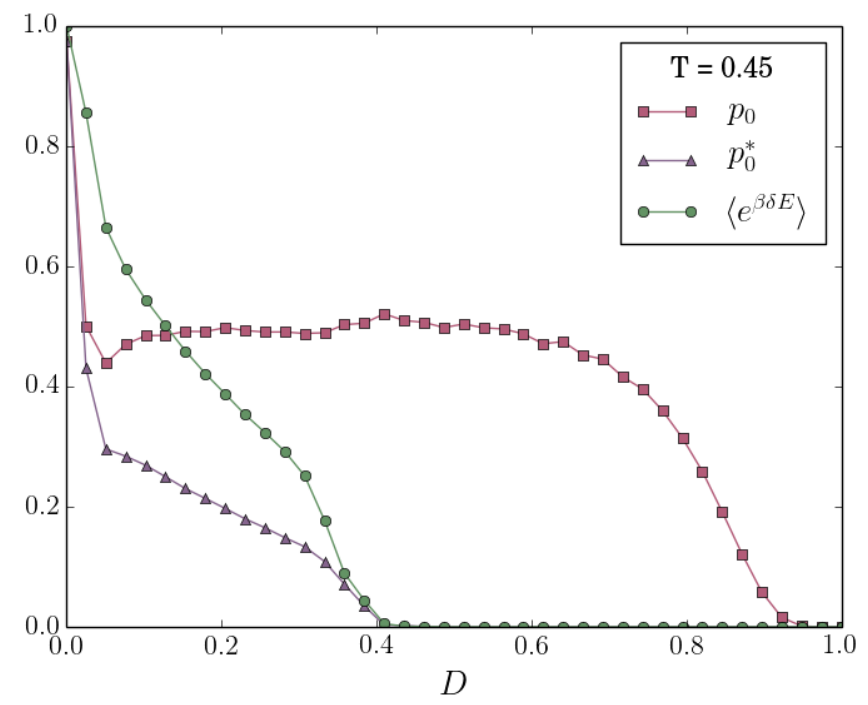

Figura A.6: Gráfico de algumas grandezas envolvidas no cálculo das pressões com e sem contorno periódico. 


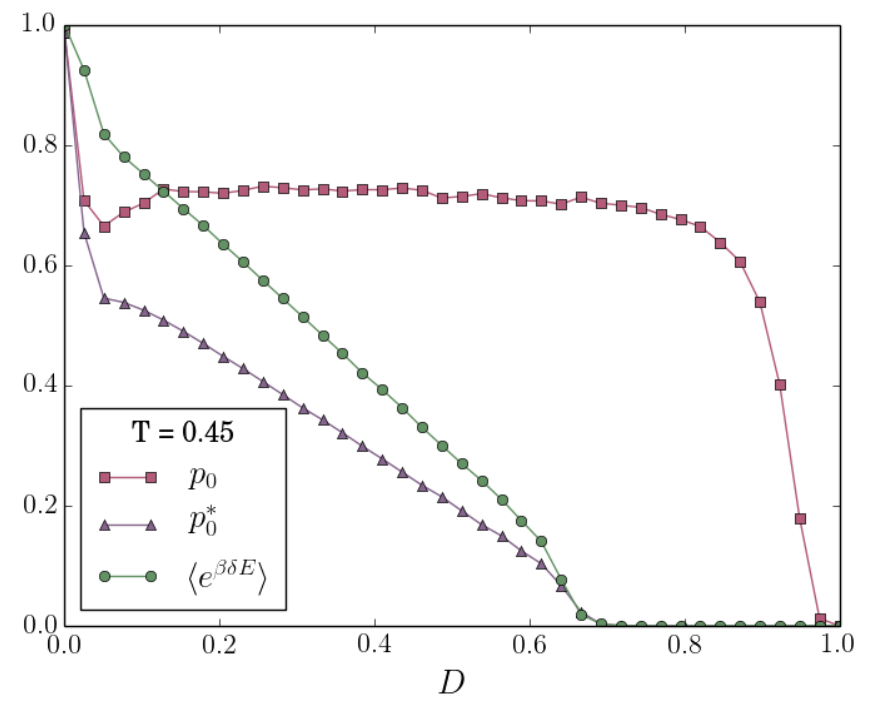

Figura A.7: Gráfico de algumas grandezas envolvidas no cálculo das pressões com e sem contorno periódico.

\section{A.2 Método II: Cálculo com segmentos ocupados}

De forma análoga ao método de buscar segmentos vazios, estaremos agora interessados na probabilidade $p_{L}$ de encontrar um dos segmentos da borda da rede (figura abaixo) inteiramente ocupado:
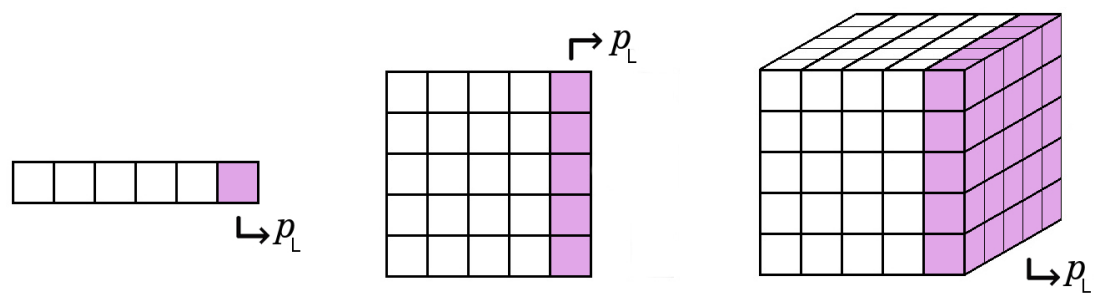

Figura A.8: Redes em 1, 2 e 3 dimensões. Em lilás segmentos da borda onde calcularemos $p_{L}$. 


\section{A.2.1 redes sem contorno periódico}

Considere que no segmento da borda escolhido não se aplique condição periódica de contorno. Digamos que esse segmento contenha L sítios e o restante da rede V sítios, logo um volume total de V+L. Nesse ensemble, então, calcularemos a seguinte probabilidade:

$$
p_{L}(N, V+L, T)
$$

notação: representaremos por $\nu_{L}(\mathrm{~N}, \mathrm{~V})$ uma configuração genérica de uma rede $(\mathrm{N}, \mathrm{V})$ cujo último segmento está cheio. A probabilidade de uma dada configuração $\nu$ será indicada por $p_{\nu}$.

Assim, por definição:

$$
p_{L}(N, V+L, T)=\sum_{\nu_{L}(N, V+L)} p_{\nu_{L}(N, V+L)}=\sum_{\nu_{L}(N, V+L)} \frac{e^{-\beta E_{\nu_{L}(N, V+L)}}}{Z(N, V+L, T)}
$$

Ora, mas se o último segmento está sempre ocupado, podemos, sem perda de generalidade, substituir a soma sobre $\nu_{L}(N, V+L)$ por uma em $\nu(N-L, V)$, já que só há variação de $N-L$ partículas entre os $V$ sítios restantes:

$$
\sum_{\nu_{L}(N, V+L)}=\sum_{\nu(N-L, V)}
$$

A energia de uma configuração pode ser dividida em três termos: a energia entre as partículas contidas no segmento cheio $(-\epsilon L$, considerando as interações de primeiros vizinhos), a das partículas contidas no volume $\mathrm{V}\left(E_{\nu(N-L, V)}\right)$ e mais uma interação de interface entre o segmento e o restante da rede $\left(E_{i}\right)$ :

$$
E_{\nu_{L}(N, V+L)}=-\epsilon L+E_{\nu(N-L, V)}+E_{i}
$$

No caso do gás de rede, como o segmento em questão está sempre ocupado, a energia 


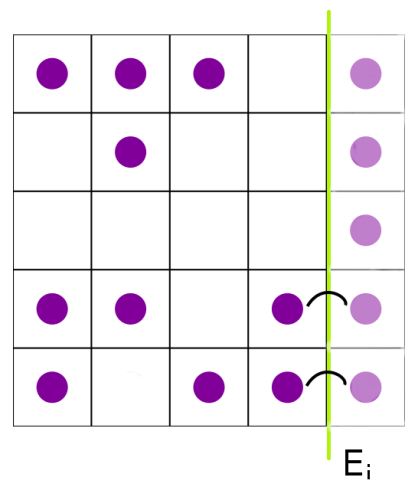

Figura A.9: $E_{i}$ é a energia na interface entre os dois segmentos vizinhos da borda.

de interface será simplesmente $E_{i}=-\epsilon n$, onde $n$ é o número de partículas no segmento vizinho. Juntando (A.21), (A.22) e (A.23), teremos:

$$
p_{L}=e^{\beta \epsilon L} \sum_{\nu(N-L, V)} \frac{e^{-\beta E_{\nu(N-L, V)}} e^{-\beta E_{i}}}{Z(N, V+L, T)}
$$

Por fim, se multiplicarmos e dividirmos a equação anterior por $Z(N-L, V, T)$ e $Z(N, V, T)$, ficamos com:

$$
p_{L}=e^{\beta \epsilon L} \frac{Z(N-L, V, T)}{Z(N, V, T)} \frac{Z(N, V, T)}{Z(N, V+L, T)} \sum_{\nu(N-L, V)} \frac{e^{-\beta E_{\nu(N-L, V)} e^{-\beta E_{i}}}}{Z(N-L, V, T)}
$$

substituindo as razões das funções de partição,

$$
p_{L}=e^{\beta \epsilon L} e^{\beta \mu L} e^{-\beta p L} \sum_{\nu(N-L, V)} p_{\nu} e^{-\beta E_{i}}=\frac{e^{\beta(\epsilon+\mu) L}}{e^{\beta p L}}\left\langle e^{-\beta E_{i}}\right\rangle
$$

ou, isolando a pressão:

$$
\left.p(N, V, T)=\mu+\epsilon+\frac{1}{\beta L} \ln \left(\frac{\left\langle e^{-\beta E_{i}}\right\rangle}{p_{L}}\right\rangle\right)
$$

onde as grandezas envolvidas são calculadas nos seguintes ensembles: $p_{L} \rightarrow(N, V+L, T)$, 
$\mu \rightarrow(N, V, T)$ e $\left\langle e^{-\beta E_{i}}\right\rangle \rightarrow(N-L, V, T)$. Portanto, é necessário realizar três simulações diferentes, uma para cada grandeza citada, e juntar os dados no final. No último caso, $E_{i}$ é calculado como se a borda da rede $(N-L, V, T)$ estivesse interagindo com um segmento cheio vizinho, embora ele não esteja lá de fato (ver figura A.9).

\section{A.2.2 redes com contorno periódico}

Como no caso do método com segmentos vazios, há uma diferença nos termos da energia de uma configuração quando levamos em conta o contorno periódico da rede.

notação: Usaremos outra vez asterisco* para indicar algumas grandezas calculadas com condição de contorno periódica.)

Por exemplo, como na equação (A.22), teremos:

$$
E_{\nu_{L}(N, V+L)}^{*}=-\epsilon L+E_{\nu(N-L, V)}+E_{i}^{*}
$$

Mas, repare que $E_{\nu(N-L, V)}$ não é a energia de uma configuração de $(N-L, V)$ com contorno, pois há o segmento cheio entre as bordas. Se quisermos recuperar o contorno da rede $(N-L, V)$ temos que adicionar um termo $E_{c}$ responsável pela "costura"das bordas separadas pelo segmento cheio. Temos também que $E_{i}^{*}$ agora leva em conta a interação dos dois lados do segmento cheio (figura abaixo). Dessa forma, a equação
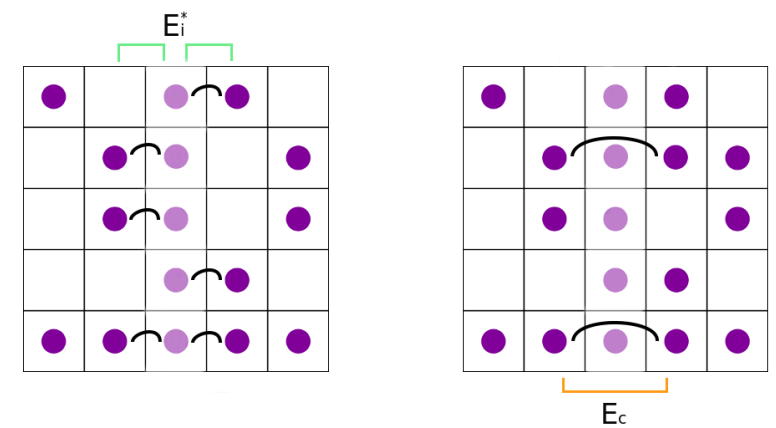

Figura A.10: $E_{i}^{*}$ é a energia na interface do segmento cheio e $E_{c}$ é a interação de "costura"entre seus vizinhos. 
anterior fica:

$$
E_{\nu_{L}(N, V+L)}^{*}=-\epsilon L+E_{\nu(N-L, V)}^{*}-E_{c}+E_{i}^{*}
$$

e o resto da dedução é análogo ao caso anterior, de onde resulta a fórmula corrigida

$$
p(N, V, T)=\mu+\epsilon+\frac{1}{\beta L} \ln \left(\frac{\left\langle e^{-\beta\left(E_{i}^{*}-E_{c}\right)}\right\rangle}{p_{L}}\right)
$$




\section{A.3 Soluções analíticas em uma dimensão}

Vimos então que podemos relacionar a pressão de uma rede sem contorno periódico com a probabilidade da fronteira estar vazia ou totalmente ocupada. Ora, mas obviamente há muitas outras configurações possíveis na borda além destas, de forma que poderíamos nos perguntar se existiria uma relação entre a pressão e a probabilidade de algum outro estado particular na fronteira. É claro que, para redes com dimensão maior ou igual a 2, o número de tais configurações é muito grande e seria exaustivo analisar todas elas em separado. Mas, no caso de redes unidimensionais, onde a borda se reduz a um único sítio, podemos facilmente enumerar todos os seus possíveis estados e, como veremos, derivar soluções exatas.

\section{A.3.1 Gás de Rede 1D}

Sistema: V sítios, $\mathrm{N}$ partículas, temperatura $\mathrm{T}$ e interação de primeiros vizinhos $-\epsilon$.

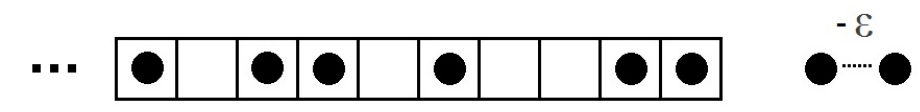

Figura A.11: "Fluido"unidimensional.

Solução: Considere uma das bordas do sistema (sem condição periódica de contorno!). Claramente, o último sítio só pode estar ou vazio ou ocupado. Logo, se chamarmos de $p_{0}$ e $p_{1}$ as probabilidades canônicas - N,V,T constantes - desse sítio estar, respectivamente, sem e com partículas, então:

$$
p_{0}+p_{1}=1
$$




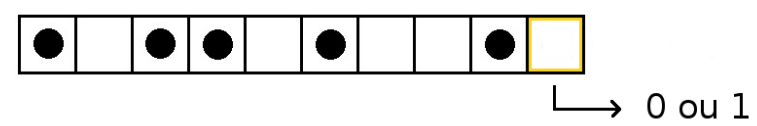

Figura A.12: A borda pode estar vazia ou ocupada.

Já obtemos uma expressão para $p_{0}$ em termos da pressão em (A.9), agora vamos ver se podemos fazer o mesmo para $p_{1}$ como no caso anterior:

$$
p_{1}(N, V, T)=\sum_{\nu_{1}(N, V)} p_{\nu_{1}(N, V)}=\sum_{\nu_{1}(N, V)} \frac{e^{-\beta E_{\nu_{1}(N, V)}}}{Z(N, V, T)}
$$

Nesse caso, temos uma partícula fixa no último sítio. Consequentemente, só há variação das outras $N-1$ partículas entre os $V-1$ sítios restantes, ou seja, a soma sobre $\nu_{1}(N, V)$ pode ser trocada por uma sobre $\nu(N-1, V-1)$ :

$$
\sum_{\nu_{1}(N, V)}=\sum_{\nu(N-1, V-1)}
$$

Em relação à energia da configuração $\nu_{1}(N, V)$ temos apenas duas possibilidades: ou o penúltimo sítio está ocupado, e portanto interagindo com a última partícula que está fixa, ou está vazio e não há interação. Ou seja,

$$
E_{\nu_{1}(N, V)}=E_{\nu(N-1, V-1)}+\delta E
$$

onde,

$$
\delta E=\left\{\begin{array}{rr}
0 & \text { para } \nu_{0}(N-1, V-1) \\
-\epsilon & \text { para } \nu_{1}(N-1, V-1)
\end{array}\right.
$$


Juntando (A.33) e (A.32) em (A.31), fica então:

$$
p_{1}=\sum_{\nu(N-1, V-1)} \frac{e^{-\beta\left(E_{\nu(N-1, V-1)}+\delta E\right)}}{Z(N, V, T)}=\frac{1}{Z(N, V, T)} \sum_{\nu(N-1, V-1)} e^{-\beta \delta E} e^{-\beta E_{\nu(N-1, V-1)}}
$$

Se multiplicarmos e dividirmos por $Z(N-1, V-1, T)$ e usarmos (A.3) com $\delta V=-1$ e a expressão análoga para o potencial químico com $\delta N=-1$, teremos:

$$
\begin{aligned}
& =\frac{Z(N-1, V-1, T)}{Z(N, V, T)} \sum_{\nu(N-1, V-1)} e^{-\beta \delta E} \frac{e^{-\beta E_{\nu(N-1, V-1)}}}{Z(N-1, V-1, T)} \\
& =\frac{e^{\beta \mu}}{e^{\beta p}} \sum_{\nu(N-1, V-1)} e^{-\beta \delta E} p_{\nu(N-1, V-1)}
\end{aligned}
$$

Por fim, a soma sobre $\nu(N-1, V-1)$ pode ser quebrada em duas, conforme o último sítio da rede $(N-1, V-1)$ estiver vazio ou ocupado:

$$
\sum_{\nu(N-1, V-1)}=\sum_{\nu_{0}(N-1, V-1)}+\sum_{\nu_{1}(N-1, V-1)}
$$

$\log 0$

$$
p_{1}=\frac{e^{\beta \mu}}{e^{\beta p}}\left(\sum_{\nu_{0}(N-1, V-1)} e^{0} p_{\nu_{0}}+\sum_{\nu_{1}(N-1, V-1)} e^{\beta \epsilon} p_{\nu_{1}}\right)=\frac{e^{\beta \mu}}{e^{\beta p}}\left(p_{0}+e^{\beta \epsilon} p_{1}\right)
$$

ou, arrumando os termos,

$$
p_{0}+\left(e^{\beta \epsilon}-e^{\beta(p-\mu)}\right) p_{1}=0
$$

Mas, repare agora que as equações (A.30) e (A.39) nos fornecem um sistema linear com duas incógnitas: $p_{0}$ e $p_{1}$, o qual pode ser facilmente resolvido: 


$$
(A .30) e(A .39) \Longrightarrow\left\{\begin{array}{c}
p_{0}+p_{1}=1 \\
\\
p_{0}+a p_{1}=0
\end{array}\right.
$$

onde chamamos $a=e^{\beta \epsilon}-e^{\beta(p-\mu)}$.

Pela regra de Cramer:

$$
p_{0}=\frac{\operatorname{det}\left(\begin{array}{ll}
1 & 1 \\
0 & a
\end{array}\right)}{\operatorname{det}\left(\begin{array}{ll}
1 & 1 \\
1 & a
\end{array}\right)}=\frac{a}{a-1}
$$

Ora, a equação A.9 nos permite relacionar diretamente $p_{0}$ com a pressão. Logo,

$$
\frac{1}{e^{\beta p}}=\frac{e^{\beta \epsilon}-e^{\beta(p-\mu)}}{e^{\beta \epsilon}-e^{\beta(p-\mu)}-1}
$$

a qual, por si só, já é uma equação de estado do sistema! Vamos ver se, a partir daí, conseguimos isolar a pressão. Para simplificar a notação, chamaremos a variável $x=e^{\beta p}$. Sendo assim, (A.42) fica:

$$
\begin{gathered}
\frac{1}{x}=\frac{e^{\beta \epsilon}-x e^{-\beta \mu}}{e^{\beta \epsilon}-x e^{-\beta \mu}-1} \\
\Longleftrightarrow x^{2}-\left(1+e^{\beta(\epsilon+\mu)}\right) x+e^{\beta \mu}\left(e^{\beta \epsilon}-1\right)=0
\end{gathered}
$$

que é uma equação do $2^{\circ}$ grau, cuja raiz positiva nos dá:

$$
x=e^{\beta p}=\frac{1+e^{\beta(\epsilon+\mu)}}{2}+\sqrt{\left(\frac{1+e^{\beta(\epsilon+\mu)}}{2}\right)^{2}-e^{\beta \mu}\left(e^{\beta \epsilon}-1\right)}
$$


ou, finalmente

$$
p(\mu, \beta)=\frac{1}{\beta} \cdot \ln \left(\frac{e^{\beta(\mu+\epsilon)}+1}{2}+\sqrt{\left(\frac{e^{\beta(\mu+\epsilon)}+1}{2}\right)^{2}+e^{\beta \mu}\left(1-e^{\beta \epsilon}\right)}\right)
$$

a qual corresponde à solução exata calculada através de outros métodos, como o da matriz de transferência.

\section{A.3.2 Mistura Binária 1D}

Sistema: V sítios, $\mathrm{N}_{a}$ partículas do tipo $\mathrm{A}, \mathrm{N}_{b}$ partículas do tipo $\mathrm{B}$, temperatura $\mathrm{T}$ e interações de primeiros vizinhos: $-\epsilon_{a a},-\epsilon_{a b}$ e $-\epsilon_{b b}$.

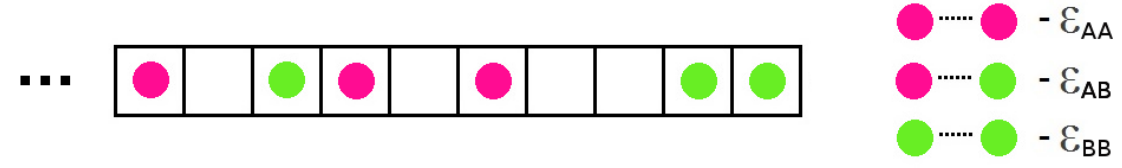

Figura A.13: Mistura binária unidimensional

\section{Conceitos envolvidos:}

$1^{a}$ Lei da termodinâmica: $\quad d E=T d S-p d V+\mu_{a} d N_{a}+\mu_{b} d N_{b}$

Energia livre de Helmholtz: $F=E-T S$

$\Rightarrow d F=-p d V+\mu_{a} d N_{a}+\mu_{b} d N_{b}-S d T$

$$
\Longrightarrow\left\{\begin{array}{l}
p\left(\mathrm{~N}_{a}, \mathrm{~N}_{b}, \mathrm{~V}, \mathrm{~T}\right)=-\frac{\partial F}{\partial V} \\
\mu_{a}\left(\mathrm{~N}_{a}, \mathrm{~N}_{b}, \mathrm{~V}, \mathrm{~T}\right)=\frac{\partial F}{\partial N_{a}} \quad, \quad \mu_{b}\left(\mathrm{~N}_{a}, \mathrm{~N}_{b}, \mathrm{~V}, \mathrm{~T}\right)=\frac{\partial F}{\partial N_{b}}
\end{array}\right.
$$

de onde obtemos, assim como antes:

$$
e^{p \beta \delta V}=\frac{Z\left(N_{a}, N_{b}, V+\delta V, T\right)}{Z\left(N_{a}, N_{b}, V, T\right)}
$$


e, analogamente,

$$
e^{-\mu_{a} \beta \delta N_{a}}=\frac{Z\left(N_{a}+\delta N_{a}, N_{b}, V, T\right)}{Z\left(N_{a}, N_{b}, V, T\right)} \quad, \quad e^{-\mu_{b} \beta \delta N_{b}}=\frac{Z\left(N_{a}, N_{b}+\delta N_{b}, V, T\right)}{Z\left(N_{a}, N_{b}, V, T\right)}
$$

válidas para $\delta V \ll V, \delta N_{a} \ll N_{a}$ e $\delta N_{b} \ll N_{b}$.

Solução: Considere uma das bordas do sistema (sem condição periódica de contorno!). Claramente, o último sítio só pode estar ou vazio ou ocupado por A ou ocupado por B. Logo, se chamarmos de $p_{0}, p_{a}$ e $p_{b}$ as probabilidades canônicas - $\mathrm{N}_{a}, \mathrm{~N}_{b}, \mathrm{~V}, \mathrm{~T}$ constantes - desse sítio estar, respectivamente, sem partículas ou com partículas A ou B, então:

$$
p_{0}+p_{a}+p_{b}=1
$$

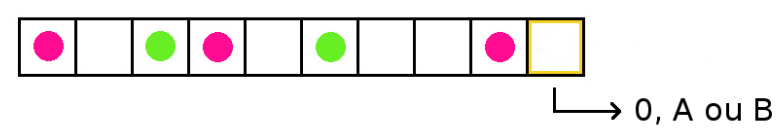

Figura A.14: A borda pode estar vazia ou ocupada por A ou B

Podemos tentar agora desenvolver expressões pra essas três probabilidades.

notação: representaremos por $\nu_{0}\left(\mathrm{~N}_{a}, \mathrm{~N}_{b}, \mathrm{~V}\right)$ uma configuração genérica de uma rede $\left(\mathrm{N}_{a}, \mathrm{~N}_{b}, \mathrm{~V}\right)$ cujo último sítio está vazio. Idem para $\nu_{a}\left(\mathrm{~N}_{a}, \mathrm{~N}_{b}, \mathrm{~V}\right)$ quando ele estiver ocupado por A e $\nu_{b}\left(\mathrm{~N}_{a}, \mathrm{~N}_{b}, \mathrm{~V}\right)$ quando ele estiver ocupado por B.

Já temos a relação (A.9) para $p_{0}$, agora vamos ver se podemos relacionar $p_{a}$ com a pressão:

$$
p_{a}\left(N_{a}, N_{b}, V, T\right)=\sum_{\nu_{a}\left(N_{a}, N_{b}, V\right)} p_{\nu_{a}\left(N_{a}, N_{b}, V\right)}=\sum_{\nu_{a}\left(N_{a}, N_{b}, V\right)} \frac{e^{-\beta E_{\nu_{a}\left(N_{a}, N_{b}, V\right)}}}{Z\left(N_{a}, N_{b}, V, T\right)}
$$


Nesse caso, temos uma partícula A fixa no último sítio. Consequentemente, só há variação das outras $N_{a}+N_{b}-1$ partículas entre os $V-1$ sítios restantes, ou seja, a soma sobre $\nu_{a}\left(N_{a}, N_{b}, V\right)$ pode ser trocada por uma sobre $\nu\left(N_{a}-1, N_{b}, V-1\right)$ :

$$
\sum_{\nu_{a}\left(N_{a}, N_{b}, V\right)}=\sum_{\nu\left(N_{a}-1, N_{b}, V-1\right)}
$$

Em relação à energia da configuração $\nu_{a}\left(N_{a}, N_{b}, V\right)$ temos apenas três possibilidades: ou o penúltimo sítio está ocupado por A, e portanto interagindo com a última partícula A que está fixa com energia $\epsilon_{a a}$, ou está ocupado por B, e portanto interagindo com a última partícula A com energia $\epsilon_{a b}$, ou está vazio e não há interação. Ou seja,

$$
E_{\nu_{a}\left(N_{a}, N_{b}, V\right)}=E_{\nu\left(N_{a}-1, N_{b}, V-1\right)}+\delta E
$$

onde,

$$
\delta E=\left\{\begin{array}{cc}
0 & \text { para } \nu_{0}\left(N_{a}-1, N_{b}, V-1\right) \\
-\epsilon_{a a} & \text { para } \nu_{a}\left(N_{a}-1, N_{b}, V-1\right) \\
-\epsilon_{a b} & \text { para } \nu_{b}\left(N_{a}-1, N_{b}, V-1\right)
\end{array}\right.
$$

Juntando (A.54) e (A.53) em (A.52), teremos então:

$$
\begin{aligned}
p_{a} & =\sum_{\nu\left(N_{a}-1, N_{b}, V-1\right)} \frac{e^{-\beta\left(E_{\nu\left(N_{a}-1, N_{b}, V-1\right)}+\delta E\right)}}{Z\left(N_{a}, N_{b}, V, T\right)} \\
& =\frac{1}{Z\left(N_{a}, N_{b}, V, T\right)} \sum_{\nu\left(N_{a}-1, N_{b}, V-1\right)} e^{-\beta \delta E} e^{-\beta E_{\nu\left(N_{a}-1, N_{b}, V-1\right)}}
\end{aligned}
$$

Se multiplicarmos e dividirmos por $Z\left(N_{a}-1, N_{b}, V-1, T\right)$ e usarmos (49) e (50) com $\delta V=-1$ e $\delta N_{a}=-1$, teremos: 


$$
\begin{aligned}
& =\frac{Z\left(N_{a}-1, N_{b}, V-1, T\right)}{Z\left(N_{a}, N_{b}, V, T\right)} \sum_{\nu\left(N_{a}-1, N_{b}, V-1\right)} e^{-\beta \delta E} \frac{e^{-\beta E_{\nu\left(N_{a}-1, N_{b}, V-1\right)}}}{Z\left(N_{a}-1, N_{b}, V-1, T\right)} \\
& =\frac{e^{\beta \mu_{a}}}{e^{\beta p}} \sum_{\nu\left(N_{a}-1, N_{b}, V-1\right)} e^{-\beta \delta E} p_{\nu\left(N_{a}-1, N_{b}, V-1\right)}
\end{aligned}
$$

Por fim, a soma sobre $\nu\left(N_{a}-1, N_{b}, V-1\right)$ pode ser quebrada em três, conforme o último sítio da rede $\left(N_{a}-1, N_{b}, V-1\right)$ estiver vazio ou ocupado por A ou B:

$$
\sum_{\nu\left(N_{a}-1, N_{b}, V-1\right)}=\sum_{\nu_{0}\left(N_{a}-1, N_{b}, V-1\right)}+\sum_{\nu_{a}\left(N_{a}-1, N_{b}, V-1\right)}+\sum_{\nu_{b}\left(N_{a}-1, N_{b}, V-1\right)}
$$

$\log 0$

$$
\begin{aligned}
p_{a} & =\frac{e^{\beta \mu_{a}}}{e^{\beta p}}\left(\sum_{\nu_{0}\left(N_{a}-1, N_{b}, V-1\right)} e^{0} p_{\nu_{0}}+\sum_{\nu_{a}\left(N_{a}-1, N_{b}, V-1\right)} e^{\beta \epsilon_{a a}} p_{\nu_{a}}+\sum_{\nu_{b}\left(N_{a}-1, N_{b}, V-1\right)} e^{\beta \epsilon_{a b}} p_{\nu_{b}}\right) \\
& =\frac{e^{\beta \mu_{a}}}{e^{\beta p}}\left(p_{0}+e^{\beta \epsilon_{a a}} p_{a}+e^{\beta \epsilon_{a b}} p_{b}\right)
\end{aligned}
$$

ou, arrumando os termos,

$$
p_{0}+\left(e^{\beta \epsilon_{a a}}-e^{\beta\left(p-\mu_{a}\right)}\right) p_{a}+e^{\beta \epsilon_{a b}} p_{b}=0
$$

Analogamente, poderíamos ter começado a conta anterior a partir de $p_{b}$, donde obteríamos de forma simétrica a seguinte equação:

$$
p_{0}+e^{\beta \epsilon_{a b}} p_{a}+\left(e^{\beta \epsilon_{b b}}-e^{\beta\left(p-\mu_{b}\right)}\right) p_{b}=0
$$


Mas, repare agora que as equações (51), (63) e (64) nos fornecem um sistema linear com três incógnitas: $p_{0}, p_{a}$ e $p_{b}$, o qual pode ser facilmente resolvido:

$$
(51),(63) e(64) \Longrightarrow\left\{\begin{array}{l}
p_{0}+p_{a}+p_{b}=1 \\
p_{0}+r \cdot p_{a}+s \cdot p_{b}=0 \\
p_{0}+s \cdot p_{a}+t \cdot p_{b}=0
\end{array}\right.
$$

onde chamamos: $r=\left(e^{\beta \epsilon_{a a}}-e^{\beta\left(p-\mu_{a}\right)}\right), s=e^{\beta \epsilon_{a b}}$ e $t=\left(e^{\beta \epsilon_{b b}}-e^{\beta\left(p-\mu_{b}\right)}\right)$.

Pela regra de Cramer:

$$
p_{0}=\frac{\operatorname{det}\left(\begin{array}{lll}
1 & 1 & 1 \\
0 & r & s \\
0 & s & t
\end{array}\right)}{\operatorname{det}\left(\begin{array}{lll}
1 & 1 & 1 \\
1 & r & s \\
1 & s & t
\end{array}\right)}=\frac{r t-s^{2}}{2 s-r-t+r t-s^{2}}
$$

Ora, a equação (A.9) nos permite relacionar diretamente $p_{0}$ com a pressão. Logo,

$$
\frac{1}{e^{\beta p}}=\frac{\left(e^{\beta \epsilon_{a a}}-e^{\beta\left(p-\mu_{a}\right)}\right) \cdot\left(e^{\beta \epsilon_{b b}}-e^{\beta\left(p-\mu_{b}\right)}\right)-e^{2 \beta \epsilon_{a b}}}{2 e^{\beta \epsilon_{a b}}-e^{\beta \epsilon_{a a}}+e^{\beta\left(p-\mu_{a}\right)}-e^{\beta \epsilon_{b b}}+e^{\beta\left(p-\mu_{b}\right)}+\left(e^{\beta \epsilon_{a a}}-e^{\beta\left(p-\mu_{a}\right)}\right) \cdot\left(e^{\beta \epsilon_{b b}}-e^{\beta\left(p-\mu_{b}\right)}\right)-e^{2 \beta \epsilon_{a b}}}
$$

Podemos tentar isolar a pressão nesta última equação chamando a variável $x=e^{\beta p}$. Sendo assim, (A.66) fica:

$$
\begin{aligned}
\Longleftrightarrow x^{3} & -\left(1+e^{\beta\left(\epsilon_{a a}+\mu_{a}\right)}+e^{\beta\left(\epsilon_{b b}+\mu_{b}\right)}\right) x^{2} \\
& +\left(e^{\beta\left(\epsilon_{a a}+\mu_{a}+\epsilon_{b b}+\mu_{b}\right)}-e^{\beta\left(2 \epsilon_{a b}+\mu_{a}+\mu_{b}\right)}+e^{\beta\left(\epsilon_{a a}+\mu_{a}\right)}+e^{\beta\left(\epsilon_{b b}+\mu_{b}\right)}+e^{\beta \mu_{a}}+e^{\beta \mu_{b}}\right) x \\
& +e^{\beta\left(\mu_{a}+\mu_{b}\right)} \cdot\left(e^{\beta \epsilon_{a a}}+e^{\beta \epsilon_{b b}}+e^{2 \beta \epsilon_{a b}}-2 e^{\beta \epsilon_{a b}}-e^{\beta\left(\epsilon_{a a}+\epsilon_{b b}\right)}\right)=0
\end{aligned}
$$


que é uma equação cúbica, cuja solução analítica existe, embora seja simbolicamente extensa. As grandezas mais fáceis de isolar em (A.66) são na verdade os potenciais químicos $\mu_{a}$ ou $\mu_{b}$, bastando algumas operações algébricas para encontrarmos:

$\mu_{a}\left(\beta, \mu_{b}, p\right)=\frac{1}{\beta} \cdot \ln \left(\frac{e^{\beta p} \cdot\left[1+\left(e^{\beta p}-1\right) \cdot\left(e^{\beta \epsilon_{b b}}-e^{\beta\left(p-\mu_{b}\right)}\right)\right]}{\left(e^{\beta p}-1\right) \cdot\left[e^{\beta \epsilon_{a a}}\left(e^{\beta \epsilon_{b b}}-e^{\beta\left(p-\mu_{b}\right)}\right)-e^{2 \beta \epsilon_{a b}}\right]-2 e^{\epsilon_{a b}}-e^{\epsilon_{a a}}-e^{\epsilon_{b b}}+e^{\beta\left(p-\mu_{b}\right)}}\right)$
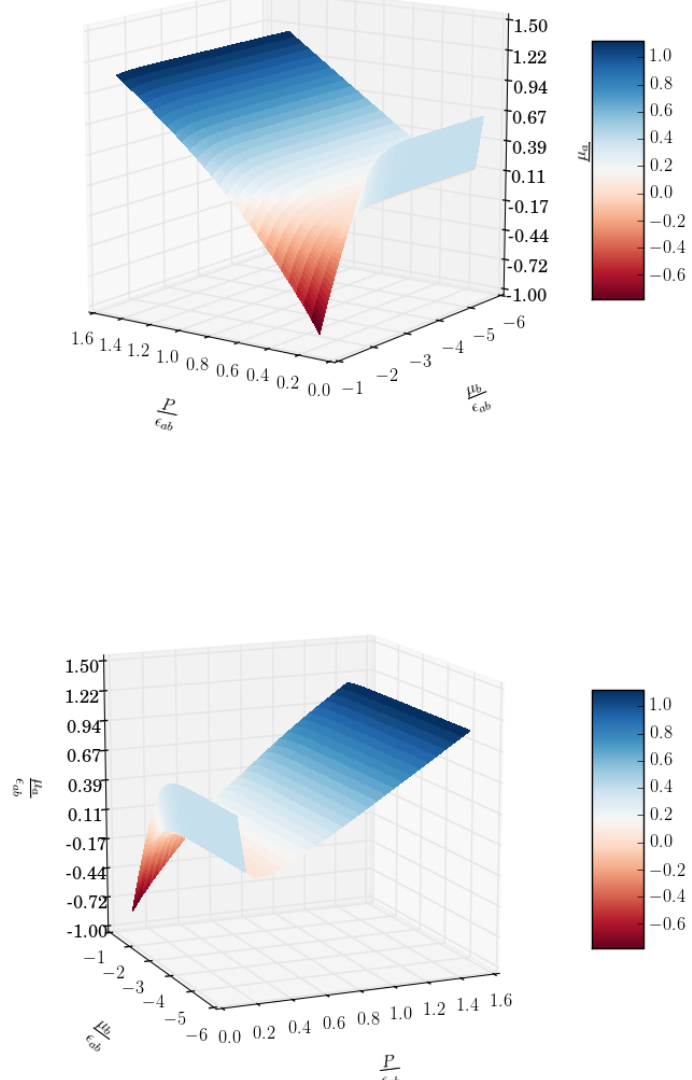

Figura A.15: $\frac{\mu_{a}}{\epsilon_{a b}}$ em função do potencial químico $\frac{\mu_{b}}{\epsilon_{a b}}$ e da pressão $\frac{p}{\epsilon_{a b}}$ à temperatura constante $\frac{k . T}{\epsilon_{a b}}=0.3$. Neste caso, fixamos as seguintes energias de interação: $\epsilon_{a a}=0.3$, $\epsilon_{b b}=0.5$ e $\epsilon_{a b}=1.0$. 


\section{A.3.3 Modelo de Bell-Lavis 1D}

O modelo de Bell-Lavis adaptado para uma dimensão (ver figura a seguir) se torna exatamente solúvel e pode ser resolvido de maneira completamente análoga ao exemplo anterior da mistura binária, sendo que ambos são modelos de 3 estados.

Sistema: V sítios, $\mathrm{N}$ partículas, temperatura $\mathrm{T}$ e interações de primeiros vizinhos do tipo van der Waals, $-\epsilon_{v}$, e com ligação de hidrogênio, $-\epsilon_{h}$, se a orientação for favorável. Se o braço na horizontal estiver apontando para a direita diremos que a partícula está na orientação 1, se apontar para a esquerda estará na orientação -1. Consideramos que ocorre uma "ligação de hidrogênio"quando dois braços estão apontando um na direção do outro. Caso contrário, duas partículas vizinhas estarão interagindo apenas por van der Waals.

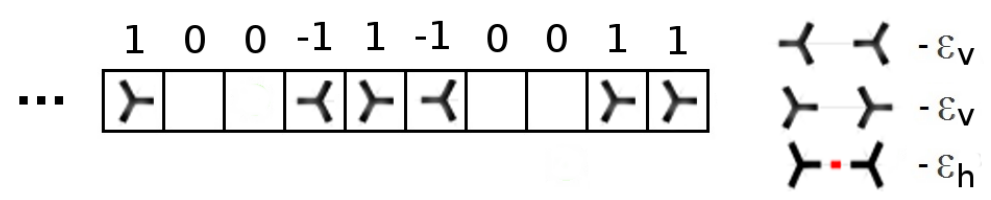

Figura A.16: Bell-Lavis unidimensional.

Solução: A ideia então será montar um sistema linear envolvendo as probabilidades do último sítio da rede (sem contorno periódico) estar vazio ou ocupado nos estados 1 ou -1. Pelo que vimos nas seções anteriores, já temos de saída duas equações:

1. $p_{0}=e^{-\beta p}$

2. $p_{0}+p_{1}+p_{-1}=1$

Falta agora desenvolver expressões para $p_{1}$ e $p_{-1}$. Em resumo, teremos:

3.

$$
p_{1}(N, V, T)=\sum_{\nu_{1}(N, V)} \frac{e^{-\beta E_{\nu_{1}(N, V)}}}{Z(N, V, T)}
$$


Neste caso, como temos uma partícula fixa no último sítio, podemos substituir a soma sobre $\nu_{1}(N, V)$ por uma sobre $\nu(N-1, V-1)$. E a energia de uma configuração fica sendo a soma da energia da rede $(N-1, V-1)$ e da interação $\delta E$ com a última partícula:

$$
p_{1}=\sum_{\nu(N-1, V-1)} \frac{e^{-\beta\left(E_{\nu(N-1, V-1)}+\delta E\right)}}{Z(N, V, T)}
$$

A somatória em $\nu(N-1, V-1)$ pode, então, ser dividida em somatórias sobre $\nu_{0}, \nu_{1} \mathrm{e}$ $\nu_{-1}$, as quais terão $\delta E$ igual a $0, \epsilon_{v}$ e $\epsilon_{v}$, respectivamente. Logo,

$$
p_{1}=\frac{\left(\sum_{\nu_{0}} 1 . e^{-\beta E_{\nu_{0}}}+\sum_{\nu_{1}} e^{\beta \epsilon_{v}} \cdot e^{-\beta E_{\nu_{1}}}+\sum_{\nu_{-1}} e^{\beta \epsilon_{v}} \cdot e^{-\beta E_{\nu_{-1}}}\right)}{Z(N, V, T)}
$$

Se multiplicarmos e dividirmos a equação acima por $Z(N-1, V-1, T)$, obteremos as probabilidades desejadas:

$$
p_{1}=\frac{Z(N-1, V-1, T)}{Z(N, V, T)} \cdot\left(p_{0}+e^{\beta \epsilon_{v}} \cdot p_{1}+e^{\beta \epsilon_{v}} \cdot p_{-1}\right)=\frac{e^{\beta \mu}}{e^{\beta p}} \cdot\left(p_{0}+e^{\beta \epsilon_{v}} \cdot p_{1}+e^{\beta \epsilon_{v}} \cdot p_{-1}\right)
$$

ou, rearranjando os termos:

$$
p_{0}+\left(e^{\beta \epsilon_{v}}-\frac{e^{\beta p}}{e^{\beta \mu}}\right) \cdot p_{1}+e^{\beta \epsilon_{v}} \cdot p_{-1}=0
$$

Analogamente, teremos para $p_{-1}$ as seguintes expressões:

4.

$$
p_{-1}=\frac{e^{\beta \mu}}{e^{\beta p}} \cdot\left(p_{0}+e^{\beta \epsilon_{h}} \cdot p_{1}+e^{\beta \epsilon_{v}} \cdot p_{-1}\right)
$$

e assim,

$$
p_{0}+e^{\beta \epsilon_{h}} \cdot p_{1}+\left(e^{\beta \epsilon_{v}}-\frac{e^{\beta p}}{e^{\beta \mu}}\right) \cdot p_{-1}=0
$$

Os três itens anteriores nos fornecem um sistema linear com três incógnitas: $p_{0}, p_{1}$ 
e $p_{-1}$ :

$$
\mathbf{1}, \mathbf{2} e \mathbf{3} \Longrightarrow\left\{\begin{array}{l}
p_{0}+p_{1}+p_{-1}=1 \\
p_{0}+a \cdot p_{1}+b \cdot p_{-1}=0 \\
p_{0}+c \cdot p_{1}+a \cdot p_{-1}=0
\end{array}\right.
$$

onde chamamos: $a=e^{\beta \epsilon_{v}}-e^{\beta(p-\mu)}, b=e^{\beta \epsilon_{v}}$ e $c=e^{\beta \epsilon_{h}}$.

Pela regra de Cramer:

$$
p_{0}=\frac{\operatorname{det}\left(\begin{array}{lll}
1 & 1 & 1 \\
0 & a & b \\
0 & c & a
\end{array}\right)}{\operatorname{det}\left(\begin{array}{lll}
1 & 1 & 1 \\
1 & a & b \\
1 & c & a
\end{array}\right)}=\frac{a^{2}-b c}{a^{2}-b c+b+c-2 a}
$$

Ora, mas 1. nos permite relacionar diretamente $p_{0}$ com a pressão. Logo,

$$
\frac{1}{e^{\beta p}}=\frac{\left(e^{\beta \epsilon_{v}}-e^{\beta(p-\mu)}\right)^{2}-e^{\beta\left(\epsilon_{v}+\epsilon_{h}\right)}}{\left(e^{\beta \epsilon_{v}}-e^{\beta(p-\mu)}\right)^{2}-e^{\beta\left(\epsilon_{v}+\epsilon_{h}\right)}+e^{\beta \epsilon_{h}}-e^{\beta \epsilon_{v}}+2 e^{\beta(p-\mu)}}
$$

Podemos tentar isolar a pressão nesta última equação chamando a variável $x=e^{\beta p}$. Sendo assim, (A.79) fica:

$$
\begin{aligned}
\Longleftrightarrow\left(e^{-2 \beta \mu}\right) x^{3} & -\left(e^{2 \beta \mu}+2 e^{\beta\left(\epsilon_{v}-\mu\right)}\right) x^{2} \\
& +\left(e^{2 \beta \epsilon_{v}}-e^{\beta\left(\epsilon_{v}+\epsilon_{h}\right)}+2 e^{\beta\left(\epsilon_{v}-\mu\right)}-2 e^{-\beta \mu}\right) x \\
& -e^{2 \beta \epsilon_{v}}+e^{\beta\left(\epsilon_{v}+\epsilon_{h}\right)}-e^{\beta \epsilon_{h}}+e^{\beta \epsilon_{v}}=0
\end{aligned}
$$

que é uma equação cúbica, cuja solução analítica existe, embora seja simbolicamente extensa. A grandeza mais fácil de isolar em (A.79) é na verdade o potencial químico $\mu$, 
bastando apenas algumas operações algébricas para encontrarmos:

$\mu(\beta, p)=\frac{1}{\beta} \cdot \ln \left(\frac{\left(e^{\beta p}-1\right) \cdot e^{\beta \epsilon_{v}}+1+\sqrt{\left(e^{\beta p}-1\right)^{2} \cdot e^{\beta\left(\epsilon_{v}+\epsilon_{h}\right)}+\left(e^{\beta p}-1\right) \cdot\left(e^{\beta \epsilon_{v}}+e^{\beta \epsilon_{h}}\right)+1}}{e^{\beta p} \cdot\left(e^{\beta p}-1\right)}\right)$
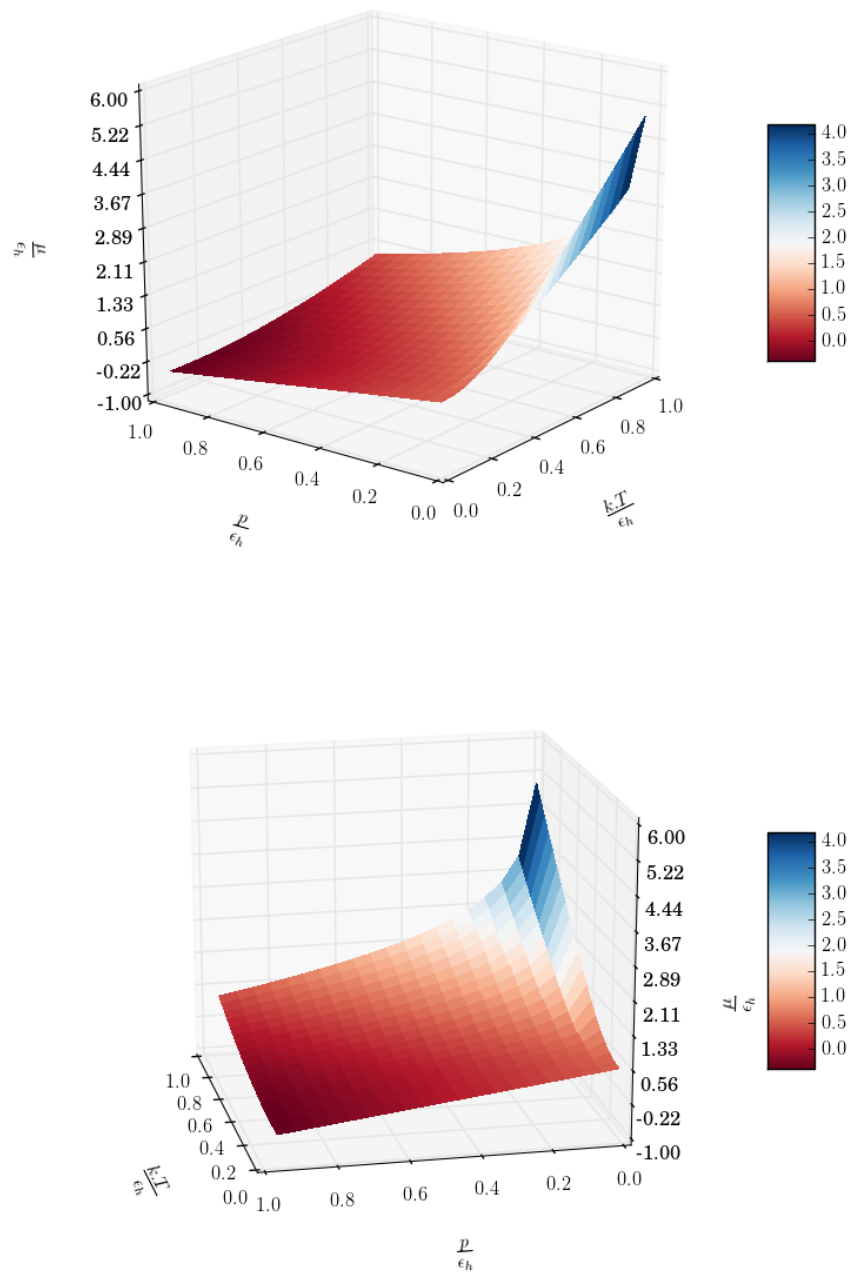

Figura A.17: $\frac{\mu}{\epsilon_{h}}$ em função da pressão $\frac{p}{\epsilon_{h}}$ e da temperatura $\frac{k . T}{\epsilon_{h}}$. Neste caso, fixamos a interação de van der Waals em $\epsilon_{v}=0.1 \mathrm{e}$ a com ligação de hidrogênio $\epsilon_{h}=1.0$. 


\section{A.4 Método III}

Os métodos anteriores buscavam, respectivamente, segmentos vazios ou segmentos cheios na rede, o que, como vimos, leva a certas dificuldades em acessar tais condições dependendo da densidade. No modelo de Bell-Lavis, por exemplo, o ordenamento preferencial em "colméia", alternando partículas e espaços vazios, torna os métodos ineficientes para densidades intermediárias, onde é particularmente difícil encontrar um segmento todo vazio ou todo ocupado. Nessa seção, propomos uma outra metodologia para calcular a pressão que busca contornar esses problemas envolvendo as densidades e sem recorrer a um estado específico de algum segmento. A ideia central aqui provém do fato de que nas fórmulas anteriores ocorriam médias envolvendo interações entre segmentos vizinhos. Então, ao invés de iniciar a dedução procurando probabilidades de achar segmentos com ou sem partículas, vamos partir diretamente para o cálculo de médias de interações entre segmentos adjacentes e desenvolver as contas até relacioná-las à pressão. Para isso, distinguiremos novamente as redes com relação às condições de contorno empregadas.

\section{A.4.1 redes sem contorno periódico}

Dada uma rede, com $N$ partículas numa temperatura $T$, ver figura A.18, chamaremos de $E_{i}$ a energia de interação entre a última e a penúltima colunas (ou linhas, tanto faz, desde que não haja condições de contorno na borda escolhida):

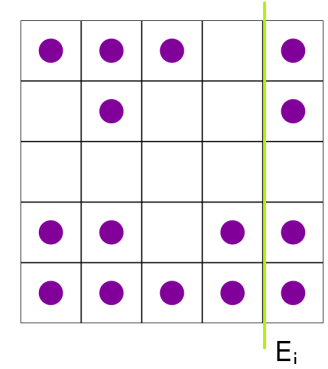

Figura A.18: $E_{i}$ entre segmentos adjacentes da borda. 
Digamos que essa última coluna tenha $L$ sítios e o restante da rede $V$ sítios, logo um 'volume' total de $V+L$. Nesse ensemble, então, calcularemos a seguinte média:

$$
\left\langle e^{\beta E_{i}}\right\rangle_{N, V+L, T}
$$

Assim, por definição:

$$
\left\langle e^{\beta E_{i}}\right\rangle_{N, V+L, T}=\sum_{\nu(N, V+L)} e^{\beta E_{i}} \frac{e^{-\beta E_{\nu(N, V+L)}}}{Z(N, V+L, T)}
$$

Note que a última coluna pode ter $n=0,1,2, \ldots, L$ partículas, de modo que o somatório acima pode ser separado em cada um desses casos. Além disso, toda configuração com $n$ partículas na coluna $L$ e, consequentemente, $N-n$ na rede $V$, pode ser gerada pela composição de duas configurações nessas subredes. Ou seja,

$$
\sum_{\nu(N, V+L)}=\sum_{n=0}^{L} \sum_{\nu(N-n, V)} \sum_{\nu(n, L)}
$$

A energia de uma $\nu(N, V+L)$ também será composta pela energia entre as partículas contidas em $V$, mais a daquelas contidas em $L$ e da interação entre essas duas redes. Este terceiro termo já foi predefinido como sendo $E_{i}$ :

$$
E_{\nu(N, V+L)}=E_{\nu(N-n, V)}+E_{\nu(n, L)}+E_{i}
$$

Logo,

$$
\left\langle e^{\beta E_{i}}\right\rangle=\sum_{n=0}^{L} \sum_{\nu(N-n, V)} \sum_{\nu(n, L)} e^{\beta E_{i}} \frac{e^{-\beta\left(E_{\nu(N-n, V)}+E_{\nu(n, L)}+E_{i}\right)}}{Z(N, V+L, T)}
$$

Segue daí que as exponenciais contendo $E_{i}$ se cancelam. Rearranjando os termos restantes, teremos: 


$$
\left\langle e^{\beta E_{i}}\right\rangle=\frac{1}{Z(N, V+L, T)} \sum_{n=0}^{L} \sum_{\nu(N-n, V)} e^{-\beta E_{\nu(N-n, V)}} \sum_{\nu(n, L)} e^{-\beta E_{\nu(n, L)}}
$$

Ora, as duas últimas somas são claramente funções de partição: uma no ensemble $(N-n, V, T)$ e outra no $(n, L, T)$, a segunda com uma dimensão a menos do que a primeira:

$$
\left\langle e^{\beta E_{i}}\right\rangle=\frac{1}{Z(N, V+L, T)} \sum_{n=0}^{L} Z(N-n, V, T) Z(n, L, T)
$$

O próximo passo será apenas multiplicar e dividir a equação acima por $\mathrm{Z}(\mathrm{N}, \mathrm{V}, \mathrm{T})$,

$$
\left\langle e^{\beta E_{i}}\right\rangle=\frac{Z(N, V, T)}{Z(N, V+L, T)} \sum_{n=0}^{L} \frac{Z(N-n, V, T)}{Z(N, V, T)} Z(n, L, T)
$$

No caso em que $L \ll V$ e $n \ll N$, as frações da fórmula anterior serão boas aproximações para a pressão e o potencial químico.

Relembrando: $1^{1} \underline{a}$ Lei + energia livre de Helmholtz $: d F=-p d V+\mu d N-S d T$

$$
\Longrightarrow\left\{\begin{array}{lll}
p(\mathrm{~N}, \mathrm{~V}, \mathrm{~T})=-\frac{\partial F}{\partial V} & \Rightarrow & e^{p \beta \delta V} \approx \frac{Z(N, V+\delta V, T)}{Z(N, V, T)} \quad \text { se } \delta V \ll V \\
\mu(\mathrm{N}, \mathrm{V}, \mathrm{T})=\frac{\partial F}{\partial N} & \Rightarrow & e^{-\mu \beta \delta N} \approx \frac{Z(N+\delta N, V, T)}{Z(N, V, T)} \quad \text { se } \delta N \ll N
\end{array}\right.
$$

Ou seja,

$$
\left\langle e^{\beta E_{i}}\right\rangle=\frac{1}{e^{p \beta L}} \sum_{n=0}^{L} e^{\mu \beta n} Z(n, L, T)
$$

e a soma que sobra tem a forma de uma grande função de partição, calculada sobre um sistema unidimensional, $\Xi_{1 D}$. A rede $\mathrm{V}$ atua como sendo um reservatório que impõe um potencial químico sobre a rede menor L. Desse modo, 


$$
\left\langle e^{\beta E_{i}}\right\rangle=\frac{\Xi_{1 D}(\mu, L, T)}{e^{p \beta L}}
$$

de onde isolamos a pressão:

$$
p(N, V, T)=\frac{\ln \Xi_{1 D}}{\beta L}-\frac{\ln \left\langle e^{\beta E_{i}}\right\rangle}{\beta L} .
$$

O primeiro termo acima nada mais é do que a pressão de um sistema $1 D$ com um potencial químico dado pelo "reservatório" $(\mathrm{N}, \mathrm{V}, \mathrm{T})$. Essa pressão tem uma complexidade reduzida devido a menor dimensionalidade da rede, em alguns casos podendo apresentar expressão analítica. O segundo, como vimos, é uma medida das interações da borda e pode ser obtida por simulação de Monte Carlo no ensemble $(\mathrm{N}, \mathrm{V}+\mathrm{L}, \mathrm{T})$.

A fórmula

$$
p(N, V, T)=p_{1 D}(\mu, T)-\frac{\ln \left\langle e^{\beta E_{i}}\right\rangle}{\beta L}
$$

exige, portanto, três coisas:

1. O potencial químico $\mu \Rightarrow$ calculado no $(\mathrm{N}, \mathrm{V}, \mathrm{T})$

2. A pressão de uma rede com uma dimensão a menos em função de $\mu$

3. $\mathrm{O}$ valor médio de $e^{\beta E_{i}} \Rightarrow$ calculado no $(\mathrm{N}, \mathrm{V}+\mathrm{L}, \mathrm{T})$

sendo que as redes em 1. e 3. não devem ter contorno periódico na borda escolhida para calcular o $E_{i}$, as outras direções são livres. Na figura A.18, por exemplo, pode haver ou não condição periódica na vertical.

\section{observações:}

A dedução feita é facilmente generalizada para qualquer dimensão, basta reinterpretar as grandezas em cada caso. Em 3 dimensões, poderíamos ter escrito: 


$$
p_{3 D}(N, V, T)=p_{2 D}(\mu, T)-\frac{\ln \left\langle e^{\beta E_{i}}\right\rangle}{\beta L},
$$

onde $\mu$ seria calculado no espaço, $p_{2 D}$ no plano e $E_{i}$ seria a energia entre uma face planar da rede com o seu segmento adjacente.

Em sistemas lineares, L seria igual a um, e

$$
\Xi_{0 D}=\sum_{n=0}^{1} e^{\mu \beta n} Z(n, 1, T)=1+\sigma \cdot e^{\beta \mu}
$$

onde $\sigma=Z(1,1, T)$ é o número de estados possíveis de uma partícula. E então,

$$
p_{1 D}(N, V, T)=\frac{\ln \left(1+\sigma \cdot e^{\beta \mu}\right)}{\beta}-\frac{\ln \left\langle e^{\beta E_{i}}\right\rangle}{\beta} .
$$

\section{A.4.2 redes com contorno periódico}

Seja uma rede idêntica à anterior, mas agora com contorno periódico entre as colunas. Tome uma coluna $k$ arbitrária e defina as seguintes grandezas:

$\mathbf{E}_{\mathbf{i}}$ : Energia de interação da coluna $k$ com o restante da rede. No caso de sistemas com interações de primeiros vizinhos, seria simplesmente a soma das energias dos pares $(k, k-1)$ e $(k, k+1)$ (figura A.19, em verde);

$\mathbf{E}_{\mathbf{c}}$ : Energia de acoplamento caso eliminássemos a coluna $k$ e juntássemos as bordas. Com primeiros vizinhos, seria a interação entre $(k-1, k+1)$, como se elas fossem colunas vizinhas (figura A.19, em laranja).

A média de partida, nesse caso, será:

$$
\left\langle e^{\beta\left(E_{i}-E_{c}\right)}\right\rangle_{N, V+L, T}
$$




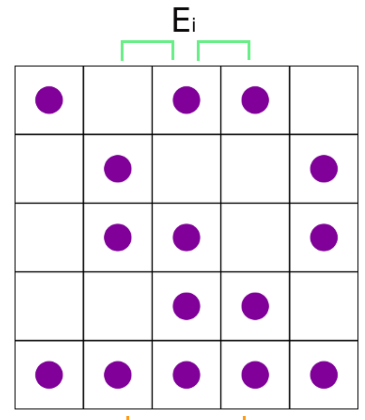

$E_{c}$

Figura A.19: $E_{i}$ e $E_{c}$ pra uma coluna qualquer

notação: Usaremos um asterisco* para indicar algumas grandezas calculadas com condição de contorno. Por exemplo,

$$
\left\langle e^{\beta\left(E_{i}-E_{c}\right)}\right\rangle_{N, V+L, T}=\sum_{\nu(N, V+L)} e^{\beta\left(E_{i}-E_{c}\right)} \frac{e^{-\beta E_{\nu(N, V+L)}^{*}}}{Z^{*}(N, V+L, T)}
$$

A energia $E_{\nu}^{*}$ de uma configuração $\nu(\mathrm{N}, \mathrm{V}+\mathrm{L})$ deve ser analisada aqui com cuidado. Como antes, podemos separar a energia das partículas contidas em V, mais a daquelas contidas em L (coluna $k$ qualquer) e a de interação entre essas duas redes $\left(E_{i}\right)$ :

$$
E_{\nu(N, V+L)}^{*}=E_{\nu(N-n, V)}+E_{\nu(n, L)}+E_{i}
$$

Mas, observe que perdemos o contorno periódico quando tomamos $E_{\nu(N-n, V)}$ separadamente, já que há a coluna $k$ separando as bordas de V. Porém, se "costurarmos"essas duas bordas eliminando a coluna $k$ entre elas, recuperamos o contorno periódico às custas de um termo de acoplamento $\left(E_{c}\right)$ :

$$
E_{\nu(N-n, V)}^{*}=E_{\nu(N-n, V)}+E_{c}
$$

$\log 0$

$$
E_{\nu(N, V+L)}^{*}=E_{\nu(N-n, V)}^{*}-E_{c}+E_{\nu(n, L)}+E_{i}
$$


Feitas essas observações, o restante da demonstração é completamente análogo aos passos anteriores. Em resumo,

$$
\begin{array}{r}
\left\langle e^{\beta\left(E_{i}-E_{c}\right)}\right\rangle=\sum_{n=0}^{L} \sum_{\nu(N-n, V)} \sum_{\nu(n, L)} e^{\beta\left(E_{i}-E_{c}\right)} \frac{e^{-\beta\left(E_{\nu(N-n, V)}^{*}-E_{c}+E_{\nu(n, L)}+E_{i}\right)}}{Z^{*}(N, V+L, T)} \\
=\frac{1}{Z^{*}(N, V+L, T)} \sum_{n=0}^{L} \sum_{\nu(N-n, V)} e^{-\beta E_{\nu(N-n, V)}^{*}} \sum_{\nu(n, L)} e^{-\beta E_{\nu(n, L)}} \\
=\frac{1}{Z^{*}(N, V+L, T)} \sum_{n=0}^{L} Z^{*}(N-n, V, T) Z(n, L, T) \\
=\frac{Z^{*}(N, V, T)}{Z^{*}(N, V+L, T)} \sum_{n=0}^{L} \frac{Z^{*}(N-n, V, T)}{Z^{*}(N, V, T)} Z(n, L, T) \\
=\frac{1}{e^{p^{*} \beta L} \sum_{n=0}^{L} e^{\mu^{*} \beta n} Z(n, L, T)} \\
=\begin{array}{l}
\Xi_{1 D}\left(\mu^{*}, L, T\right) \\
e^{p^{*} \beta L}
\end{array}
\end{array}
$$

enfim,

$$
p^{*}(N, V, T)=p_{1 D}\left(\mu^{*}, T\right)-\frac{\ln \left\langle e^{\beta\left(E_{i}-E_{c}\right)}\right\rangle}{\beta L}
$$

